\title{
The Emotional Citizen: Emotion as a Function of Political Sophistication
}

\author{
Patrick Ryan Miller
}

A dissertation submitted to the faculty of the University of North Carolina at Chapel Hill in partial fulfillment of the requirements for the degree of Doctor of Philosophy in the Department of Political Science.

Chapel Hill

2010

Approved by:

Pamela Johnston Conover, Advisor

Francesca Dillman Carpentier

Thomas M. Carsey

Michael B. MacKuen

Donald D. Searing 
(C) 2010

Patrick Ryan Miller All Rights Reserved

-ii- 


\section{Abstract \\ PATRICK R. MILLER: The Emotional Citizen: Emotion as a Function of Political Sophistication (Under the direction of Pamela Johnston Conover)}

Emotion is often stereotyped as a crutch that less informed and less engaged citizens rely upon in their political decision-making in place of hard fact and reasoned thought. This dissertation reexamines that stereotype, and instead argues that political sophistication is positively related to being emotional about politics. Thus, citizens who are more politically knowledgeable and engaged should be more emotional about political stimuli. Chapter 1 discusses emotion from a psychological perspective, linking theories from that field to work in political science. Chapter 2 presents my sophistication theory and tests it on individual-level survey data dealing with emotional appraisals of presidential candidates. I further test my theory with response paradata from an original web-based survey. Chapter 3 discusses the interaction of sophistication and information context. I show that high sophisticates are more responsive to emotional appeals in campaign advertising, and that emotions are a stronger influence on their voting and attitude expression than for low sophisticates. Chapter 4 reconceptualizes information context as the emotional cues in traditional news media. I show that high sophisticates are more responsive to emotional cueing, and that emotion biases the learning of high sophisticates more than that of low sophisticates. Thus, high sophisticates are more emotional about politics, more responsive to emotional cues in the world around them, and more prone to act on their emotions in their political behavior. 


\section{Acknowledgements}

Though I am not especially prone to sentimentality (pure irony for having written a dissertation on emotion), there are a great many people I must thank for getting me through graduate school and, in fact, my life. Let me do this somewhat chronologically, and bear with me because I can never say in three words what can better be said in ten.

First, I must thank my family, especially my parents, Forrest W. Miller and Shirley A. Miller, for whom I never manage to express my gratefulness adequately. My parents were both born into extreme poverty during the Great Depression, but, through struggle and determination, managed to raise reasonably normal children (well, at least one) and provide us with a decent life. My father died of brain cancer on March 1, 2008. A veteran of Korea and Vietnam, he served his country for more than thirty years in the U.S. Navy, and was a constant and reassuring presence in my life. Though he disagreed with my going to graduate school, I hope he would be proud of me today.

Indeed, I am the first member of my family to go to college since my greatgrandparents arrived in America at Ellis Island nearly a century ago. I have no clue what they expected when they came here. Nevertheless, I hope that they and my grandparents would have been happy to know that I am grateful for their bravery and hard work. The pictures of the ships they arrived on hang on my wall today as a reminder of them, where they came from, and how far my family has come. 
I also want to thank several faculty members at the College of William \& Mary for encouraging me to do an undergraduate honors thesis and nagging me to try graduate school - Professors Thomas Linneman, John McGlennon, Ronald Rapoport, and Kate Slevin. I am especially indebted to Ron Rapoport (and his wife, Patricia) for being the quirkiest, most encouraging, and most enthusiastic friend and mentor possible. He encouraged me to quit dodging bullets (literally) with my Teach for America job and trade it in for graduate school at UNC. It was wise advice.

Of course, I am deeply indebted to many people in the Political Science Department at UNC Chapel Hill for their support throughout graduate school. Foremost, I must thank my advisor, Pamela J. Conover. I learned to fear Pam as her TA, but, after a rough MA thesis and a case of first dissertation advisor abandonment, I gathered the courage to knock on her door one day and ask her to be my new advisor. It was one of the best decisions I ever made, though it did take about a year before my hand quit trembling when I knocked on her door. Most of all, Pam taught me to appreciate good theory, and hammered into me that theory must come before empiricism. She has been a brilliant sounding-board for ideas, rants about the insanity that is my life, and, of course, my dissertation. I cannot say enough to praise her. I will forever be indebted to her.

Tom Carsey has also gone above and beyond the call of duty to advise and mentor me. As all graduate students in the department will agree, Tom is one of the nicest people ever to walk the Earth. I hope one day to become half the political scientist he is. He also paid for the NES contextual data that made Chapter 3 possible. One day I will surprise him with a gold-plated cardboard box so that he can carry his papers to class in style. 
I am grateful for the advice and kindness of Professors Erik Engstrom, Michele Hoyman, Michael MacKuen, Donald Searing, Marco Steenbergen, Jim Stimson, and John Transue. Francesca Dillman Carpentier of the UNC School of Journalism and Mass Communication gave me top notch advice on how to run an experiment and provided insightful commentary on drafts. I also want to thank Christine Reynolds and Shannon Eubanks of the Political Science Department for everything they have done for me and for being the best sources of candy and gossip this side of the Pit.

Last but not least, I want to thank my friends, especially those whom I met here in graduate school, for making the last six years bearable and fun: Christine Carpino, Adam Chamberlain, Mary Deason, my fabulous twin Delia Goolsby, Ellen Gutman, Katja Kleinberg, Nick Pyeatt (and his wife, Trista), and Laura Shaffer. They are the best friends a neurotic and self-doubting political science dork can have. Most of all, I want to thank Peter Bobkowski for everything past, present, and future. If I forgot anyone else, please do not hate me. 


\section{Table of Contents}

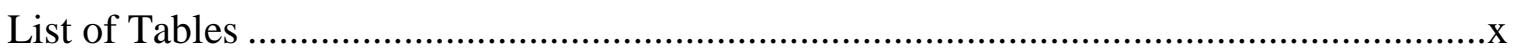

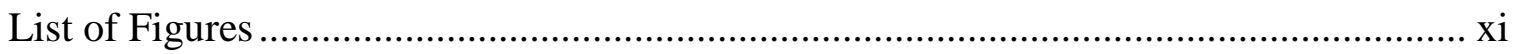

Chapter

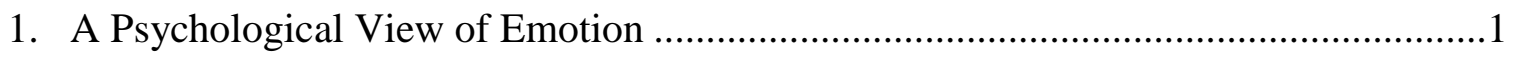

Defining Affective Phenomena.............................................................. 3

The Structure of Emotion..............................................................................

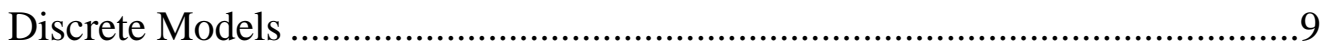

Valence Models ............................................................................ 18

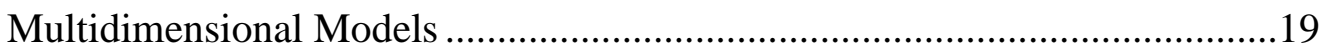

2. Political Sophistication as a Predictor of Emotion ..............................................24

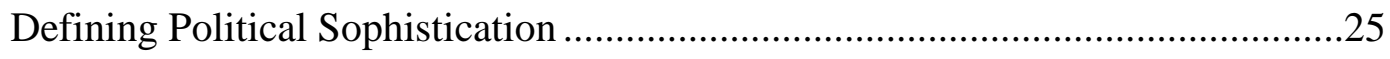

Political Sophistication and Emotion ......................................................26

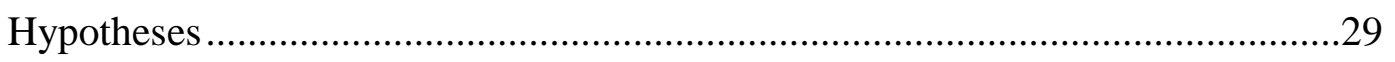

Emotional Appraisals of Presidential Candidates .......................................... 31

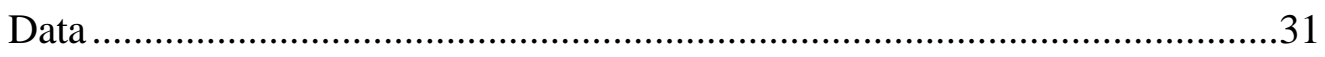

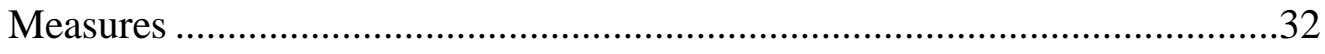

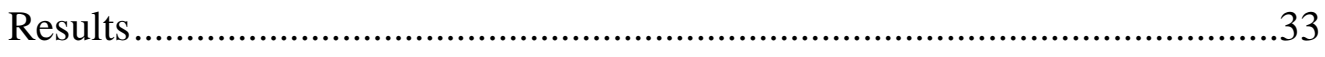

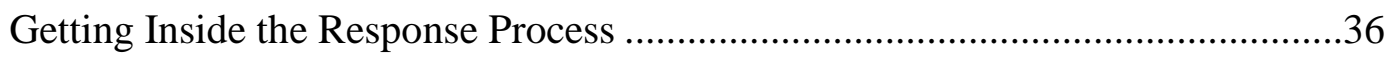

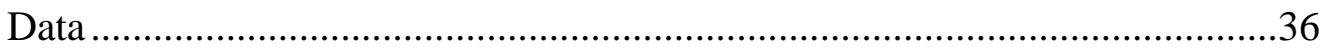




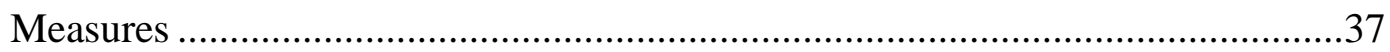

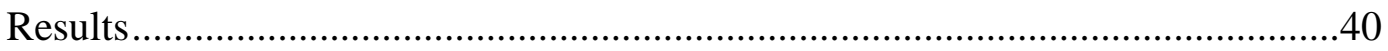

Discussion .......................................................................................... 44

3. Introducing Information Context: Emotional Appeals in Campaign Advertising .......48

Information Context............................................................................49

Campaign Advertising as Information Context ...........................................51

Sophistication and the Behavioral Consequences of Emotion ...........................54

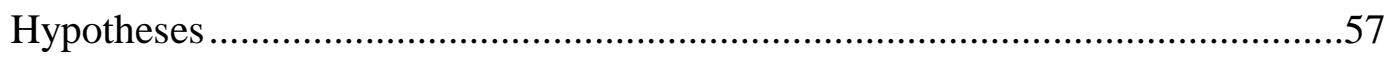

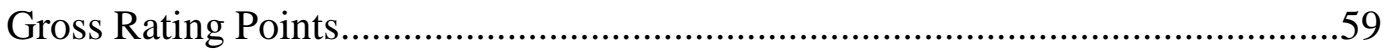

Content Analysis of Campaign Advertising ..............................................62

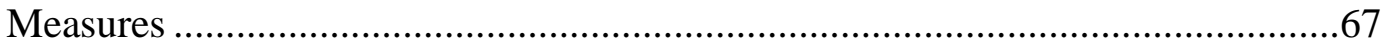

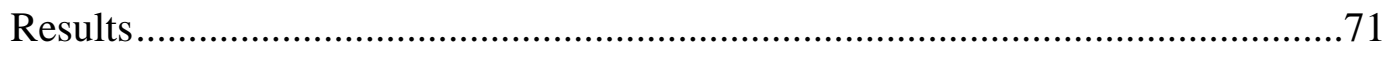

Direct Effects of Sophistication and Information Context ..........................71

Sophistication as a Moderator of Responsiveness to Information Context .....76

Effects on Voting Behavior .............................................................83

Sophistication as a Moderator in Policy Attitudes .....................................8 88

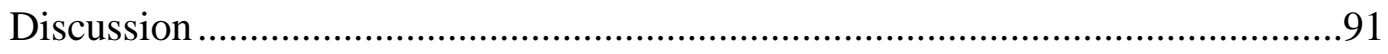

4. An Experimental Exploration of Emotional Cues in News Media ............................95

News Media as Information Context ......................................................... 96

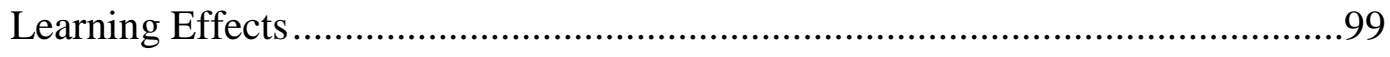

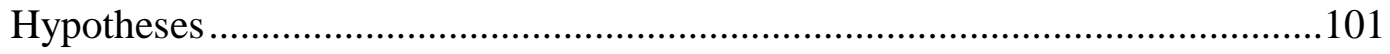

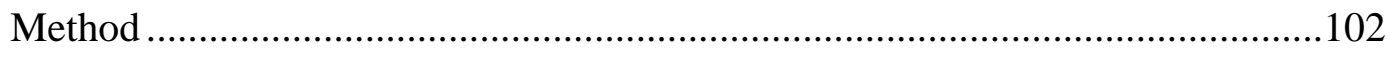

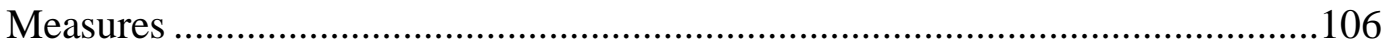




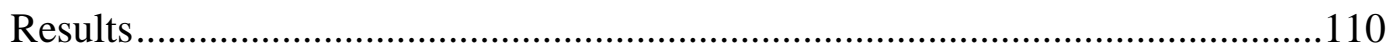

Eliciting Emotions toward Illegal Immigration .............................................110

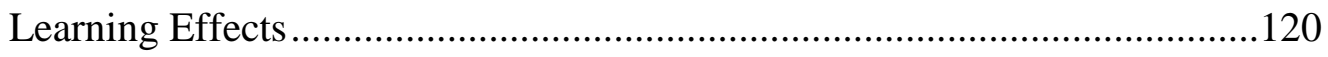

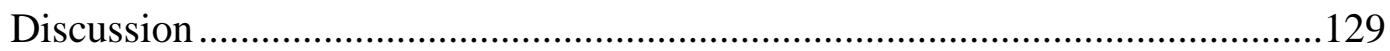

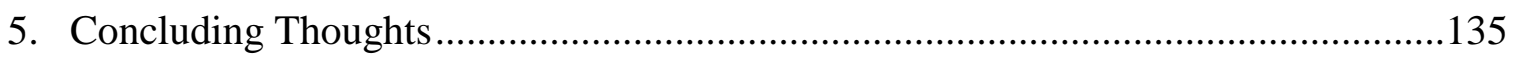

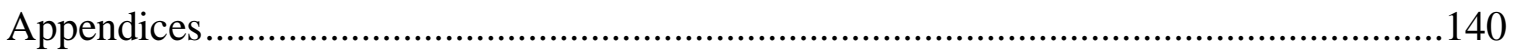

A: Iraq War Web Survey Questions ......................................................................140

B: Media Markets Tracked by CMAG in 2000 ....................................................142

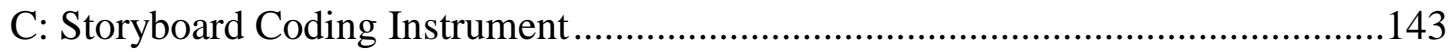

D: Demographic Controls, Tables 3.3 - 3.5 ...........................................................

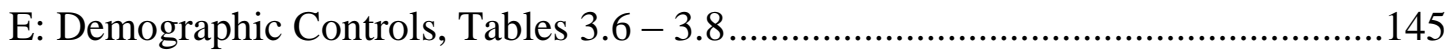

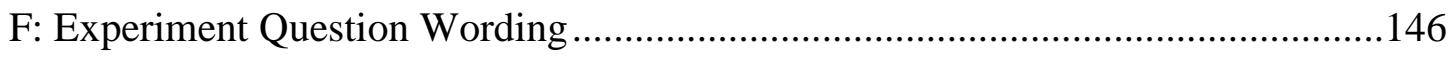

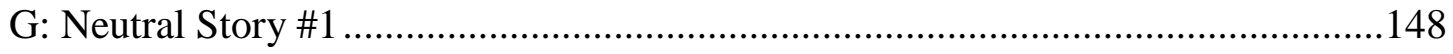

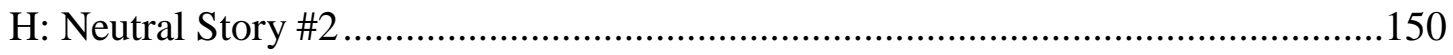

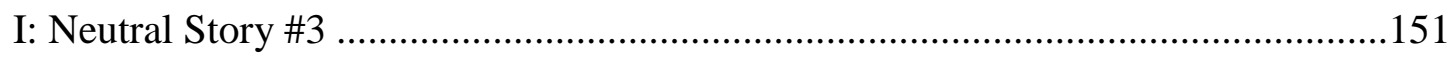

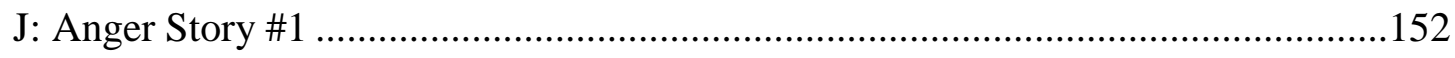

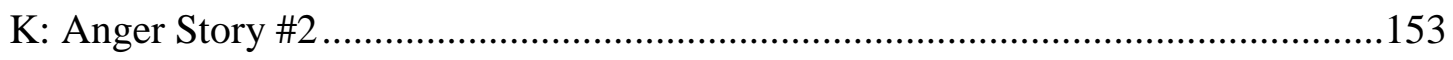

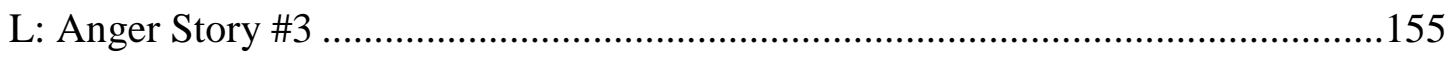

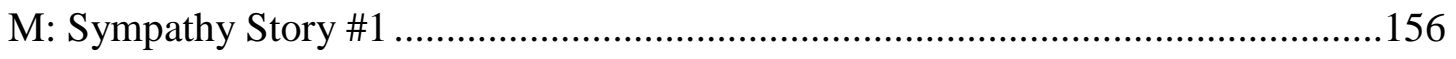

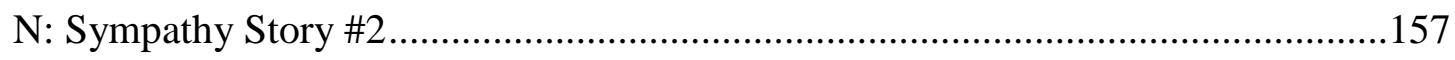

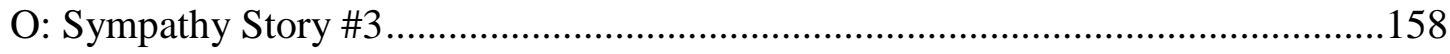

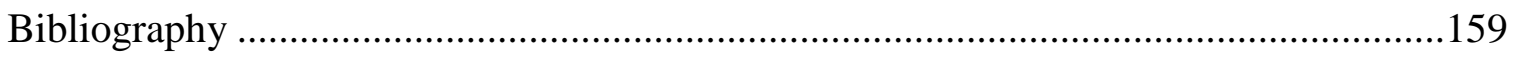




\section{List of Tables}

1.1 Core Relational Themes for Discrete Emotions ...............................................14

2.1 Emotions toward Presidential Nominees in Pooled NES, 1980-2004 ..................34

2.2 Latency Ratios of Emotion and Policy Items .................................................39

2.3 Response Change Count Models for Emotion and Policy Items .........................42

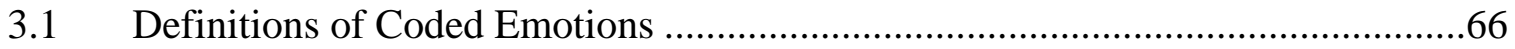

3.2 Candidate Emotions, NES Respondents in 75 Largest Media Markets.................72

3.3 Candidate Emotions, Individual Characteristics and Advertising GRPs..............74

3.4 Bush Emotions with Sophistication and Advertising Interactions .......................78

3.5 Gore Emotions with Sophistication and Advertising Interactions.......................80

3.6 Presidential Vote with Sophistication and Advertising Interactions ....................85

3.7 Presidential Vote with Sophistication and Emotion Interactions ........................86

3.8 Emotion Effects on Iraq War Policy Attitudes ............................................89

4.1 Means and Standard Deviations of Emotions by Condition.............................109

4.2 Immigration Emotions with Sophistication and Media Interactions ..................114

4.3 Learning Effects with Sophistication and Media Interactions ..........................124 


\section{List of Figures}

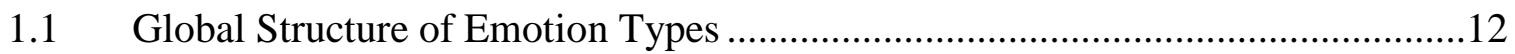

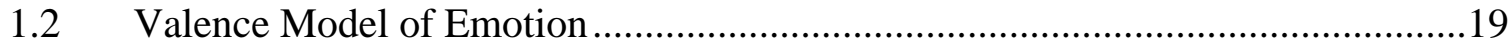

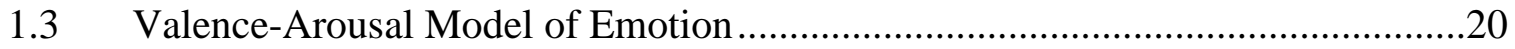

1.4 Plotted Two-Factor Structure of the Circumplex..........................................21

2.1 Political Sophistication as a Latent Concept...................................................26

2.2 Sample Obama Associative Networks .........................................................28

2.3 Probability of Discrete Emotions toward Presidential Nominees.........................36

2.4 Latency Ratios for Emotion and Policy Items by Sophistication ........................40

2.5 Change Counts for Emotion and Policy Items by Sophistication ........................43

3.1 Total GRP of Presidential Advertising by Market...........................................62

3.2 GRP of Emotional Advertising Directed toward Bush by Media Market ............69

3.3 GRP of Emotional Advertising Directed toward Gore by Media Market .............70

3.4 Emotional Appraisals of Candidates, Respondents in Tracked Markets ..............71

3.5 Predicted Probabilities of Bush Emotions with Sophistication and Advertising

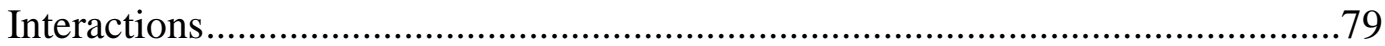

3.6 Predicted Probabilities of Gore Emotions with Sophistication and Advertising

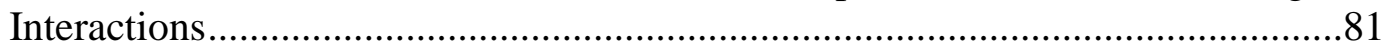

3.7 Predicted Probability of Gore Vote, Sophistication and Emotion Interactions .....87

3.8 Sophistication and Emotion Interactions for Policy Attitudes ...........................91

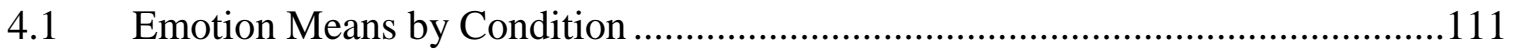

4.2 Anger Predicted Probabilities, Sophistication Effect by Condition....................115

4.3 Sympathy Predicted Probabilities, Sophistication Effect by Condition ..............116 
4.4 Learning Means by Condition

4.5 Learning Effect of Anger and Sophistication Interaction by Condition ..............126

4.6 Learning Effect of Sympathy and Sophistication Interaction by Condition ........127 


\section{Chapter 1}

\section{A Psychological View of Emotion}

Emotion and politics are not and never have been strangers. Philosophers from antiquity through the Enlightenment traditionally viewed emotion as an undesirable and even dangerous impediment to the ability of average citizens to exercise their democratic responsibilities and to reason about political affairs (for more thorough discussions see Clarke, Hoggett, and Thompson 2006; Marcus 2002; Marcus, Neuman, and MacKuen 2000). The view that emotion is incompatible with reasoned political thought influenced the modern social sciences, and led to the neglect of emotion in the earliest studies of mass political behavior in the United States (e.g. Lazarsfeld, Berelson, and Gaudet 1948; Berelson, Lazarsfeld, and McPhee 1954; Campbell et al. 1960).

Nevertheless, a major scholarly trend in the last thirty years has been the rebirth of emotion as a positive, or at least undeniable, element of democratic citizenship and competent decision-making. Political scientists have realized that emotion plays a critical role in shaping attitudes and behavior, including candidate evaluations (Abelson et al. 1982; Ottati, Steenbergen, and Riddle 1992), perceptions of officeholder performance (Conover and Feldman 1986), support for public policies (Huddy, Jones, and Chard 
2001; Huddy et al. 2005; Pagano and Huo 2007), and how the public reacts to campaign appeals (Brader 2006). Other work has demonstrated that emotional phenomena are essential to well-reasoned decisions and even facilitate learning (Dolan and Holbrook 2001; Marcus and MacKuen 1993; Marcus et al. 2000).

Despite these advances, there is still room to expand our understanding of emotion in political behavior. While we know a great deal about the effects of emotions on a variety of political variables, we know little about how the psyche facilitates emotional appraisals of political stimuli. This dissertation has several goals. First, it aims to understand how psychological factors, namely political sophistication, promote emotional responsiveness to political attitude objects. Second, it explores how information context moderates the effect of sophistication on emotional appraisals. Lastly, it demonstrates how sophistication moderates the effect of emotion on political attitudes and behaviors. Specifically, I argue that high political sophisticates are more likely to be emotional about politics than low sophisticates, but that this difference is highly contingent upon the emotional cues present in political stimuli. Furthermore, I posit that emotion has a more powerful effect on the behavior of more informed and engaged citizens than it does on the less sophisticated

This work has important implications for how we think about the role of emotion in politics. Stereotypes that date back to the ancient philosophers of Greece and Rome have engendered a common sentiment in both academic and everyday political discourse that emotions are somehow inferior to reasoned and rational thought as a basis for political action (Brader 2006; Marcus et al. 2000). This view purports that emotions are cheap, relatively effortless cues that uninformed and unengaged citizens rely upon 
because they are either unable or unwilling to think seriously about political affairs. Thus, it is unsophisticated citizens who supposedly vote their hopes or fears rather than weighing the issues, or who form opinions about policy questions that are more informed by their feelings than any rational assessment of costs and benefits. This work challenges that stereotype, demonstrating that it is high sophisticates, those who are normatively thought of as being "good" citizens as they are more informed about and engaged with the political world (Delli Carpini and Keeter 1996), who are in reality more emotional about politics and more swayed by those emotions in their behavior.

\section{Defining Affective Phenomena}

Social scientists use a number of terms to refer to emotional phenomena, including emotion, feeling, mood, and affect. Outside of psychology, scholars tend to use these terms interchangeably; however, as work on emotion becomes more nuanced and more advanced in both theory and the research tools used, it becomes increasingly important to distinguish these terms from one another. There are important differences between these four concepts that can have substantial consequences for political psychology research. Thus, as other political scientists working on emotion advocate (e.g. Brader 2006; Spezio and Adolphs 2007), we should use language that is more precise in our theories and define the conceptual boundaries of the phenomena we explore.

Emotions are commonly defined as mental and physical responses to identifiable stimuli deemed consequential for individual or group objectives. They consist of five constituent processes: an appraisal that a stimulus has potential consequences for one's goals, physiological change in preparation for action, changes in cognitive activity that 
aid adaptation, an action tendency, and the conscious experience of an emotion called a “feeling” (e.g. Brader 2006; Damasio 1994; Ekman 1982; Ellsworth 1991; Frijda 1986; Lazarus 1991; Ortony, Clore and Collins 1988; Scherer 1994). Emotions are generally brief, lasting only a few minutes at most (Fiske and Taylor 1991; Watson 2000). Though psychologists bitterly disagree about many aspects of emotion ranging from its basic neurobiological structure to similarities in cross-cultural facial expressions of emotion, there is consensus over the fundamental question of what an emotion is.

This fifth component of emotion is a "feeling," or the conscious, subjective experience of an emotion (Damasio 1994, 1999). Discrete emotions trigger various psychological and physiological responses that are characteristic of each particular emotion, but these responses are not necessarily sensed or felt in a conscious way. It is the awareness of feeling an emotion that we should more properly call a "feeling." An emotion, then, is a much broader experience than a feeling in that the former encompasses a wide array of mental and physical reactions whose occurrence need not be conscious. A feeling, on the other hand, is fundamentally a conscious event. Feelings are also the only emotion component that is unnecessary as emotions often occur outside of conscious perception (Hamm, Schupp, and Weike 2003; Scherer 2003).

Emotion also differs from mood. Common moods include tenseness, cheerfulness, depression, grouchiness, angst, confusion, and contentment. Mood and emotion both involve subjective feeling states (Gray and Watson 2007). Thus, one can feel depressed (a mood) in general or feel disgust (an emotion) at a certain object, and both subjective descriptions would be valid reports. The differences between mood and emotion, however, are more extensive. Moods last much longer than emotions, sometimes for days 
or even weeks (Davidson 1994; Gray and Watson 2001; Watson and Clark 1994). Though emotions generally last minutes at most, they can be chronically experienced in reaction to a specific stimulus. George W. Bush can make a person angry often and that individual can certainly encode the association of anger with Bush in long-term memory (Christianson and Engelberg 1999; McGaugh 2003), but she does not feel continuous anger for hours or days. Indeed, emotions can occur in such frequent spurts that it seems like the emotion is a continuous experience even though it is not.

Moods and emotions also differ in frequency (Gray and Watson 2001; Watson 2000). Moods are experienced more often than emotions, a difference attributable to evolutionary biology. Emotions tend to be intense experiences, whereas moods tend to be more subdued. The frequent experience of intense emotion can be counterproductive to routine functioning (Watson 2000). In contrast, less intense moods are always present while humans are awake (Ekman 1994; Watson and Clark 1994), a theory popularly labeled "the stream of affect" (Watson 2000). For example, while the full, intense experience of anger occurs relatively infrequently, milder negative moods related to anger such as annoyance, frustration, or grouchiness are both more frequent and more central to everyday, conscious perceptions (Gray and Watson 2007). Even when someone believes they feel nothing, that person is actually experiencing a mood called calmness. Thus, humans are always in an affective state of some sort.

Mood and emotion also differ in their causes and targets (Brader 2006; Davidson 1994; Gray and Watson 2001). Emotions have specific events or objects that induce the reaction process, and the actions that stem from emotions are targeted at the objects that caused the emotion in the first place. For example, seeing the plight of people stranded on 
their roofs after Hurricane Katrina might induce sympathy and elicit actions such as volunteering or donating money that are meant to alleviate that suffering. Moods, however, need not have identifiable causes (Davidson 1994). Thus, it is psychologically valid to say that one "got up on the wrong side of the bed" as a description of a bad mood with no additional justification. Further, moods usually do not elicit action tendencies in the same way emotions do, even when the cause of a mood is known (Davidson 1994; Frijda 1994). Indeed, moods often lead to no action at all.

Given how moods permeate our waking lives, one can imagine that they influence political behavior. Whereas emotions occur when adaptive action is necessary, moods modulate or bias cognition on a more regular basis. Positive moods cause individuals to be less critical of attitude objects and to engage in peripheral rather than central processing, whereas the opposite is true for negative states (MacKenzie 1998; Mineka and Sutton 1992; Teasdale and Fogarty 1979). Mood effects probably do influence political cognitions, but to date the application of moods to political phenomena has been nonexistent. Rahn (2000) and Stimson (1999) have appropriated the term "mood" to describe their respective public opinion theories, but these phenomena are not moods in the psychological sense nor do these concepts behave in a manner similar to real moods.

Lastly, emotion and affect also differ in important ways. Affect refers to conscious evaluative feelings of liking or disliking (Gray and Watson 2007; Parkinson et al. 1996; Rozin 2003). Like mood, affect does not always have an identifiable cause. Positive affect is any state that individuals seek to reproduce or maintain, whereas negative affect is a state to avoid, eliminate, or reduce given the displeasure it causes. Many psychologists frame affect in terms of approach and avoidance with positive affect 
causing approach behavior and negative affect eliciting avoidance (Davidson et al. 1990; Schneirla 1959), but affect does not necessarily lead to action as emotion does.

Affect, unlike mood, has not been ignored in political science. The feeling thermometer, often used in surveys like the American National Election Study (NES) to assess feelings toward a group or person, is a purely affective measurement item. Feeling thermometers are useful for providing global assessments of respondent evaluations (Greene 2002; Rahn et al. 1990), though other scholars have correctly pointed out that these tools are not useful for measuring emotion because they confound emotions into one summary measure (Marcus et al. 2006). Thus, one cannot disentangle the effects of contempt or anger from a cold thermometer score of zero. Likewise, it is unclear what a "neutral" thermometer score of fifty means. It could represent complete indifference, or it could represent perfect ambivalence through a mixture of positive and negative emotions that evenly balance. There is no way to test either of these interpretation hypotheses.

If we are to apply psychology to political problems, then it is important to be precise in our terminology. Though many social scientists use the terms emotion, affect, and mood interchangeably, there are important differences between these concepts that make them distinct in their experience and in their effects on behavior. Though related in the sense that they are all called "affective states," these phenomena are not the same, and treating them as such makes our theories at the very least less precise and possibly even wrong. Though feelings are not emotions, they are part of the emotional reaction process. Thus, using "feeling" in place of "emotion" is more an incomplete description than a wrong one. This dissertation focuses solely on emotion. The findings herein do not 
necessarily apply to mood or affect, and the same can be said of the latter two concepts and relating the more limited literature on them to emotion.

\section{The Structure of Emotion}

Though there is consensus in psychology on the definition of emotion, there is less agreement on its structure. Certainly different emotions exist, but the debate over structure is concerned with how those emotions are related. This debate has implications for political psychology as it informs how we should theorize about and measure emotion. Political scientists draw on multiple models of structure that are often conflicting at the very least or, in some instances, mutually exclusive. Some scholars (e.g. Conover and Feldman 1986; Pagano and Huo 2007) prefer discrete models that focus on the unique aspects of individual emotions like anger or disgust, and not on how these emotions relate. Affective intelligence theory, however, is based upon dimensional models that argue that unique emotions like anger and disgust do not exist; instead, those names are just different labels humans put on one underlying dimension of emotion called aversion to convey its experience (Marcus et al. 2000). For theoretical purists, it is impossible to believe in both the discrete and dimensional schools as their basic assumptions are mutually exclusive. ${ }^{1}$ Further complicating the debate is hot cognition theory (e.g. Lodge and Tabor 2000) which argues that humans cannot remember

\footnotetext{
${ }^{1}$ Political science has created a misleading debate over the structure of emotion that would baffle many psychologists. Our literature normally asks which structural model is "correct," treating each in isolation as if it is the right way to approach emotion. Most psychologists have realized, however, that emotions are both distinct yet related in various ways (see Lazarus 1991 for a summary). Psychologists generally treat the different structural models as if they are all valid rather than asking which is right, and their questions deal more with what those models say about the manifestation of emotion in certain circumstances. Thus, anger and disgust can both exist independently, but still be related in some broad dimensional sense.
} 
experiencing feelings other than broad positive or negative affect; thus, from this perspective, the entire enterprise of studying emotion through surveys is basically futile.

The point of this discussion is that structural models dictate how scholars must measure emotion and the kinds of effects about which they theorize. Thus, we need to understand the debate over structure before we study how emotion shapes political behavior. At the very least, a better understanding of the various models helps us draw connections between works that are based upon competing theories. Neuman et al. (2007) identify three major structural schools: discrete (also known as functional or appraisal), multidimensional, and valence models. I give a basic overview of each model below, focusing mostly on the discrete approach since that is the basis for my work.

\section{Discrete Models}

The discrete school of emotion focuses on individual emotions such as pride and pity, their identifiable causes, and their associated action tendencies. By studying emotions separately, the discrete school focuses less on how they are related and more on what makes each unique. Arnold laid the foundation for appraisal theory through her excitatory theory of emotion $(1950,1960)$, but it has since undergone various modifications. Subsequent work has expanded the universe of known emotions, explored the interaction of emotion and cognition, and employed modern neuroscience techniques to locate the sources of discrete emotions in specific parts of the brain (key studies include: Ellsworth 1991; Frijda 1986; Lazarus 1966; Lazarus, Averill, and Opton 1970; Ortony, Clore, and Collins 1988; Roseman, Antoniou, and Jose 1996; Schachter and Singer 1962; Scherer 
1979; Weiner 1974). Appraisal is the dominant approach in psychology, though some scholars in that field do adopt dimensional perspectives.

At its core, appraisal theory is the idea that emotions are affective reactions to cognitive interpretations of the world. In its simplest theoretical form it is a theory of cognitive primacy, though functional theorists have shown that in the more complex real world the relationship between emotion and cognition is nonrecursive in that they influence each other in myriad ways (Bower 1981; Isen et al. 1978; Johnson and Tversky 1983; Ortony, Turner, and Antos 1983; Schwarz and Clore 1983). As Clore et al. (1988, p. 4) write, "to say that emotions arise from cognition is to say that they are determined by the structure, context, and organization of knowledge representations and the processes that operate on them." Thus, it is our individual understandings and perceptions of the world that shapes the emotions we feel in reaction to it.

In the discrete perspective, the emotions we feel depend upon several dimensions of evaluation. When confronted with a stimulus, individuals arrive at a particular emotional reaction by making assessments of desirability, blame, the prospect of an outcome's occurring, the consequences an action has for their own goals, and the magnitude of those consequences. Specific emotions are differentiated based upon where they fall on these dimensions. Despite the popular notion that emotions are irrational and dangerous passions, functional theory frames emotion in a very rational light. It argues that people have emotions because of the perception that some stimulus has consequences for their individual or group goals. Emotions focus our attention and direct our actions in ways that promote the realization of those goals. Thus, emotions are entirely compatible with rational choice theories of goal seeking behavior, not contrary to them. 
Figure 1.1 illustrates how Ortony et al. (1988) conceptualize the appraisal process. Their model assumes that emotions are valenced reactions to three types of stimuli: events, agents, and objects. Not all stimuli in these categories will elicit emotional reactions, but emotions will occur when individuals find something of consequence in an attitude object. The first branch of reactions, those toward events, Ortony et al. label as emotions of pleasure or displeasure. Pleasure and displeasure are merely broad labels that represent undifferentiated valenced assessments, and not affect. Reactions to agents are broadly labeled as approving versus disapproving, whereas those toward objects are liking or disliking. All labels in upper case represent structural elements of the Ortony et al. model which show how discrete emotions as a group are related. Lower case labels represent potential emotional states, mainly discrete emotions.

Let us examine anger to illustrate the appraisal process. Figure 1.1 shows that events can be interpreted in a displeasing way with an undesirable impact on the self. The "prospects irrelevant" branch means that the likelihood of an event does not enter into a cognitive evaluation as it does with emotions of uncertainty like hope and fear. Anger, instead, deals with certain events that have occurred in the present or the past. Likewise, some aspect of another agent can be evaluated in a disapproving way, leading to a sentiment of reproach or blame toward the "other." The blame attribution then elicits an anger response. Anger, then, is a compound of negative evaluations of agents and events.

Appraisal theorists posit that people verbally express feeling those emotions in various ways that indicate the intensity of the reaction and other aspects of the experience. Ortony et al. call these terms "tokens." For example, anger is a core emotion, but one may choose tokens other than "angry" to label feelings in certain situations. 
Saying that one is "annoyed" indicates mild anger, "incensed" communicates extreme anger, and "steaming" offers more behavior-oriented imagery. Rather than being three different emotions, these terms are all anger labeled in various ways.

\section{Figure 1.1: Global Structure of Emotion Types}

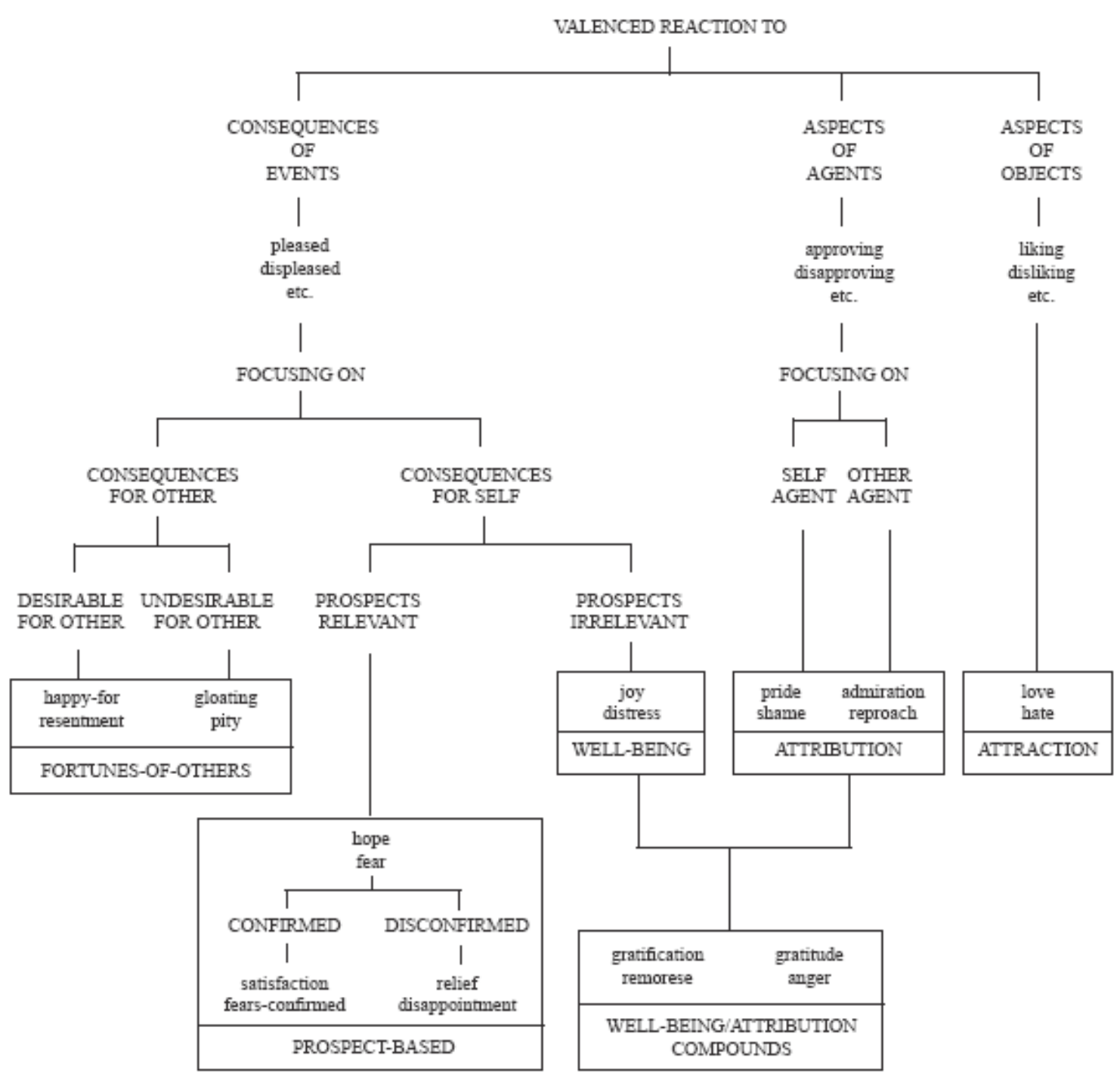


A necessary component of emotion in the discrete view is an action tendency. That is, specific emotions are associated with certain types of actions related to the core theme of the emotion. Anger, for example, results from the perception that another actor has violated common values or norms. This sense of violation normally leads to behavior - the action tendency - that involves punitive acts against the transgressor. Thus, anger is basically an attack emotion, with the resulting aggressive actions often aimed at preserving the status or moral superiority of an in-group (Roseman 1984; Roseman et al. 1996). In some circumstances, however, anger can lead to avoidance, so the action tendency associated with it is not universal (Berkowitz 2003). Politically, anger has been shown to mobilize subordinate social groups to gain recognition through social movements or other forms of protest, though their moral challenges often engender anger among members of dominant groups who respond with actions meant to preserve the status quo (Mackie, Devos, and Smith 2000; Nussbaum 2004).

Though this discussion shows the power and political relevance of anger, there are many discrete emotions for which we could tell similar stories. Sympathy elicits actions meant to alleviate suffering, for example, whereas pride leads to actions intended to praise an in-group in some manner. One can imagine how these action tendencies might translate into various political sentiments or actions. Table 1.1 summarizes the core relational themes that Lazarus $(1991,2001)$ uses to define a number of basic discrete emotions. This table, though, does not exhaust the list of discrete emotions, nor does it cover every possible way various scholars have defined each emotion in their own work.

As the discussion of anger illustrates, emotions involve both biological and social processes. Indeed, psychologists generally advocate a biocultural model of emotion, 
wherein emotional reactions are a product of both natural and social forces (Levenson 1994; Mesquita and Ellsworth 2001). All human are biologically capable of experiencing the same emotions. All discrete emotions, their general types of causes, the ways in which they are expressed physically and mentally, and their action tendencies tend to be similar across cultures. Grief, for example, is a reaction to loss for all humans and has a certain set of actions and facial expressions that accompany it.

Table 1.1: Core Relational Themes for Discrete Emotions

\begin{tabular}{|c|c|}
\hline Emotion & Theme \\
\hline Anger & A demeaning defense against me and mine \\
\hline Anxiety & Facing uncertain, existential threat \\
\hline Fright & An immediate, concrete, and overwhelming physical \\
\hline Guilt & Having transgressed a moral imperative \\
\hline Shame & Failing to love up to an ego-ideal \\
\hline Sadness & Having experienced an irrevocable loss \\
\hline Envy & Wanting what someone else has \\
\hline Jealousy & Resenting a third party for loss or threat to another's affection or favor \\
\hline Disgust & Taking in or being too close to an indigestible object or idea \\
\hline Happiness & Making reasonable progress toward the realization of a goal \\
\hline Pride & $\begin{array}{l}\text { Enhancement of ego by taking credit for a valued object or achievement, } \\
\text { either one's own or that of someone or group with whom we identify }\end{array}$ \\
\hline Relief & $\begin{array}{l}\text { A distressing goal incongruent condition that has changed for the better or } \\
\text { gone away }\end{array}$ \\
\hline Hope & $\begin{array}{l}\text { Fearing the worst but yearning for better, and believing a favorable } \\
\text { outcome is possible }\end{array}$ \\
\hline Love & $\begin{array}{l}\text { Desiring or participating in affection, usually but not necessarily } \\
\text { reciprocated }\end{array}$ \\
\hline Gratitude & Appreciation for an altruistic gift that provides personal benefit \\
\hline Compassion & Being moved by another's suffering and wanting to help \\
\hline
\end{tabular}

Culture does condition emotion, however. Social norms, values, and expectations train us to react to the world in certain ways. Political culture, for example, shapes how we interpret politics in our own countries. Many Americans have Puritanical moral expectations for their leaders, as evidenced by the negative emotions the Monica 
Lewinsky scandal elicited. The French, however, have less saintly expectations that are consistent with their political culture. Francois Mitterand's mistresses were public figures in their own rights, and Nicholas Sarkozy won the presidency despite the fact that he and his then-wife both admitted to multiple extramarital affairs. None of these actions aroused the outrage among the French that similar actions by an American president surely would. Thus, the emotional reactions to the same type of action (philandering) in these examples are largely the result of the expectations political culture instills.

Individual differences also shape emotional reactions. Though people may experience the same emotion in reaction to some stimulus, there are disparities in how they handle these feelings that stem from personality and their individual goals. Roller coasters may cause fear in two people for all the same reasons and both the inward and outward experience of that emotion may be the same, but one person may avoid the ride as a way of coping with that fear while the other takes the ride because he enjoys thrillseeking activities. Some people may not even experience fear in this context at all, depending upon individual goals and interests.

The cognitive processes that constitute emotional reactions also vary by individual. Appraisals might occur instantaneously depending upon how familiar a person is with the attitude object; indeed, they can happen so quickly that we perform our cognitive processing outside of conscious awareness. If an individual is chronically exposed to an attitude object that elicits an emotion, that feeling can be stored in memory, especially if the emotion is strongly felt (Christianson and Engelberg 1999; McGaugh 2003). With familiar objects in these instances, mere exposure to the object is sufficient 
to bring stored feelings from the past into working memory. ${ }^{2}$ Once these remembered feelings are activated, they can significantly shape our present thoughts and actions. The only "thinking" that occurs in such circumstances is the simple act of recognition. On the other hand, cognitive evaluation can be a drawn out, complex process, and emotions may arise only after extended, conscious contemplation (Clore 1994; Ellsworth 1994).

Appraisal theory, as discussed, is based on the idea of cognitive primacy, meaning that cognition precedes emotion. Feelings are not possible without some sort of "thought" that causes them - an appraisal. The notion of cognitive primacy is counter to the idea of affective primacy which posits that emotional responses are often automatic reactions elicited in mental processes that occur outside of consciousness (e.g. Forgas 1995; Zajonc 1980, 1984, 2001). Thus, feeling may not require thinking. Affective primacy does not challenge the existence of discrete emotions, just the process that elicit them.

In a sense, the choice between affective and cognitive primacy is misleading. As this debate evolved, it became evident that even the key proponents of the opposing views (Lazarus 1982, 1984 for cognitive primacy; Zajonc cited above for affective primacy) agree that some sort of mental processing has to happen for emotion to occur. The disagreement, though, lies in their respective definitions of "cognition." For affective primacy, cognition must be conscious, whereas cognitive primacy allows it to be either conscious or unconscious. Thus, the real debate is over the need to be aware of evaluations taking place in the mind that might ultimately lead to emotion. If we imagine

\footnotetext{
2 "Mere exposure" is a loaded phrase in psychology. Mere exposure to a novel object is sometimes enough to elicit spontaneous cognitive and affective evaluations (Bargh 1997). This is consistent with the process of cognitive appraisal outlined here. With an unfamiliar object, the appraisal process that leads from cognition into emotion can begin immediately upon exposure, and elicit those emotions almost instantaneously. Mere exposure effects, then, can cause assessments of novel objects quickly, but also recall evaluations of familiar objects from long term memory.
} 
a voter who sees Barack Obama and feels an emotion so quickly that she is not aware of the assessments occurring in her own mind, this is precisely the situation where affective and cognitive primacy partisans would see the same exact process and call it two different things. Indeed, while political science still discuss the merits of both primacy theories (e.g. Neuman, Marcus, and MacKuen 2007), psychologists have moved so far beyond that debate that breaking down the very distinction between emotion and cognition is now one of the hottest trends in their field.

Defining cognition in a manner consistent with affective or cognitive primacy has serious implications for measuring emotion (Redlawsk 2006). Affective primacy rejects typical introspective NES questions asking respondents if they have ever felt a certain emotion toward a candidate. Emotions occurring outside of conscious awareness still have consequences for subsequent cognitive processing (Beck 1976; Corteen and Wood 1972; Freud 1915; Edwards 1990, Kitayama 1991; Lang 1988; Murphy and Zajonc 1993; Zajonc 1994). From the affective primacy perspective, whatever emotional report a respondent gives is biased by emotions they do not necessarily know they have. Since emotion is largely automatic in this view, any survey answer is likely an error-ridden jumble of current feelings unknowingly influenced by unconscious emotion, not a genuine report of remembered emotional states. Researchers in this mold prefer less obtrusive measures like latency timers to assess whether affect, the remembered "residue" of a discrete emotion, has been stored as part of an object schema in long-term memory (Cassino and Lodge 2007; Lodge and Tabor 2000, 2005; Redlawsk 2002; Redlawsk, Civenttini, and Lau 2007). Theories like hot cognition do not dispute the existence of discrete emotions, but they abandon all hope of accurately measuring them. 
Cognitive primacy, however, has no quarrel with the introspective question approach. It recognizes the individual ability to encode the memories of emotional states in long-term memory and recall those memories when prompted (Christianson and Engelberg 1999; McGaugh 2003). Such items certainly cannot capture unconscious emotion and likely underestimate weak or infrequent emotions. Nevertheless, they can provide some insight into previous emotional states, particularly the strong and frequent emotions that are most likely to influence individual behavior.

\section{Valence Models}

A second school of emotion structure that has influenced political science advocates valence models (Neuman et al. 2007). The feeling thermometer and most hot cognition research (e.g. Lodge and Tabor 2000) are based upon this model. It posits a single bipolar dimension of emotion, with positive/approach anchoring one end and negative/avoidance the other. Though valence models are normally described as an emotion model, they are theoretically more consistent with affect than emotion since valenced emotional states are general, diffuse feelings rather than distinct emotions with unique causes, expressions, and action tendencies. Figure 1.2 illustrates the valence model.

Discrete and valence models have little in common. The one link between them stems from the Ortony et al. (1988) model discussed previously. They posit that emotions toward familiar, frequently encountered objects may ultimately evolve into a love/hate emotional response. For example, individuals may have experienced such a wide array of emotions toward Barack Obama for so long that their feelings have transformed into a pure liking or disliking sentiment. This is not to say that individuals do not experience 
discrete emotional states toward him, but it may be that these emotions are so frequently felt and accessed from memory that, to the extent that they are related, they have become melded into something resembling affect. Thus, whether valence models are actually a separate structural model or a subset of appraisal theory is debatable.

Figure 1.2: Valence Model of Emotion

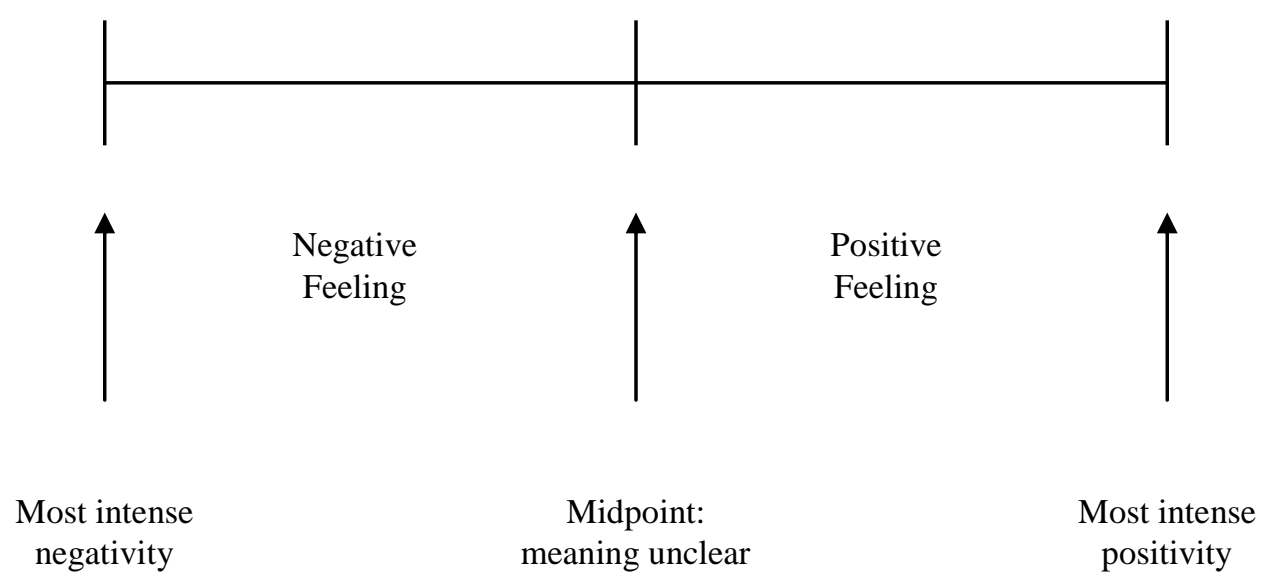

\section{Multidimensional Models}

A third school with a significant following in political science conceives of emotion as existing in multiple dimensions. Most theories posit two orthogonal dimensions (Fabrigar, Visser, and Browne 1997, Larsen and Diener 1992; Plutchik and Conte 1997; Remington, Fabrigar, and Visser 2000; Russell 1980), though others hypothesize three (e.g. Marcus 2002). Most evidence for the dimensional school comes from factor loadings on discrete emotion items asked in surveys like the NES (e.g. Marcus et al. 2006) and work showing that individuals tend to experience certain emotions together in reaction to stimuli (e.g. Lang et al. 1993). The argument for dimensionality is that the 
variance that discrete emotions share is more important than anything making those emotions unique (Lazarus 1991).

Scholars disagree about the dimensions that should characterize multidimensional models (Marcus et al. 2006; Neuman et al. 2007). The fact that emotion structure is dynamic rather than static complicates this debate, causing scholars to talk past one another rather than engage in genuine debate over the specific contexts that give rise to a particular dimensional structure (Lazarus 1991). The term "circumplex" describes any multidimensional emotional space. Researchers have proposed numerous ways to define the circumplex, but let us review the few models that have influenced political science.

\section{Figure 1.3: Valence-Arousal Model of Emotion}

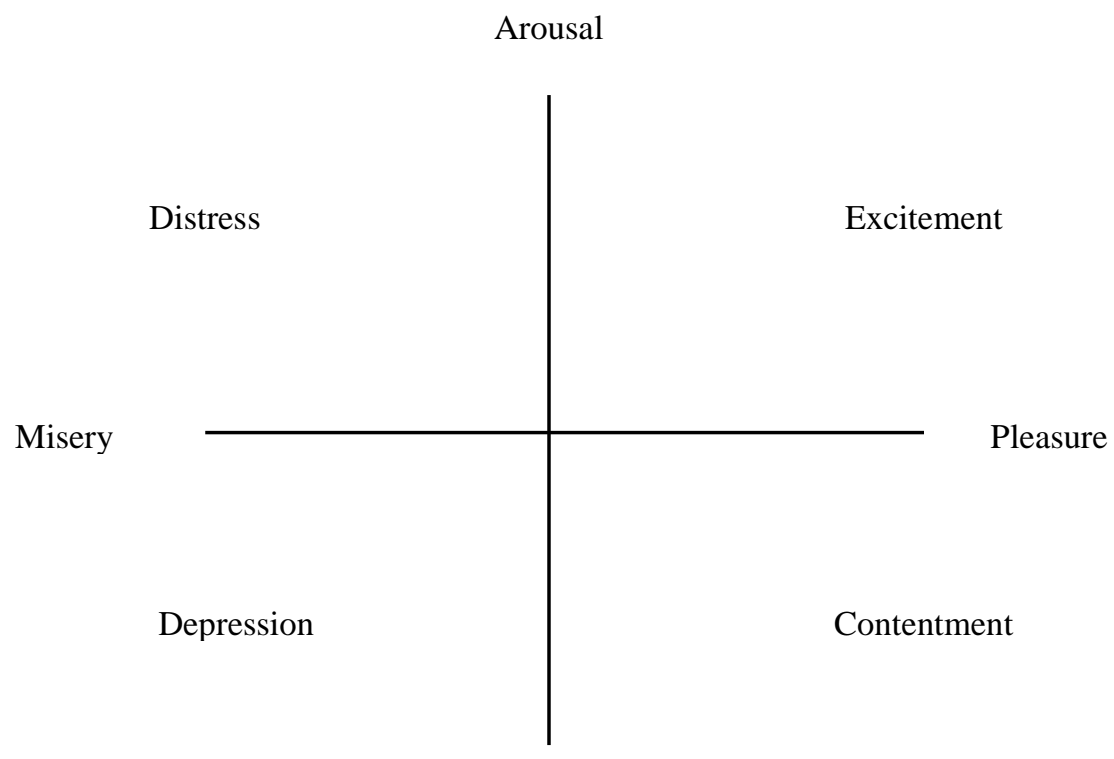

Sleepiness

One popular version of the circumplex posits a valence dimension and a second arousal dimension (Figure 1.3; Russell 1980). The poles of the valence dimension 
represent the most extreme positive and negative emotions possible, though the meaning of the midpoint is ambiguous much like that of the feeling thermometer. In practice, most scholars ignore the arousal dimension because of disagreement over its interpretation, though most who do address it interpret it as intensity of feeling (Clore and Ortony 2000).

\section{Figure 1.4: Plotted Two-Factor Structure of the Circumplex}

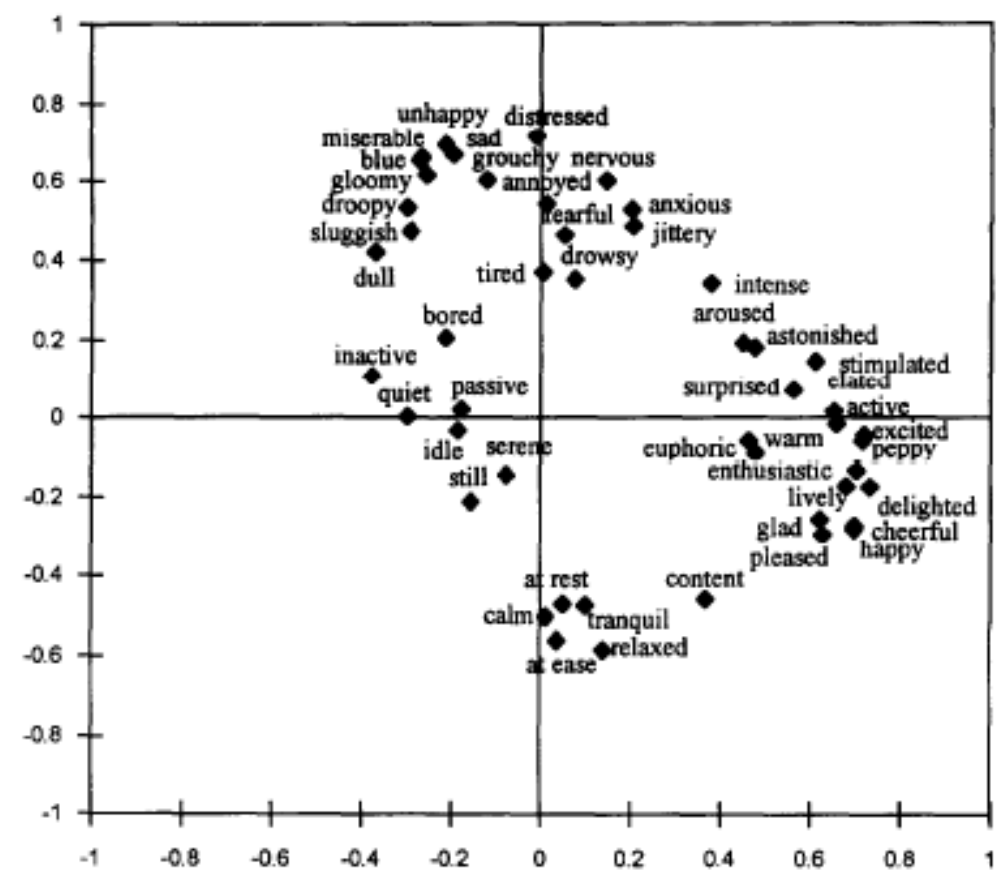

An alternative model hypothesizes orthogonal positive and negative dimensions that vary in intensity (Cacioppo and Berntson 1994, 1999; Cacioppo, Gardner, and Berntson 1997, 1999; Watson et al. 1999). The affective intelligence model is grounded in this definition of the circumplex. It posits that the negative dimension, labeled "anxiety," is activated by novelty when unusual or unfamiliar stimuli are encountered that merit extra thought or attention and a deviation from routine behavior (Marcus and MacKuen 1993; Marcus et al. 2000). The positive dimension, called "enthusiasm," reacts 
to familiar stimuli that elicit habitual patterns of behavior. Figure 1.4 illustrates this variant of the circumplex (Rusting and Larsen 1995). Marcus (2002) has partially revised the theory to add a third dimension, aversion, but it has received less scholarly attention.

In sum, though there is consensus on defining emotion, there is significant disagreement over its structure. The goal of the dissertation is not to provide answers to the questions that have captivated psychologists for decades, but writing about emotion necessitates certain assumptions about the answers to some of these questions. I adopt the core definition of an emotion as a psychological and physiological response to the evaluation that an attitude objects holds consequences for individual or group goals. In the structure debate, my work is grounded in appraisal theory, so I presume that discrete emotions exist. This choice necessarily means that I view emotions as based on cognition, though, as discussed, that debate is largely one of terminology and does not change the basic psychological processes upon which most scholars agree. Lastly, though I recognize there are certain deficiencies in introspective emotion questions, I clearly believe they have some validity as measures of emotion. No measurement tool is perfect, and the weakness of NES questions in assessing unconscious processes is not of such overwhelming concern to me that I would opt for a less obtrusive alternative.

This chapter has provided a basic introduction to emotion with an emphasis on how psychological theories and debates inform political science research. Chapter 2 proposes my theory of how political sophistication promotes emotional responsiveness to political stimuli and tests that theory empirically. Chapter 3 offers a quasi-experiment using campaign advertising in the 2000 election to introduce the role of information context in 
moderating the sophistication-emotion relationship, and to show how sophistication moderates the effect of emotion on attitudes and voting behavior. Chapter 4 describes a web-based randomized experiment I conducted to further test the sophistication-emotion relationship and to explore how sophistication moderates the effect of emotion on learning. I offer a summary of the empirical results in my conclusion section and discuss the broader implications of my research for the study of emotion in political science. 


\title{
Chapter 2
}

\section{Political Sophistication as a Predictor of Emotion}

\begin{abstract}
This chapter proposes a theory of how political sophistication promotes emotional responsiveness to politics, challenging the view that emotion is a function of low sophistication. It argues explicitly that high sophisticates are more likely to experience emotion in reaction to politics than low sophisticates, then tests this proposal empirically. I use pooled 1980-2004 NES data to examine the effect of individual sophistication on reported emotions toward presidential candidates. To rule out an alternative satisficing hypothesis that might explain my results, I analyze paradata from a web-based survey of approximately 390 undergraduates I conducted in the fall of 2008 . The reported results strongly support the sophistication hypothesis. High sophisticates are indeed more likely to feel emotions toward political stimuli than low sophisticates. Furthermore, the emotions of high sophisticates are more accessible and certain to them than they are to low sophisticates, ruling out the alternative satisficing explanation.
\end{abstract}




\section{Defining Political Sophistication}

"Political sophistication" is a concept that has had many identities. Scholars have variously used "political expertise," "political knowledge," “cognitive complexity," "political information," "citizen competence," and "political literacy" to label the idea that some citizens possess a deeper understanding and grasp of politics than others. The recent consensus is to define sophistication as individual political knowledge (e.g. Lupia 1994; Bartels 1996; Delli Carpini and Keeter 1996), the rational being that as more learning occurs knowledge becomes more organized and complex (Fiske, Kinder, and Larter 1983). Thus, the knowledgeable are more likely to understand and think about politics in a nuanced manner. Though scholars have not always agreed on one standard of sophistication, the core of all their characterizations is the notion that sophisticated citizens are knowledgeable about and engaged with the political system; they understand it and have mastery over it, whereas the unsophisticated do not.

Some scholars suggest, however, that sophistication is merely am umbrella term for a concept that should rightly include more than just knowledge of political facts and that our sophistication measures should not be limited to one indicator. Proposed components include interest, participation, attention, information exposure, the ability to link political concepts when reasoning, and the ability to think critically about political questions (e.g. Druckman 2003; Fiske et al. 1983; Krosnick 1990; Neuman, 1986; Rahn, Aldrich, and Borgida, 1994). I opt for a broad yet reasonably parsimonious definition of sophistication that includes some of the traits normally deemed desirable characteristics of "good" citizens (Delli Carpini and Keeter 1996). Sophisticates, from my view, should possess several qualities that make them more engaged with politics, including greater 
political interest, attention, and knowledge. Sophistication, then, is best thought of as a latent construct, with these traits acting as indicators. Figure 2.1 depicts how I construe sophistication, with the circle representing sophistication qualities as a latent quality represented by three constituent indicators.

\section{Figure 2.1: Political Sophistication as a Latent Construct}

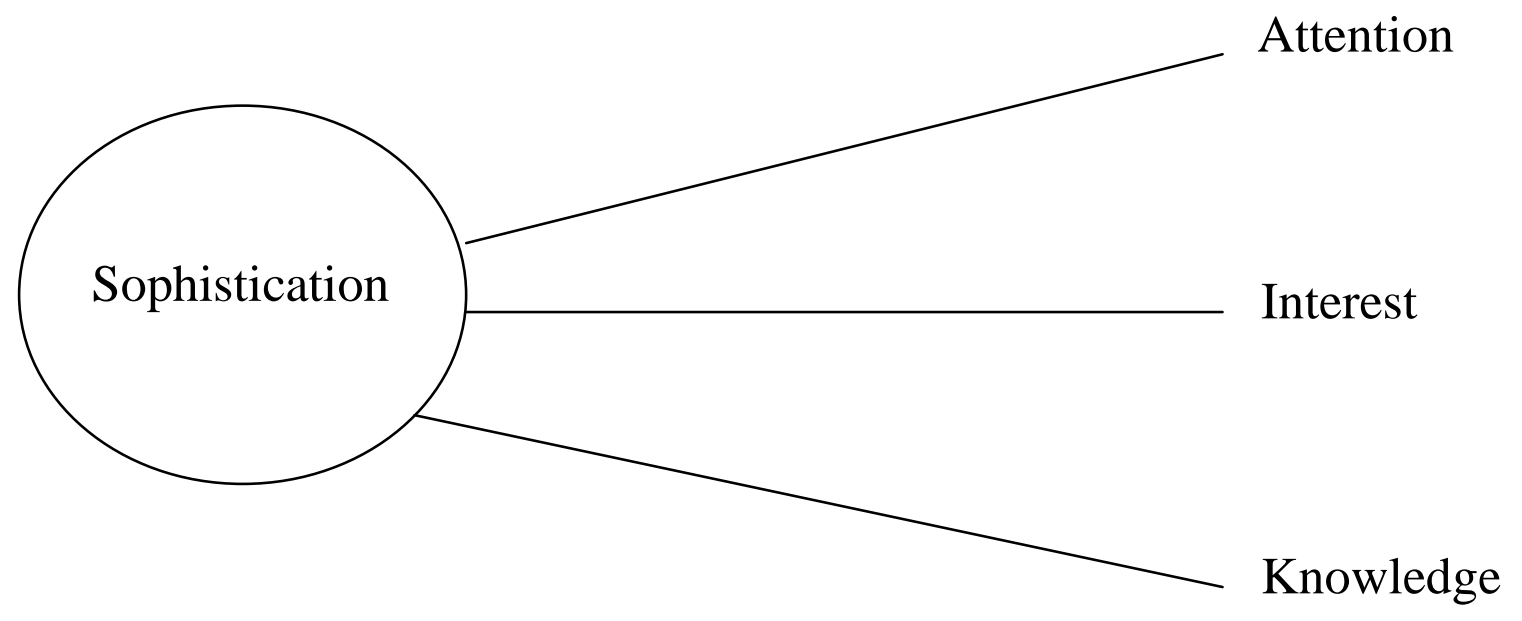

\section{Political Sophistication and Emotion}

Discrete models carry significant implications for our understanding of how political stimuli elicit emotion. Appraisal theory suggests that individuals who are more capable of making the appraisals that are the first step in the emotional reaction process should be more emotionally responsive to stimuli. I argue that high political sophisticates are better able to make those appraisals than low sophisticates, thereby making the high sophisticate more emotionally responsive to political attitude objects. Thus, empirical analyses should reveal that high sophisticates, given their greater knowledge of and engagement with the political system, are more likely to experience emotion in reaction to political objects than low sophisticates. 
The qualities that represent sophistication - attention, interest, and knowledge work together to facilitate engagement and understanding, making those individuals possessing more of these attributes more emotional about political objects. Interest and attention encourage information exposure (Steenbergen and Lodge 2003), so the high sophisticate arguably knows more about politics given those characteristics. As information is encountered and processed into long-term memory, it is stored along associative networks consisting of nodes that represent concepts and links between nodes that represent associations between concepts (Anderson 1983; Collins and Quillian 1969; Collins and Loftus 1975; Lau 1989). High sophisticates are more motivated to consume political information and, as a result, have more of it, so they have richer associative networks than low sophisticates. Greater learning creates more links between nodes in long-term memory. These linkages deepen understanding of specific attitude objects and help individuals are better engage with new political information (Fiske et al. 1983).

For example, most people have a node for Barack Obama, but the nodes of high sophisticates are likely linked to nodes of more objects than those of low sophisticates. Low sophisticates may know that Obama is a Democrat and link him to a Democratic Party node, and probably connect him to a few high profile issues. High sophisticates, however, can make more of those links, connecting Obama to nodes for more issues and other objects than the low sophisticate. Indeed, high sophisticates likely know more about specific issues than low sophisticates, so the links between Obama and those issues cascade through spreading activation to a wealth of information stored in memory about other political objects only indirectly linked to the President (Anderson 1983; Collins and Loftus 1975; Collins and Quillian 1969; Steenbergen and Lodge 2003). Thus, as high 
sophisticates maintain richer associative networks, they understand political objects better than low sophisticates and are more capable of connecting disparate political concepts.

Figure 2.2 depicts two associative networks. The network on top belongs to a low sophisticate who knows just a few facts about Obama and health care, and only links the two concepts with one piece of information. Maybe this person only knows that Obama is a health care reform advocate. The bottom network belongs to a high sophisticate. This individual knows more about both Obama and health care independently since both nodes have more spokes attached than those for the low sophisticate, and has three pieces of information linking the two concepts. The high sophisticate likely links Obama to more issues than the low sophisticate as well, but this depiction is limited to just two nodes.

Figure 2.2: Sample Obama Associative Networks

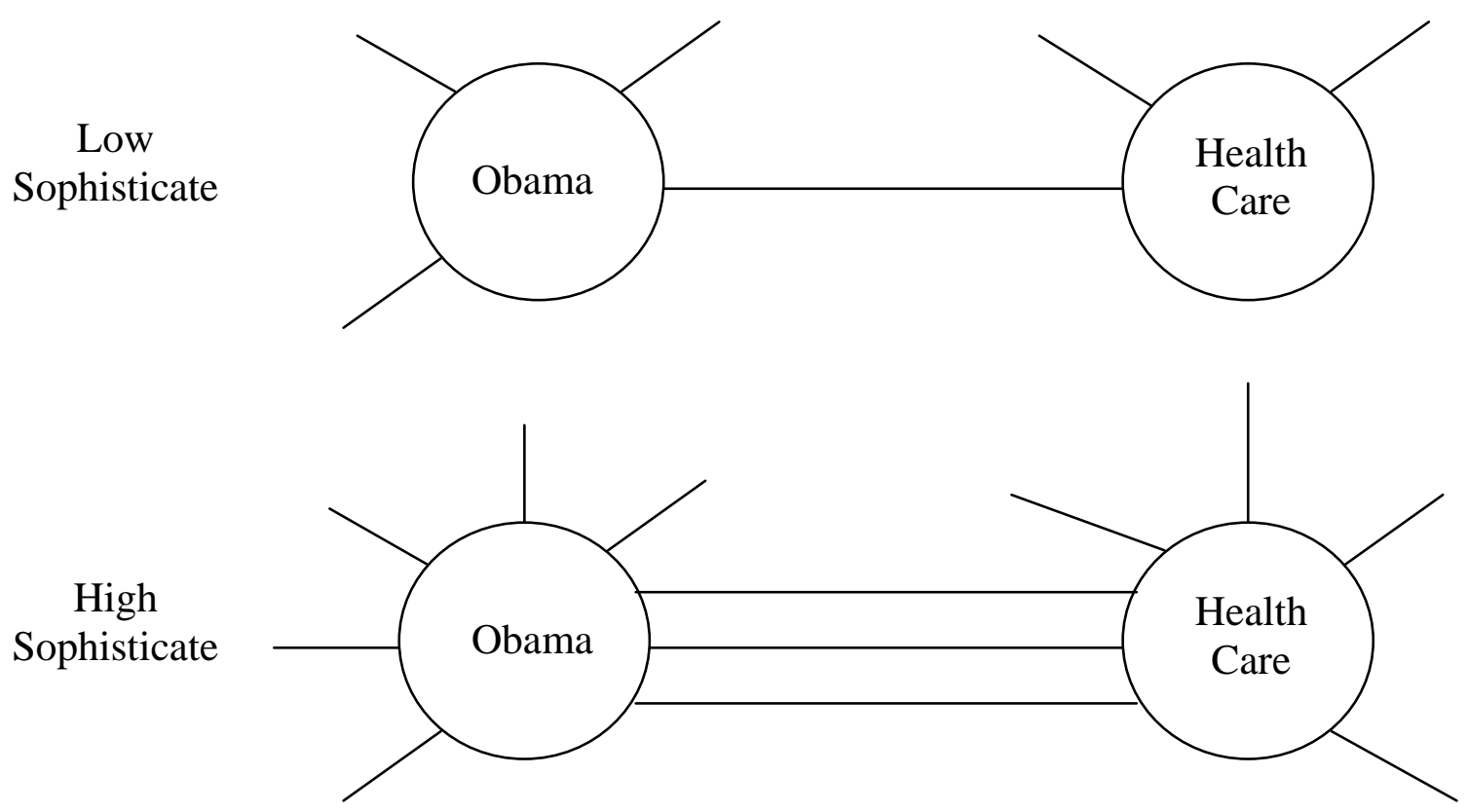

When high sophisticates encounter political stimuli, their greater knowledge and understanding of politics enhance their ability to connect those objects to their goals and 
desires, so the high sophisticate is better able to make emotional appraisals. For example, Lyndon Johnson's infamous Daisy ad is a classic case of fear in campaign advertising (Jamieson 1996). The ad intended to scare voters into thinking that Barry Goldwater would be reckless with nuclear weapons, thereby threatening the desire for peace and security. The logical action associated with that fear was to vote for Johnson. To grasp the full meaning and react appropriately, viewers needed a certain level of understanding. Those who paid enough attention to know about Goldwater's hawkishness and Johnson's arms control position and who were interested in Cold War tensions were arguably more likely to understand the ad well enough to react with fear. Conversely, unsophisticated voters may not have gotten the nuances of the message.

The same logic applies any political stimulus, including issues, candidates, parties, and myriad other objects. Citizens must recognize their interests and understand how politics affects those interests in order to have emotional reactions to the political world. If individuals do not comprehend what is at stake in an election or policy debate because they do not grasp the substance, then they cannot put all the pieces of political puzzles together. If people cannot make these connections with politics, they are unlikely to react emotionally to its stimuli. This is not to say that low sophisticates are incapable of emotionally appraising politics, just that high sophisticates are more likely to do so.

\section{Hypotheses}

H1: Sophistication positively affects the likelihood of experiencing emotions in reaction to political stimuli. 
Given the discussion above, sophistication should be positively related to emotion self-reports in reaction to political stimuli. Thus, high sophisticates will be more likely to say they experience an emotion toward a political object than low sophisticates.

H2: Emotions are more accessible to high sophisticates than to low sophisticates.

To test $\mathrm{H} 1$ more rigorously, I analyze two types of survey paradata - response latency and response change - to understand how sophistication affects responses. High sophisticates may report more emotion because they take the survey more seriously. They might spend more time thinking about responses, making their reports more genuine reflections of emotions stored in long-term memory. Low sophisticates might satisfice, answering with quick and superficial responses to finish the survey faster (Krosnick and Alwin 1987). Saying a fast "no" is easier than searching for memories of emotions, and avoids the follow-up frequency of emotion question in the NES.

If high sophisticates are more emotional about politics, however, their feelings should be more accessible than those of low sophisticates for whom emotion is less frequent. Accessibility is measured by latency, the time taken to answer a question. More accessible attitudes are retrieved from long-term memory faster than those requiring greater effort to remember (Fazio and Williams 1986). Thus, rehearsed opinions are reported faster than attitudes that are constructed on the spot or rarely expressed (Fazio, Powell, and Herr 1983). Chronic emotions are also more likely to be stored in long-term memory, making them more accessible (McGaugh 2003; Robinson and Clore 2002). Sophistication should, thus, reduce response time, with high sophisticates having shorter 
latencies on emotion items than low sophisticates. If sophistication lengthens latency, though, this would support the alternative satisficing explanation.

\section{H3: Emotions are more certain to high sophisticates than to low sophisticates.}

The number of times survey respondents change answers is an indicator of uncertainty (Bassili and Fletcher 1991; Heerwegh 2003). Respondents with unstable or uncertain attitudes are generally more uncertain of their answer choices, so they tend to change their initial responses more often. Emotions should be easier for high sophisticates to recall since they experience them more often than low sophisticates. Thus, high sophisticates should be more certain of their emotions, and, as a result, change their answers fewer times as an indicator of that certainty. Conversely, low sophisticates should be more uncertain as they are less likely to have accessible memories of their feelings, so they should exhibit more response changes.

\section{Emotion Appraisals of Presidential Candidates}

\section{Data}

H1 is tested on pooled 1980-2004 NES data. The NES is the only widely available representative national study that regularly incorporates emotional reactions to political objects, namely major party presidential candidates. It is a useful starting point for analysis because it has substantial variance in respondent education, a variable that is positively correlated with sophistication. 


\section{Measures}

Emotion. Every NES since 1980 has measured emotions toward presidential candidates, with anger, fear, hope, and pride being the four consistent items. The 2004 NES asks, "Has (Bush/Kerry), because of the kind of person he is or because of something he has done, ever made you feel (emotion)?" This is a yes/no question, and respondents saying "yes" answer a subsequent frequency item indicating how often they have felt a particular emotion. For easier presentation, I report analyses on the dummy item, but the findings are comparable when the dependent variable is an ordinal measure ranging from "no" to "very often." I also find similar results when the dependent variable is a dummy indicating whether the respondent reports at least one emotion. Thus, the reported results are robust to changes in the form of the dependent variable. In each NES, less than $1 \%$ of respondents do not recognize candidates, answer "don't know," or refuse to respond, so almost all responses are valid reports.

Sophistication. Political sophistication is a factor score constructed from interest, knowledge, and attention. The NES has used a stable political interest item since 1980 . Every NES has different knowledge questions about recognition of figures, knowledge of political processes, or knowledge of majority parties in Congress. For all respondents additive scales are created using all knowledge questions in their respective years. The NES has measured general campaign attention since 1996, but previous versions only gauged attention to campaign news in specific media. Thus, general attention is used for 1996-2004, but attention to campaign news on TV and in newspapers are used for 19801992. The original media items are not consistent after 1992, so a single attention measure over time is not available. The knowledge, interest, and attention measures fit 
well empirically. Each indicator loads strongly on a single dimension in principal components analysis. ${ }^{3}$ The factor score combines these sophistication indicators into a standardized variable comparable across NES versions $(M=0, S D=1)$.

Controls. The NES analysis includes several controls which might influence emotions. Demographics include age, race $(1=$ white, $0=$ non-white $)$, sex $(1=$ female, 0 $=$ male $)$, education $(1=$ less than high school, $7=$ graduate degree $)$, and the cumulative NES income quintile measure $(1=$ bottom $20 \%, 5=$ top $20 \%)$. The standard 7 -point partisanship scale is recoded as party similarity matching respondent and candidate party ( 1 = strong out-partisan, $7=$ strong in-partisan $)$. The standard 7 -point ideology scale is scaled similarly $(1=$ strong opposite ideology, $7=$ strong same ideology $) .{ }^{4}$ Issue distance is measured as the average squared deviation between the respondent's positions and the mean candidate position (Alvarez 1997). Issue items are not consistent across NES versions, but the final distance measure is standardized.

\section{Results}

There is substantial variation in how respondents emotionally appraise the 14 candidates in the pooled data. The least common emotion in both the aggregated and disaggregated data is fear, with only $24.95 \%$ of cases reporting that feeling in the pooled analysis. Hope is the most common emotion in the pooled data and for most individual candidates as

\footnotetext{
${ }^{3}$ The factor score is constructed separately for each NES sample in the pooled analysis and then merged with the pooled data. Were attention operationalized similarly across years, the factor score could be calculated in the pooled data itself. However, the 1980-1992 samples have two attention measures whereas later samples have one. The seven Eigenvalues range from 1.944 to 2.26. All factor loadings for the constituent indicators are above .72 across the seven samples.

${ }^{4}$ Democratic nominees are assumed liberal and Republicans conservative in matching respondent ideology. Only emotions toward the major party nominees are included in this analysis.
} 
$47.6 \%$ of cases report it in the aggregate. Anger and pride are more moderately felt with $36.66 \%$ and $38.9 \%$ of cases reporting them respectively.

Table 2.1: Emotions toward Presidential Nominees in Pooled NES, 1980-2004

\begin{tabular}{|c|c|c|c|c|}
\hline & Anger & Fear & Hope & Pride \\
\hline Sophistication & $.383 * * *$ & $.279 * * *$ & $274 * * *$ & $.33 * * *$ \\
\hline & $(.022)$ & $(.023)$ & $(.022)$ & $(.022)$ \\
\hline Partisanship & $-.279 * * *$ & $-.277 * * *$ & $.453 * * *$ & $.374 * * *$ \\
\hline & $(.01)$ & $(.011)$ & $(.01)$ & $(.01)$ \\
\hline Ideology & $-.09 * * *$ & $-.123 * * *$ & $.143 * * *$ & $.078 * * *$ \\
\hline & $(.014)$ & $(.016)$ & $(.015)$ & $(.014)$ \\
\hline Issue Distance & $\begin{array}{c}.116^{* * * *} \\
(.009)\end{array}$ & $\begin{array}{c}.129 * * * \\
(.01)\end{array}$ & $\begin{array}{c}-.135 * * * \\
(.01)\end{array}$ & $\begin{array}{c}-.11 * * * \\
(.01)\end{array}$ \\
\hline Age & $\begin{array}{c}-.012^{* * * *} \\
(.001)\end{array}$ & $\begin{array}{c}-.011 * * * \\
(.001)\end{array}$ & $\begin{array}{c}-.004 * * \\
(.001)\end{array}$ & $\begin{array}{l}-.002 \\
(.001)\end{array}$ \\
\hline Education & $\begin{array}{c}.059 * * * \\
(.013)\end{array}$ & $\begin{array}{l}.066 * * * \\
(.014)\end{array}$ & $\begin{array}{l}.012 \\
(.013)\end{array}$ & $\begin{array}{l}-.032 * \\
(.013)\end{array}$ \\
\hline Female & $\begin{array}{l}.086^{*} \\
(.037)\end{array}$ & $\begin{array}{c}.106 * * \\
(.04)\end{array}$ & $\begin{array}{c}.213^{* * * *} \\
(.038)\end{array}$ & $\begin{array}{c}.177 * * * \\
(.038)\end{array}$ \\
\hline Income & $\begin{array}{l}-.013 \\
(.018)\end{array}$ & $\begin{array}{l}.018 \\
(.019)\end{array}$ & $\begin{array}{l}-.033+ \\
(.019)\end{array}$ & $\begin{array}{l}-.016 \\
(.019)\end{array}$ \\
\hline White & $\begin{array}{c}.263^{* * * *} \\
(.056)\end{array}$ & $\begin{array}{c}.183^{* * *} \\
(.06)\end{array}$ & $\begin{array}{l}-.079 \\
(.056)\end{array}$ & $\begin{array}{l}.033 \\
(.055)\end{array}$ \\
\hline Constant & $\begin{array}{c}1.752 * * * \\
(.152)\end{array}$ & $\begin{array}{l}-.213 \\
(.159)\end{array}$ & $\begin{array}{c}-.896^{* * * *} \\
(.154)\end{array}$ & $\begin{array}{c}-1.139 * * * \\
(.149)\end{array}$ \\
\hline LR & $3415.36 * * *$ & $2666.25^{* * * *}$ & $4683.5^{* * * *}$ & $3992.24 * * *$ \\
\hline $\begin{array}{l}\text { Pseudo-R2 } \\
\mathrm{N}\end{array}$ & .162 & .144 & .216 & .188 \\
\hline
\end{tabular}

Note. Entries are unstandardized logistic regression coefficients; standard errors in parentheses; fixed effects were estimated with dummies for individual candidates (not shown); cluster corrected standard errors used with cases clustered on the respondent as all respondent appear in the model twice; results above are virtually identical when missing predictor values are imputed; $+\mathrm{p}<.1,{ }^{*} \mathrm{p}<.05, * * \mathrm{p}<.01, * * * \mathrm{p}<.001$

The pooled data strongly support $\mathrm{H} 1$ that that sophistication is positively related to the experience of emotion toward political objects. Table 2.1 presents logit results for discrete emotion dummies. In each model, higher levels of political sophistication make respondents more likely to experience emotional reactions to candidates. This 
relationship is maintained after controlling for political factors that might affect emotionality (partisanship, ideology, and issue distance), and the demographic controls. Though partisanship has the largest effect on emotions when all variables are standardized, sophistication and issue distance are second with roughly similar effects.

Figure 2.3 shows predicted probabilities for anger, fear, hope, and pride when sophistication is at its mean (0) and $\pm 1 / \pm 2 S D$. Let us consider those respondents scoring above the mean as high sophisticates, and those below as low sophisticates. Though $95 \%$ confidence intervals are not shown, each of the five plotted points on a curve is significantly different from the others. High sophisticates are significantly more likely to experience any of the four emotions as each of the curves slopes substantially upwards. Low sophisticates, the ones most stereotyped as being emotional about politics, are likely to feel none of the four emotions as each of the plotted points below 0 is under the $50 \%$ probability mark. Thus, low sophisticates are always more likely to be emotionless than emotional, at least in candidate appraisals. Indeed, the only respondents with a better than even chance of feeling any of the emotions are high sophisticates.

These results vividly demonstrate the degree of emotional disengagement among low sophisticates, but, more importantly, they also strongly support the sophistication hypothesis in H1. Figure 2.3 directly counters the idea that the least informed and engaged citizens are most likely to react emotionally in political contexts. Low sophisticates on average lack emotion. It is the high sophisticate who is most likely to experience emotion in reaction to political stimuli. Indeed, the NES consistently shows that as individuals become more engaged, they gain the understanding of politics that is the necessary precursor to being emotional about it. 
Figure 2.3: Probability of Discrete Emotions toward Presidential Nominees

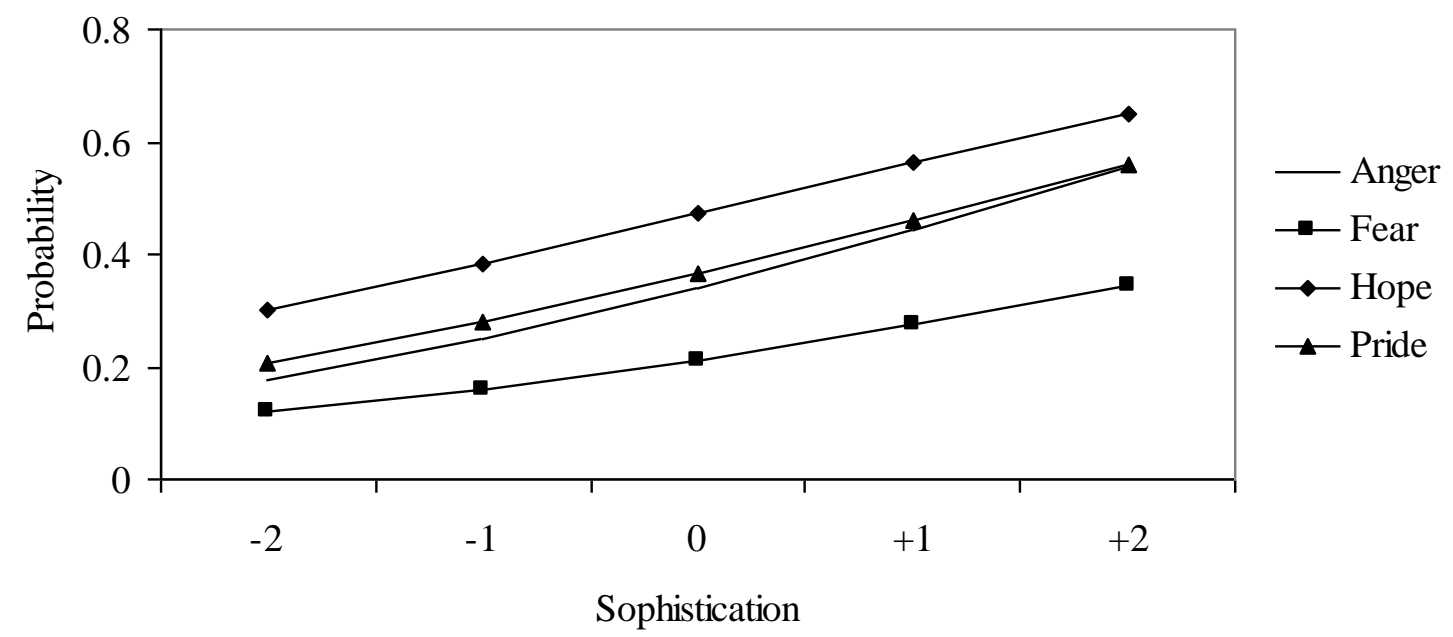

\section{Getting Inside the Response Process}

The NES can show a relationship between sophistication and emotion, but it does not provide the means to test this association more rigorously. To further test the sophistication hypothesis, I conducted an original survey to gather paradata, information about the process of answering questions, to understand how sophistication affects respondent answers. Two types of paradata, latencies and response changes, are analyzed.

\section{Data}

A web survey of 388 undergraduates at the University of North Carolina at Chapel Hill was conducted in late November of 2008. Students participated to fulfill a political science research requirement. ${ }^{5}$ Participants were 18 to 33 years old $(M=19.35, S D=$

\footnotetext{
${ }^{5}$ Age, education, and computer familiarity affect web latency in the broader population (Fricker, Galesic, Tourangeau, and Yan 2005; Yan and Tourangeau 2005). Though student samples hold age and education relatively constant, I control for academic year as a proxy for the small variance among students on those variables. UNC students are required to own a laptop, so computer familiarity is constant. Bias is not a major concern as student and population samples perform similarly in emotion research (Zucker and Weiner 1993), and the same emotion model used in Table 2.1 gives similar results in the web survey.
} 
1.69) with a plurality being first year students $(M=1.97, S D=.98)$. Most students were female $(62 \%)$ and white $(78 \%$; 9\% black, 5\% Asian, 3\% Hispanic), demographics reflective of the university population. The sample leaned Democratic $(M=3.62, S D=$ 2.03; 7-point scale) and slightly liberal $(M=3.69 ; S D=1.65 ; 7$-point scale). See Appendix A for the wording of questions from this survey used in analyses presented in this dissertation.

\section{Measures}

Latency Ratios. Respondents answered four questions about their emotions toward the Iraq War: anger at the US, anger at Iraqis, guilt about US actions, and sympathy for Iraqis. Responses were timed using a latent timer that measured the time respondents took to read and answer each question. Analyzing latencies can be problematic, though, because of outliers and their potential influence (Fazio 1990). Latency distributions are invariably skewed rightward, with most observations grouped near zero and long right tails. The most common outlier remedy is controlling for baseline response, or each person's average response time on a set of filler items (Fazio 1990). Baselining minimizes outlier influence, and controls for the natural tendency of some people to take longer answering questions. I average latencies on five demographic items - religious affiliation, race, academic year, sex, and whether the respondent is presently in the military - to construct a baseline response time for each respondent.

To place respondents on the same time scale, ratios of emotion latency to the sum of the emotion latency plus each respondent's baseline, or (emotion/[emotion + baseline]), were calculated for each emotion (Fazio 1990). Thus, each respondent has 
four unique ratios representing their response times. Ratios range from 0 to 1 . Scores of .5 mean the emotion question time is equivalent to the baseline. Scores below .5 indicate emotion latencies faster than the baseline, and scores above .5 indicate slower latencies. ${ }^{6}$

Response Changes. The survey program I used, Qualtrics, counts the number of button clicks on a webpage. Respondents choosing only one answer score a 2 (one click for choosing an answer and another click for hitting submit), so a change count on emotion items was constructed by subtracting 2 from the raw data. To deter response optimizing (Krosnick 1991), one question was displayed per page and respondents could not return to previous items. Similar to the latency baseline, an average response change was calculated using the five baseline items to account for tendencies to make errors with the web instrument and the propensity to change answers regardless of question type.

Controls. Several controls were included for factors that might affect latency. There were partisan strength $(0=$ pure Independent, $3=$ strong partisan $)$ and ideological strength $(0=$ moderate, $3=$ strong ideologue $)$ variables. Respondents also answered a blame attribution item that was transformed into a 3-point blame strength variable $(0=$ Iraqis and US equally to blame; 2 = Iraqis or US entirely to blame). To determine whether latency results are specific to emotion questions or apply to survey questions in general, respondents evaluated four agree-disagree items about Iraq policy: humanitarian aid, infrastructure repair, keeping troops in Iraq, and sending more troops.

\footnotetext{
${ }^{6}$ Beta regression is normally more appropriate for ratios than OLS, but both yield identical predicted ratios.
} 
Table 2.2: Latency Ratios of Emotion and Policy Items

\begin{tabular}{|c|c|c|c|c|c|c|c|c|}
\hline & \multicolumn{4}{|c|}{ Emotion Items } & \multicolumn{4}{|c|}{ Policy Items } \\
\hline & Anger at US & $\begin{array}{l}\text { Guilt about } \\
\text { US Actions }\end{array}$ & $\begin{array}{l}\text { Anger at } \\
\text { Iraqis }\end{array}$ & $\begin{array}{l}\text { Sympathy } \\
\text { for Iraqis }\end{array}$ & $\begin{array}{c}\text { Humanitarian } \\
\text { Aid }\end{array}$ & $\begin{array}{c}\text { Repair } \\
\text { Damage }\end{array}$ & $\begin{array}{l}\text { Keep } \\
\text { Troops }\end{array}$ & $\begin{array}{l}\text { Send } \\
\text { Troops }\end{array}$ \\
\hline Sophistication & $\begin{array}{c}-.034 * * * \\
(.008)\end{array}$ & $\begin{array}{c}-.026 * * * \\
(.007)\end{array}$ & $\begin{array}{c}-.037 * * * \\
(.007)\end{array}$ & $\begin{array}{c}-.033 * * * \\
(.008)\end{array}$ & $\begin{array}{l}.009 \\
(.008)\end{array}$ & $\begin{array}{l}.023 * * \\
(.008)\end{array}$ & $\begin{array}{l}.021 * * \\
(.008)\end{array}$ & $\begin{array}{l}.013 \\
(.008)\end{array}$ \\
\hline Party Strength & $\begin{array}{l}-.007 \\
(.009)\end{array}$ & $\begin{array}{c}-.008 \\
(.009)\end{array}$ & $\begin{array}{l}-.003 \\
(.009)\end{array}$ & $\begin{array}{c}-.018 * \\
(.009)\end{array}$ & $\begin{array}{l}-.018 * \\
(.009)\end{array}$ & $\begin{array}{l}-.004 \\
(.009)\end{array}$ & $\begin{array}{l}-.02 * \\
(.009)\end{array}$ & $\begin{array}{l}-.019 * \\
(.009)\end{array}$ \\
\hline $\begin{array}{l}\text { Ideology } \\
\text { Strength }\end{array}$ & $\begin{array}{l}-.004 \\
(.009)\end{array}$ & $\begin{array}{c}.003 \\
(.009)\end{array}$ & $\begin{array}{l}-.007 \\
(.009)\end{array}$ & $\begin{array}{c}.003 \\
(.009)\end{array}$ & $\begin{array}{c}.007 \\
(.009)\end{array}$ & $\begin{array}{l}-.006 \\
(.01)\end{array}$ & $\begin{array}{l}-.001 \\
(.009)\end{array}$ & $\begin{array}{c}.007 \\
(.011)\end{array}$ \\
\hline $\begin{array}{l}\text { Blame } \\
\text { Strength }\end{array}$ & $\begin{array}{l}.008 \\
(.013)\end{array}$ & $\begin{array}{l}-.004 \\
(.013)\end{array}$ & $\begin{array}{l}-.007 \\
(.013)\end{array}$ & $\begin{array}{l}-.003 \\
(.013)\end{array}$ & $\begin{array}{l}.001 \\
(.013)\end{array}$ & $\begin{array}{l}.015 \\
(.013)\end{array}$ & $\begin{array}{l}.012 \\
(.013)\end{array}$ & $\begin{array}{l}-.016 \\
(.014)\end{array}$ \\
\hline Year & $\begin{array}{l}-.005 \\
(.007)\end{array}$ & $\begin{array}{l}.004 \\
(.007)\end{array}$ & $\begin{array}{l}.004 \\
(.007)\end{array}$ & $\begin{array}{l}-.001 \\
(.007)\end{array}$ & $\begin{array}{l}-.002 \\
(.007)\end{array}$ & $\begin{array}{l}-.004 \\
(.007)\end{array}$ & $\begin{array}{l}.003 \\
(.008)\end{array}$ & $\begin{array}{l}.005 \\
(.008)\end{array}$ \\
\hline Constant & $\begin{array}{c}.563 * * * \\
(.024)\end{array}$ & $\begin{array}{c}.592 * * * \\
(.023)\end{array}$ & $\begin{array}{c}.615 * * * \\
(.023)\end{array}$ & $\begin{array}{c}.579 * * * \\
(.023)\end{array}$ & $\begin{array}{c}.656 * * * \\
(.024)\end{array}$ & $\begin{array}{c}.614 * * * \\
(.024)\end{array}$ & $\begin{array}{c}.596 * * * \\
(.024)\end{array}$ & $\begin{array}{c}.615 * * * \\
(.025)\end{array}$ \\
\hline Adjusted $\mathrm{R}^{2}$ & .061 & .033 & .075 & .124 & .001 & .014 & .024 & .009 \\
\hline $\mathrm{N}$ & 368 & 366 & 366 & 364 & 369 & 370 & 369 & 372 \\
\hline
\end{tabular}

Note. Entries are unstandardized OLS coefficients; standard errors in parentheses; latencies shorter than $300 \mathrm{~ms}$ or longer than 3 SD above the mean were trimmed from the data before analysis (Bargh and Chartrand 2000) $+\mathrm{p}<.1, * \mathrm{p}<.05, * * \mathrm{p}<.01, * * * \mathrm{p}<.000$ 


\section{Results}

Table 2.2 reports OLS estimates for emotion and policy latency ratios. Sophistication reduces response time on all emotions in comparison to respondent baselines, but it does the opposite to policy items. Figure 2.4 plots predicted ratios for variables with significant sophistication effects. The downward slopes of emotion ratios demonstrate the negative effect of sophistication on emotion latencies, in contrast to the positive policy slopes. A key aspect of these results is how emotion ratios compare to baseline times. High sophisticates answer most emotion items at speeds slightly slower than their baselines. Respondents at two $S D$ above the mean, though, respond to anger at the US (.495) and sympathy for Iraqis (.48) slightly faster on average than their baselines.

\section{Figure 2.4: Latency Ratios for Emotion and Policy Items by Sophistication}

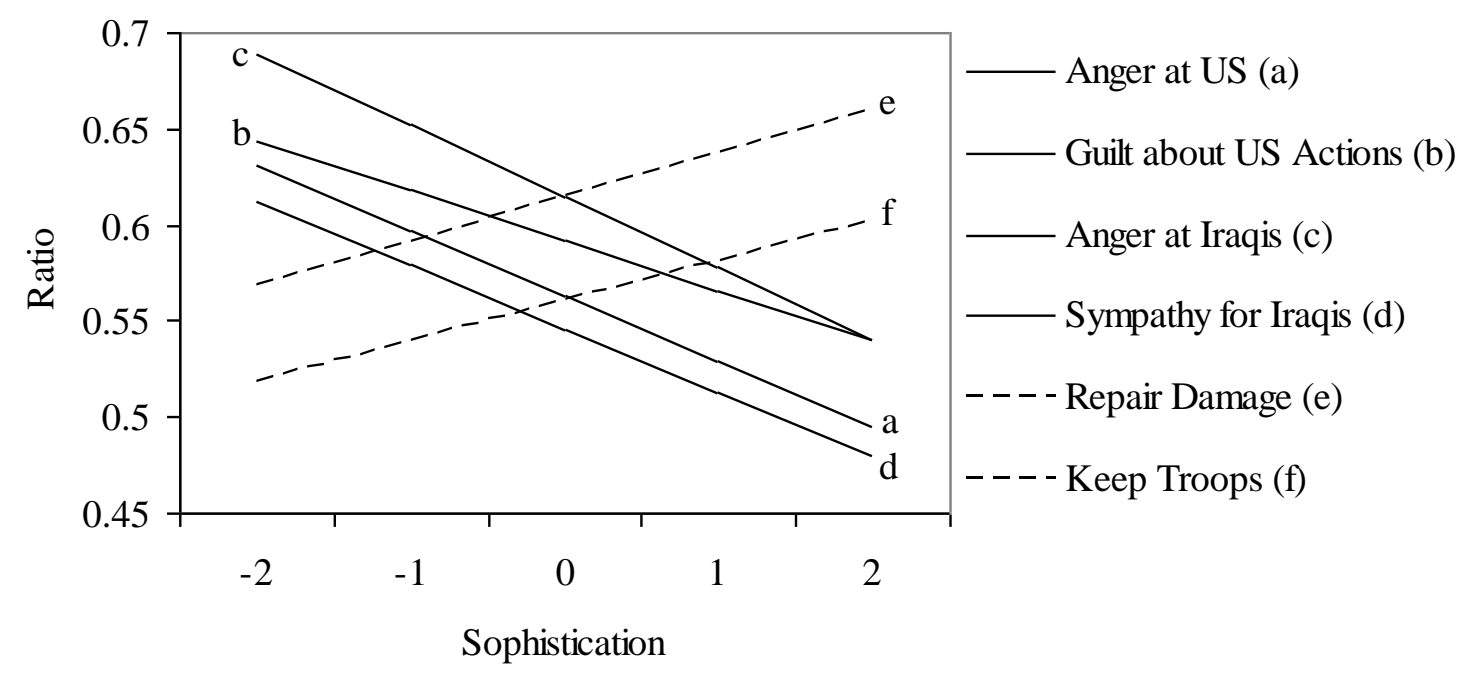

These results strongly support the argument that sophistication positively affects emotional responsiveness to politics. High sophisticates report emotions faster, evidence that memories of feelings are more accessible to them because those feelings are 
experienced more often. Indeed, the latencies of the highest sophisticates indicate that emotion questions are simple recall tasks to them. They respond to these inquiries about as fast as they answer the simple demographic items in the baseline. Low sophisticates, however, are not only less emotional, but take longer to say so. Their emotions are less frequent, so any feelings they remember are less accessible. They must work harder to search long-term memory, but are more likely to find nothing. This pattern is solid evidence against the alternative satisficing explanation. Were low sophisticates satisficing, they would not take longer to do it.

More importantly, the sophistication sign flips for the policy ratios, evidence that its effect is specific to emotion and not more cognition-oriented items or survey questions in general. Low sophisticates exhibit faster policy latencies, evidence of either satisficing or having fewer considerations to sort when constructing responses (Zaller 1992). High sophisticates, though, may weigh more considerations when judging policy options, so they take longer to submit answers. These longer latencies indicate that policy questions are not recall matters for the sophisticated. If they had rehearsed policy opinions, those attitudes would be more accessible and elicit smaller ratios. If satisficing applies anywhere, then, it is with low sophisticates and policy attitudes, not their emotions.

Table 2.3 presents response change estimates for the same emotion and policy items in the latency analysis. I estimate the count models with zero-inflated Poisson and zero-inflated negative binomial regression. ${ }^{7}$ Sophistication again affects emotion items one way and policy questions another. It reduces uncertainty in emotion questions, but

\footnotetext{
${ }^{7}$ The two methods produce similar results. Count models assume all observations experience the same time period, but my data violate that assumption since respondents differ in response times. To remedy this problem, I include an exposure offset, the natural $\log$ of individual latency, in the model with a coefficient constrained to 1 (Long and Freese 2006).
} 
Table 2.3: Response Change Count Models for Emotion and Policy Items

\begin{tabular}{|c|c|c|c|c|c|c|}
\hline & $\begin{array}{l}\text { Anger } \\
\text { at US }\end{array}$ & $\begin{array}{c}\text { Guilt } \\
\text { about US } \\
\text { Actions }\end{array}$ & $\begin{array}{l}\text { Anger } \\
\text { at Iraqis }\end{array}$ & $\begin{array}{l}\text { Sympathy } \\
\text { for Iraqis }\end{array}$ & $\begin{array}{c}\text { Repair } \\
\text { Damage }\end{array}$ & $\begin{array}{c}\text { Send } \\
\text { Troops }\end{array}$ \\
\hline \multicolumn{7}{|l|}{ Change: } \\
\hline Sophistication & $\begin{array}{c}-.816^{* * *} \\
(.215)\end{array}$ & $\begin{array}{c}-.546^{* *} \\
(.184)\end{array}$ & $\begin{array}{l}-.271 * \\
(.117)\end{array}$ & $\begin{array}{c}-.281 * * \\
(.102)\end{array}$ & $\begin{array}{c}.693 * * * \\
(.137)\end{array}$ & $\begin{array}{c}.463 * * \\
(.14)\end{array}$ \\
\hline Average & $.809 *$ & $.651 * *$ & $1.01 * * *$ & $.827 * * *$ & .062 & $.57 * *$ \\
\hline Change & $(.32)$ & $(.235)$ & $(.165)$ & $(.181)$ & $(.19)$ & $(.216)$ \\
\hline Party & .263 & $.31 *$ & $.176+$ & -.102 & $.262+$ & -.02 \\
\hline Strength & $(.192)$ & $(.138)$ & $(.102)$ & $(.079)$ & $(.154)$ & $(.168)$ \\
\hline Ideology & .016 & .001 & -.165 & $.239 * *$ & -.147 & $-.441 *$ \\
\hline Strength & $(.194)$ & $(.135)$ & $(.103)$ & (.091) & $(.167)$ & $(.203)$ \\
\hline Blame & .059 & $.472 *$ & .002 & -.105 & -.126 & -.403 \\
\hline Strength & $(.237)$ & $(.197)$ & $(.141)$ & $(.122)$ & $(.21)$ & $(.266)$ \\
\hline Year & $\begin{array}{l}.377^{*} \\
(.159)\end{array}$ & $\begin{array}{l}.041 \\
(.119)\end{array}$ & $\begin{array}{c}.095 \\
(.078)\end{array}$ & $\begin{array}{c}.05 \\
(.076)\end{array}$ & $\begin{array}{l}.262^{*} \\
(.108)\end{array}$ & $\begin{array}{l}.247+ \\
(.134)\end{array}$ \\
\hline Constant & $\begin{array}{c}-2.977 * * * \\
(.49)\end{array}$ & $\begin{array}{c}-1.673 * * \\
(.614)\end{array}$ & $\begin{array}{l}-.717 * \\
(.308)\end{array}$ & $\begin{array}{l}-.611 * \\
(.255)\end{array}$ & $\begin{array}{c}-1.135^{*} \\
(.474)\end{array}$ & $\begin{array}{l}-.247 \\
(.432)\end{array}$ \\
\hline \multicolumn{7}{|l|}{ Zero Inflated: } \\
\hline Sophistication & $\begin{array}{l}5.565 \\
(3.79)\end{array}$ & $\begin{array}{c}1.498 * * * \\
(.398)\end{array}$ & $\begin{array}{c}3.544 * * * \\
(.591)\end{array}$ & $\begin{array}{c}3.365^{* *} \\
(1.142)\end{array}$ & $\begin{array}{l}.882+ \\
(.496)\end{array}$ & $\begin{array}{c}.44 \\
(.341)\end{array}$ \\
\hline Average & -7.313 & -1.654 & $-3.119 * *$ & 1.624 & $-1.244 *$ & $-1.206 *$ \\
\hline Change & $(5.991)$ & (1.439) & $(.944)$ & (1.066) & $(.525)$ & $(.564)$ \\
\hline Party & 3.641 & .513 & .069 & .075 & $.869 *$ & .168 \\
\hline Strength & $(5.526)$ & $(.672)$ & $(.531)$ & $(.557)$ & $(.436)$ & $(.415)$ \\
\hline Ideology & -3.411 & .317 & .708 & -.199 & -.337 & $-1.644 *$ \\
\hline Strength & $(3.875)$ & $(.637)$ & $(.507)$ & $(.66)$ & $(.392)$ & $(.71)$ \\
\hline Blame & -.247 & 1.995 & .381 & -1.378 & .157 & -.316 \\
\hline Strength & $(2.075)$ & (1.539) & $(.706)$ & $(.838)$ & $(.501)$ & $(.742)$ \\
\hline Year & 4.345 & -.003 & .417 & .175 & .504 & $.971 *$ \\
\hline & $(3.365)$ & $(.511)$ & $(.353)$ & $(.736)$ & $(.319)$ & $(.386)$ \\
\hline Constant & $\begin{array}{c}-12.648 \\
(13.882)\end{array}$ & $\begin{array}{l}-3.658 \\
(4.425)\end{array}$ & $\begin{array}{l}-2.611 \\
(1.675)\end{array}$ & $\begin{array}{l}-4.188 \\
(.2649)\end{array}$ & $\begin{array}{l}-2.573 \\
(1.812)\end{array}$ & $\begin{array}{c}.31 \\
(.941)\end{array}$ \\
\hline LR & $-193 *$ & $-304 * *$ & $-303 * *$ & $-389 * * *$ & $-307 * *$ & $-252 * *$ \\
\hline Pseudo- $\mathrm{R}^{2}$ & .187 & .159 & .275 & .095 & .054 & .08 \\
\hline NBR v. Psn. & $8.96 * *$ & $3.92 *$ & .19 & .000 & $46.91 * * *$ & $19.63 * * *$ \\
\hline Vuong & $3.02 *$ & $2.53 *$ & $3.65 * *$ & $2.31 *$ & $2.42 * *$ & $2.12 *$ \\
\hline $\mathrm{N}$ & 371 & 371 & 371 & 371 & 371 & 372 \\
\hline
\end{tabular}

Note. Entries are unstandardized coefficients based on either zero-inflated Poisson or zeroinflated negative binomial regression; standard errors in parentheses; only models with significant sophistication effects are reported, so keeping troops in Iraq and humanitarian aid are not shown; $+\mathrm{p}<.1, * \mathrm{p}<.05, * * \mathrm{p}<.01, * * * \mathrm{p}<.000$ 
increases it in policy ones. Thus, highly sophisticated respondents make fewer changes to their initial responses when asked about their feelings toward the Iraq War, but the opposite is true on policy questions. Sophisticates change their answers more when asked about spending on infrastructure repair and sending more troops. High sophisticates are likely balancing more considerations than low sophisticates, leading to more unstable attitudes, or low sophisticates might be satisficing.

Figure 2.5: Change Counts for Emotion and Policy Items by Sophistication

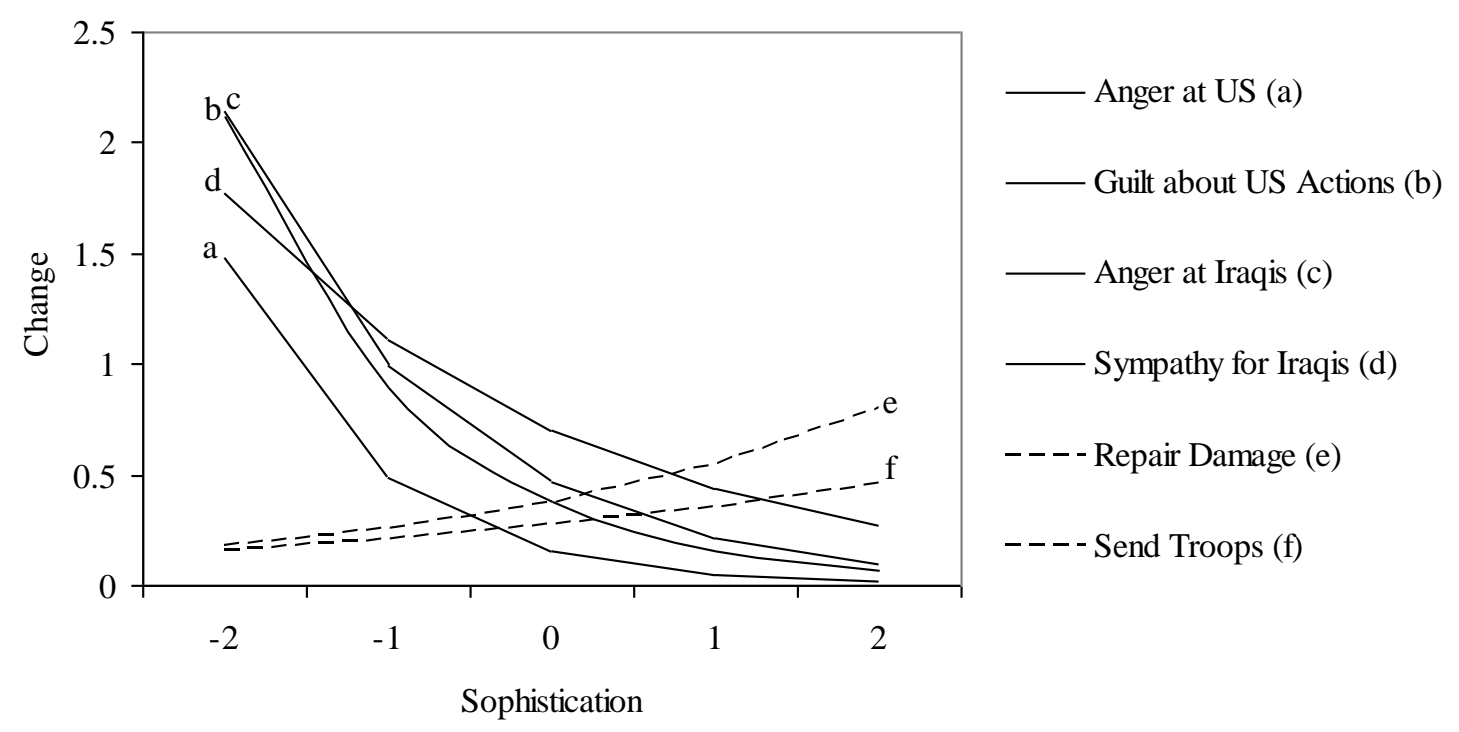

Figure 2.5 shows predicted changes by sophistication level. Low sophisticates are more uncertain about feelings, as seen in the extraordinary degree to which they switch emotion answers. High sophisticates change more on policy questions, but their predicted changes pale in comparison to those of low sophisticates on emotion items. The big picture of the response process, then, is that low sophisticates are more likely to have no emotions toward the Iraq War, but they think harder to give more uncertain responses. High sophisticates give quick and certain answers that lean toward more emotionality. 
More importantly, the same is not true of policy questions. These results confidently rule out the alternative satisficing hypothesis, and strongly support both $\mathrm{H} 2$ and $\mathrm{H} 3$ about how sophistication affects the question response processes. More importantly, these results offer further evidence for the theory that sophistication positively affects the likelihood of emotional appraisals of political stimuli (H1).

\section{Discussion}

This chapter directly challenges the old stereotype that emotionality about politics is an attribute of the poorly informed and politically disengaged citizen. Low sophisticates, those thought to be so distant from or ignorant about politics that they substitute emotion for fact and critical thought, are not the citizens who are the most emotional about political affairs. In fact, it is high sophisticates, the citizens most valued for their greater knowledge, interest, and attention, who are more emotionally engaged with politics. The high sophisticate is more likely to experience emotion in reaction to political stimuli, whether in the context of candidates or issues like the Iraq War. Indeed, sophistication consistently and quite powerfully predicts emotional appraisals in analyses presented here, and paradata about the question response process come as close as one possibly can in a cross-sectional analysis to demonstrating that this is a causal relationship.

This work should not be interpreted as arguing that low sophisticates are emotionally unengaged with politics or that emotion has no bearing on their political behavior. Some low sophisticates are capable of emotionally appraising political attitude objects, and those emotions likely factor into their behaviors and attitudes. However, low sophisticates have a poorer understanding of the political world and how it connects to 
their goals and desires than high sophisticates, meaning that low sophisticates are less capable of making the appraisals that elicit emotion in political contexts. Thus, low sophisticates just do not understand politics well enough to be very emotional about it, and whatever feelings they do have are not that frequent or accessible to them.

These findings have considerable implications for our understanding of the role emotion plays in politics. Political science now recognizes that emotions powerfully affect a variety of political behaviors, and that emotion can normatively be a desirable force for the civic competence of the average citizen. What we have failed to understand as a field, however, is what role the psyche plays in eliciting or inhibiting emotional responsiveness to the political world. This chapter sheds some light on those "black box" dynamics of the mind with its finding about political sophistication, and in doing so questions fundamental assumptions about emotion that have guided its treatment in both scholarly circles and the broader political culture. Emotion depends upon the ability to link stimuli to objectives, and acting upon those emotions necessitates the understanding and motivation to connect feeling to behavior. It is the high sophisticate who not only thinks more about politics, but feels more about it.

It is worth reemphasizing that the theory and findings of this article are limited to the construct which political scientists call sophistication. To the extent that any academic measure of sophistication assesses respondent knowledge, it is general political knowledge in which we are interested - recognition of figures and knowing political processes or political history. We can all agree that there are objectively true answers to the knowledge questions we regularly incorporate in our studies. In reality, however, citizens need not have "correct" beliefs or knowledge to be emotional about specific 
political objects. The infamous "death panels" that many critics accuse Barack Obama's health reform plan of including are an example of an incorrect piece of information many people believe to be true. Likewise, some citizens falsely believe that weapons of mass destruction were found in Iraq, or that Obama is a Muslim or not an American citizen.

Some people believe these mistruths, and that false information factors into their emotional appraisals. Though we cannot know for sure, furious health care town hall participants whose ire is raised over death panels they heard about on talk radio or some other media outlet may score as high sophisticates on the measures of sophistication political scientists normally use. Such persons may report being very interested in and attentive to politics, and may know a great deal of true general political knowledge, but our measures do not penalize them for their otherwise incorrect beliefs. Most surveys do not include the sort of open-ended questions that would be needed to grade the veracity or logic of justifications that respondents may offer for their emotions. Though one may criticize the imperfect measures the field uses for assessing knowledge and sophistication on the grounds discussed here, this work can only speak to how those concepts as they are normally conceived are related to the emotions citizens feel about the political world.

This chapter offers strong support for the core hypothesis advanced in this dissertation the idea that sophistication promotes emotional responsiveness to politics. That finding is interesting and important by itself as it undermines the traditional way of thinking about emotion in politics. Rather than being a low sophistication trait, emotionality is a product of knowledge and engagement with the political world. Still, the question remains as to whether this relationship matters for anything other than proving the conventional 
wisdom wrong. Does it have any consequences for individual attitudes and behavior? How does the information surrounding citizens mitigate or exacerbate the differences between high and low sophisticates? The next two chapters answer both of these questions by exploring the moderating role of information context on the sophisticationemotion relationship and demonstrating how sophistication moderates the effect of emotion on attitudes and behavior. 


\title{
Chapter 3
}

\section{Introducing Information Context:}

\section{Emotional Appeals in Campaign Advertising}

\begin{abstract}
This chapter introduces information context, the environment surrounding citizens and the stimuli in the environment, as a moderator of the relationship between sophistication and emotion. I conceptualize context here as presidential campaign advertising and the emotional appeals in that advertising. I content analyze ads from the 2000 election to develop media market-level measures of advertising exposure, then merge those data with the 2000 NES to create a quasi-experimental design. My results show that high sophisticates are more emotionally responsive to emotional appeals in advertising than low sophisticates. Indeed, the lowest sophisticates are largely unresponsive to these appeals. I then demonstrate that emotions are a stronger influence on the voting and attitude expression of high sophisticates, undermining the traditional view that emotions tend to sway the least engaged citizens. Thus, my results show that high sophisticates are not only more emotional about politics, but more emotionally responsive to political stimuli and more reliant upon emotion in their political behavior.
\end{abstract}


The previous chapter presented strong evidence that supports the basic hypothesis that political sophistication is positively related to the experience of emotion in political contexts. The results demonstrated that high sophisticates are indeed more likely to report emotional reactions in response to both presidential candidates and public policies. Survey paradata that examine the response process further supported that hypothesis. Still, even if high sophisticates are more emotional about politics than low sophisticates, what consequence does that greater emotionality have for political behavior? While it is interesting to know that the conventional way of stereotyping emotion in politics is likely wrong, this fact would be more important were there behavioral consequences to it.

The next two chapters further test the sophistication hypothesis, but also tease out the behavioral consequences of that relationship. They show that high sophisticates are not only more emotional about political stimuli, but that emotions have a greater effect on their behaviors than for low sophisticate. Specifically, emotion more strongly influences policy attitudes, voting behavior, and learning among high sophisticates than among low sophisticates. The role of information context is also introduced using both a natural experiment involving campaign advertising and a web-based randomized experiment that manipulates news about illegal immigration. These chapters show that high sophisticates are more emotionally responsive to the political information around them, and that this responsiveness disproportionately shapes the behavior of high sophisticates.

\section{Information Context}

The case has been made for a psychological factor - political sophistication - that facilitates emotionality in reaction to political stimuli. All citizens, however, inhabit 
certain political contexts and encounter different political situations to which they react. Thus, the internal "black box" dynamics of the psyche and the emotions those dynamics produce are influenced by the external environment. After all, emotion is by definition a reaction to an identifiable external stimulus, so it is logical to argue that emotion may result from the interaction of the environment with individual psychology.

Context refers to the environment surrounding individuals: the information available, various types of stimuli, and the qualities of those stimuli. Every citizen is embedded in an information environment consisting of news, advertising, discussion networks, and myriad other sources of political information, though everyone does not pay equal attention to their respective environments. Scholars conceptualize context in many ways, some broader than others. Some define it in aggregate as the demographics of a neighborhood or county (e.g. Campbell 2006; Glaser 1994; Key 1949; Wright 1977) or as the content of an actual political campaign (Carsey 2001; Freedman, Franz, and Goldstein 2004; Kam 2006), but others portray context as interpersonal discussion networks (e.g. Huckfeldt and Sprague 1995; Huckfeldt, Johnson, and Sprague 2004; Mutz 2002). The core of all these conceptualizations is the idea that information varies by context and that this information has important consequences for political behavior.

Information context varies along several dimensions. First, it encompasses the amount of information accessible to citizens. More political information becomes available during campaigns, for example, as candidates air ads and make appearances. Second, context includes the specific attitude objects to which individuals are exposed politicians, issues, social groups, and so forth. Lastly, context takes in the specific qualities of information and attitude objects, including familiarity, contentiousness, 
source, tone, and other factors. Some issues like abortion are more familiar and divisive than others. Similarly, information may be encountered in print venues such as the New York Times or in local television newscasts, but these formats vary in ways that may affect how information is processed and appraised.

Context, then, is a broad term that can be operationalized in many ways. This chapter will focus on campaign advertising. Specifically, I operationalize the term by matching survey respondents with measures of actual advertising in the media markets in which they live. Chapter 4, however, conceptualizes context as the conventional news media, meaning television and print outlets. Both chapters show similar behavioral patterns, so the findings presented herein are robust to how one conceptualizes information context. Whether context means advertising or news, these chapters demonstrate that it is the high sophisticate who is more emotionally responsive to information stimuli and whose behavior is shaped more by that emotion.

\section{Campaign Advertising as Information Context}

Campaign advertising has been a fashionable research topic for political scientists of late. Ads are flashy and sexy. The media often tell us that these ads are among the most decisive factors in electoral outcomes (West 2001). Many of the landmark ads in past decades such as Lyndon Johnson's Daisy ad from 1964, the Willie Horton and Revolving Door ads from 1988, or the Swift Boat Veterans for Truth spots from 2004 are depicted as pivotal elements in the narratives of recent presidential elections. Though most scholars are hard pressed to find large direct effects of advertising on most important political variables such as turnout and trust in government (see Lau and Pomper 2004 for 
a more thorough review), we seem incapable of shaking the notion that ads somehow matter given their pervasiveness and their prominent place in political commentary.

Advertising, however, serves an important role in educating the electorate about its choices and, under certain circumstances, can be effective in shaping perceptions of candidates and the electoral process. Campaigns in general educate the electorate and activate latent political predispositions such as partisanship and ideology (Alvarez 1997; Gelman and King 1993; Popkin 1991; Simon 2002). Many scholars have identified advertising as a vehicle through which candidates educate voters about party affiliation and issue positions, and familiarize them with candidate biography and personality (Brians and Wattenberg 1996; Franz, Freedman, Goldstein, and Ridout 2008; Hitchon and Chang 1995; Just, Crigler, and Wallach 1990; Patterson and McClure 1976; Zhao and Chaffee 1995). Indeed, Franz et al. (2008) call ads "informational multivitamins" that provide needed information supplements for voters lacking in political information.

Thus, advertising is an important part of the information context surrounding voters during an election. All ads are not created equal, however. Many studies show that the affective tone of advertising, meaning its positive or negative slant, is an important moderator of how messages shape political behavior (e.g. Ansolabehere and Iyengar 2005; Franz et al. 2008; Geer 2006; Lau and Pomper 2004; Lau and Rovner 2009; Lau, Sigelman, and Rovner 2007; Stevens 2009). Negative ads are generally more memorable and persuasive, a logical finding given prospect theory which demonstrates the survival tendency of humans to weight negative information more strongly than positive information (Jervis 1992; Kahneman and Tversky 1979; McDermott 1998). However, there is substantial disagreement over how negative advertising affects voter turnout, 
perceptions of campaign quality, and attitudes toward government. Some studies show positive effects on these variables whereas others show negative effects or no effect whatsoever (see Lau and Rovner 2007 and Stevens 2009 for reviews).

However, as discussed in Chapter 1, affect and emotion are not the same. Affect often lacks cause and consequence, so it may not necessarily translate into political action when communicated through advertising. Emotion, however, must have a specific cause that is recognized at some conscious level, and every emotion is linked to an action tendency. Thus, if emotion is elicited through advertising, the likelihood that it leads to a political action is greater than if an ad only conjures affect. If one is interested in the broad tone of advertising, then the affective approach may be appropriate; however, if emotion is the subject of inquiry, then this approach is insufficient. A fear ad may be negative in the same sense that an ad with an anger appeal is negative as both convey undesirable information. Analyzing both as just "negative ads," however, ignores the specific qualities of information that elicit fear rather than anger, and discounts the possibility that these two "negative emotions" may differ in action tendencies.

For all the work devoted to affect, remarkably little empirical attention is given to emotion in campaign ads. ${ }^{8}$ Brader (2006) shows differing effects of enthusiasm and anxiety advertisements, but his affective intelligence approach does not distinguish between different positive or negative emotions with its basis in dimensional models. He does content analyze presidential ads from 2000 for discrete emotional appeals, and other scholars have done similar descriptive work on what emotions are used in campaign

\footnotetext{
${ }^{8}$ I emphasize "empirical" as many scholars who discuss advertising often mention the role of emotional ads in campaigns (e.g. Jamieson 1996; Kern 1989; Nesbit 1988; Perloff and Kinsey 1992; Richardson 2003). They often decry emotional advertising, though they generally assert its effectiveness and pivotal nature in elections. For my purposes, I distinguish between this type of scholarship and studies which employ quantitative analysis to study emotional appeals in election advertising. The latter are rare.
} 
advertising (Kaid and Johnston 1991; Kern 1989; Marmor-Lavie and Weimann 2005). However, there has been no empirical attempt to examine advertising effects using a discrete framework that allows for different types of positive and negative emotional appeals to have differential effects. This chapter does exactly that.

\section{Sophistication and the Behavioral Consequences of Emotion}

Emotions are critical to politics because they guide behavior in ways that promote the realization of goals. Emotions are multi-faceted, with one part of the emotional reaction process being an action tendency that motivates behavior in ways relevant to the core theme of each emotion. In political contexts, for example, emotions shape learning in different ways. Fear and anxiety focus attention on threatening stimuli that produce uncertainty (e.g. Eysenck 1992; LeDoux 1996), eliciting information seeking behavior in the context of candidate evaluations to reduce that uncertainty (Marcus and MacKuen 1993; Marcus et al. 2000). On the other hand, Valentino et al. (2008) show that anger depresses learning in political situations. Anger is an emotion that results from certainty, and they argue that situations about which people are certain do not require learning.

Emotions affect a variety of political behaviors, from learning to voting (e.g. Goren 1997) and opinion formation (e.g. Conover and Feldman 1986), but there is a long tradition of normative concern about the role that emotion plays in human behavior, particularly among the unsophisticated. Philosophers of the ancient (e.g. Aristotle 1954; Plato 1974) and Enlightenment (e.g. Hobbes 1968; Hume 1739) eras believed emotion to be detrimental to reasoned, rational behavior. Aristotle, for example, wrote in Rhetoric (1954) of how leaders could use emotional appeals to persuade and manipulate the 
masses. The same stereotype of emotion as an irrational force driving an uneducated and unthinking mass has influenced modern social science, with many political scientists characterizing emotional phenomena as low information heuristics that often substitute for factual information in decision-making and attitude formation (Brady and Sniderman 1985; Carmines and Kuklinski 1990; Graber 2001; Lodge, McGraw, and Stroh 1989; Marcus, Neuman, MacKuen, and Sullivan 1996; Redlawsk and Lau 2003; Sears and Citrin 1982; Sniderman, Brody, and Tetlock 1991; also Arkes 1993; Kaid 1991; Le Bon 1952). Brader (2006) also documents many instances of popular commentators voicing this same concern about emotional appeals in campaign ads.

The question of whom emotion influences in political contexts, however, is largely unexplored. No empirical evidence validates the stereotype that emotion is a stronger influence on the unsophisticated, or that sophisticated citizens can better reign in their emotions and act upon reason. Indeed, the sole empirical investigation of how sophistication and emotion interact shows exactly the opposite. Brader $(2006)^{9}$ finds that enthusiasm and anxiety appeals in campaign ads are more influential on the behavior of high sophisticates. They are more likely to participate in political activities and vote in ways consistent with their emotions when exposed to emotional ads. In contrast, he finds that low sophisticates relatively unmoved by emotional appeals. Indeed, they demonstrate a slight tendency to withdraw from political action as a consequence of being emotional about candidates at the same time as high sophisticates are mobilized to action. Thus, even though high sophisticates are generally better at resisting persuasion (Zaller 1992),

\footnotetext{
${ }^{9}$ Brader (2006) cites Sniderman et al. (1991) as arguing that high sophisticates rely less on emotion. That work is on the "likeability heuristic," the tendency to make judgments based upon liking or disliking some "other." The likeability heuristic, however, is not emotion, as Brader characterizes it. It represents affect. Thus, Sniderman et al. suggest that affect is a low information decision making tool, but not emotion.
} 
they are the ones whom emotion most moves, and not the unsophisticated, distant-frompolitics "unreachables" with little political information (Converse 1962, 1964, 1990).

I posit that emotion, in fact, affects the behavior of high sophisticates more than that of the less sophisticated. If high sophisticates are more likely to emotionally appraise political stimuli because they understand politics better, they may also better understand how to translate emotion into political action. In a policy debate, for example, high and low sophisticates may both feel anger, but high sophisticates may better understand which policy options best assuage that anger. Angry low sophisticate may not have enough information about policy options or even understand the information they do have well enough to realize that a particular course of action would shape policy in a fashion they might find desirable. Thus, they may be less able to act upon their feelings.

High sophisticates may also be more motivated to act upon their emotions given their more intense interest in politics. Brader (2006) terms this the "relevancy hypothesis." The power of emotion may be more compelling to someone who is genuinely interested in the situation that elicited that emotion in the first place. Thus, the high and low sophisticate may both feel fear in response to a campaign ad, for example, but the high sophisticate may find that fear a more motivating factor in voting decisions than the low sophisticate who may care less about the content of that message. Emotions motivate certain actions, but that motivation may be amplified when the person experiencing that emotion is naturally more engaged with the situation. In political contexts, then, high sophisticates may be both more emotional and better able to connect their emotions to actions that logically express those feelings. 


\section{Hypotheses}

H1: Sophistication positively affects the likelihood of experiencing emotions in reaction to presidential candidates.

This chapter deals solely with the 2000 presidential election between Republican George W. Bush and Democrat Al Gore. As in the previous chapter, I first demonstrate that high sophisticates are more likely to experience the four NES emotions - anger, fear, hope, and pride - in reaction to both presidential nominees than low sophisticates.

H2: High sophisticates will be more emotionally responsive to information context than low sophisticates. Specifically, as the amount of campaign advertising targeting a particular discrete emotion in relation to certain candidates increases, high sophisticates will be more likely to experience that emotion in response to the candidate in question.

In this chapter, I conceptualize information context as campaign advertising. Ads possess many qualities, but I deal specifically with the discrete emotional appeals in presidential ads and the volume of that advertising. I measure volume in gross rating points (GRP), a measure of audience penetration that is standardized across markets.

High sophisticates are not only more knowledgeable about politics, but also more interested in and more attentive to it. They intentionally consume more political information than low sophisticates, and are more likely to experience and remember passive exposure (Neuman 1986). Thus, all things being equal, high sophisticates are more likely to pay attention to campaign ads during an election. Let us imagine a context with no external information whatsoever. In this case, there is no campaign advertising to 
cue emotions among viewers. Absent any stimulus, high sophisticates in this environment should be more emotional about stimuli such as candidates than low sophisticates.

As more information is injected into the environment, high and low sophisticates will not respond equally to this new information. For my purposes, as the GRP of a particular emotional theme increases in a market, high sophisticates in that market will be more attentive to that advertising than low sophisticates also living there. Given their greater understanding of politics and ability to translate that understanding into emotional appraisals, high sophisticates will be more likely to experience the emotion advertising targets as the GRP of advertising with that emotional theme increases.

Take proud in Gore as an example. Everything being equal, the least proud voter should be a low sophisticate living in a market with zero advertising that makes a pride appeal on behalf of Gore. The voter most likely to feel proud of Gore would be a high sophisticate living in a market with the maximum GRP of pride appeals aired during the campaign. Thus, we should observe significant interactions of sophistication and GRP. Given my discrete framework, advertising targeting a specific candidate should predict emotion toward that candidate and not others. Fear appeals about Bush, for example, should increase the likelihood of being afraid of Bush, but not how one feels about Gore.

H3: Emotion will influence the political behavior of high sophisticate more than that of low sophisticates.

As discussed earlier, emotions bias human toward certain action tendencies. I posit that in political contexts, high sophisticates will be more influenced by their emotions than low sophisticates given their greater understanding of political affairs, and 
their greater motivation to act upon their political emotions. The goal of campaign advertising is to sway voters. Thus, to the extent that emotional appeals shape vote choice, they should be more influential in the voting calculus of high sophisticates. The logical courses of action in voting are simpler and clearer than in policy decisions, so understanding how to translate emotion into action is likely not an issue. Rather, high sophisticates may weigh emotional appeals and their own emotional experiences more heavily because of their greater general interest in politics, so emotion should influence their decisions more than those of low sophisticates. Thus, we should observe a significant interaction of sophistication and emotion.

\section{Gross Rating Points}

I use advertising data from the Wisconsin Advertising Project at the University of Wisconsin-Madison. It uses TNS Media Intelligence/Campaign Media Analysis Group (CMAG) to electronically track campaign ads aired in different media markets (see Franz et al. 2008 for a thorough discussion of CMAG methodology). For the 2000 election, CMAG tracked advertising in the 75 most populous media markets in the country, covering roughly $80 \%$ of Americans. The full list of markets is available in Appendix B. Gaps do exist in these data as some markets such as Tallahassee and Gainesville which cover highly contested swing states are omitted even though thousands of ads aired there (Shaw2006), but many less heavily contested and even uncontested markets are also absent. NES respondents not living in covered markets are dropped from analyses here, though their omission introduces little to no bias into the analysis (see footnote 17). 
CMAG documents every time an ad in a tracked market plays, plus information about time of day, its length, its estimated cost, and the cost-per-point (CPP) of purchasing one GRP in the market. The end product for 2000 is a data set containing more than one million unique airings. The NES does not assess emotional reactions to down-ballot candidates, so I discard all non-presidential advertising. This reduces the data to 302,269 unique airings representing 305 different commercials. I then sorted airings by market and calculated GRP per spot. GRPs measure market penetration and account for differing viewership rates and advertising costs across markets. Media buyers purchase air time for commercials by GRP, not the total number of airings. GRP are interpreted in blocs of 100. If a media buy for one commercial equals 100 GRP, this means that the average television viewer in that market saw the ad one time.

GRP are calculated as GRP $=($ media cost/CPP $) \mathrm{X}$ (time multiplier). Nielsen, the main source of media ratings information, divides the day into eight "dayparts": early morning (1 AM to $9 \mathrm{AM}$ ), daytime (9 AM to $4 \mathrm{PM}$ ), early fringe (4 PM to $6 \mathrm{PM}$ ), early news (6 PM to $7 \mathrm{PM}$ ), prime access (7 PM to $8 \mathrm{PM}$ ), primetime (8 PM to $11 \mathrm{PM}$ ), late news, (11 PM to 11:30 PM), and late fringe (11:30 PM to $1 \mathrm{AM})$. CPP varies by daypart both within markets as viewership rates vary and across markets due to audience size and viewing habits. For example, one GRP during early morning costs $\$ 79$ in the Albuquerque market, but $\$ 907$ in New York City. Thus, the same $\$ 900$ will expose typical viewers to an ad once in New York, but about nine times in New Mexico. The quotient of (media cost/CPP) is then multiplied by a time multiplier to account for ad length. Thirty-second ads have a multiplier of 1 , a value which varies by ad length (10 
sec. $=.5,15$ sec. $=.7,60 \mathrm{sec} .=2)$. Thus, the GRP of each airing in the data set is calculated and used to construct cumulative GRP measures.

GRPs measure the true penetration of advertising and are comparable across markets, whereas other common advertising proxies such as spending and ad counts are misleading. The variability of CPP within and across markets makes cost meaningless in terms of volume and viewership. Likewise, simply counting the number of airings ignores the penetration aspect of advertising. One ad in a large market does not reach the same audience as an ad in a smaller market. Whereas GRP are standardized and comparable between any two markets, using cost or count biases estimates by as much as $35 \%$ when randomly comparing any two markets. ${ }^{10}$ As CMAG provides an actual accounting of ads, GRP is the ideal way to measure advertising as it represents the actual ad buy rather than being a proxy and provides a standardized, interpretable measure.

Figure 3.1 plots the total GRP of advertising by market purchased by all presidential campaigns over the course of the 2000 election from the first nomination contests in January through Election Day in November. ${ }^{11}$ Only one market, San Antonio, experienced zero advertising the entire year. Less than 100 GRP were purchased in eight other markets, including some of the most populous (Houston and Dallas). At the high end are markets in hotly contested swing states. The campaigns bought the most GRP in Des Moines, though it is followed closely by several markets in states that did not feature a highly contested nomination campaign as Iowa did. Thus, there is dramatic "natural"

\footnotetext{
${ }^{10}$ I randomly selected ten market dyads to compare how GRP ratios fare against ratios of ad cost and ad count between those same markets, so these are my original calculations.

${ }^{11}$ GRP measures in this chapter are all highly skewed. I do not use any transformation to normalize their distributions since the actual GRP value itself has substantive meaning and is standardized across markets. Transforming those distributions would lose both that meaning and their comparability.
} 
variation in advertising across markets over the course of the campaign. By matching market-level advertising measures to the counties in which NES respondents live, ${ }^{12}$ this study provides an excellent quasi-experiment that connects the actual advertising context surrounding respondents to their emotional appraisals of the candidates.

\section{Figure 3.1: Total GRP of Presidential Advertising by Market}

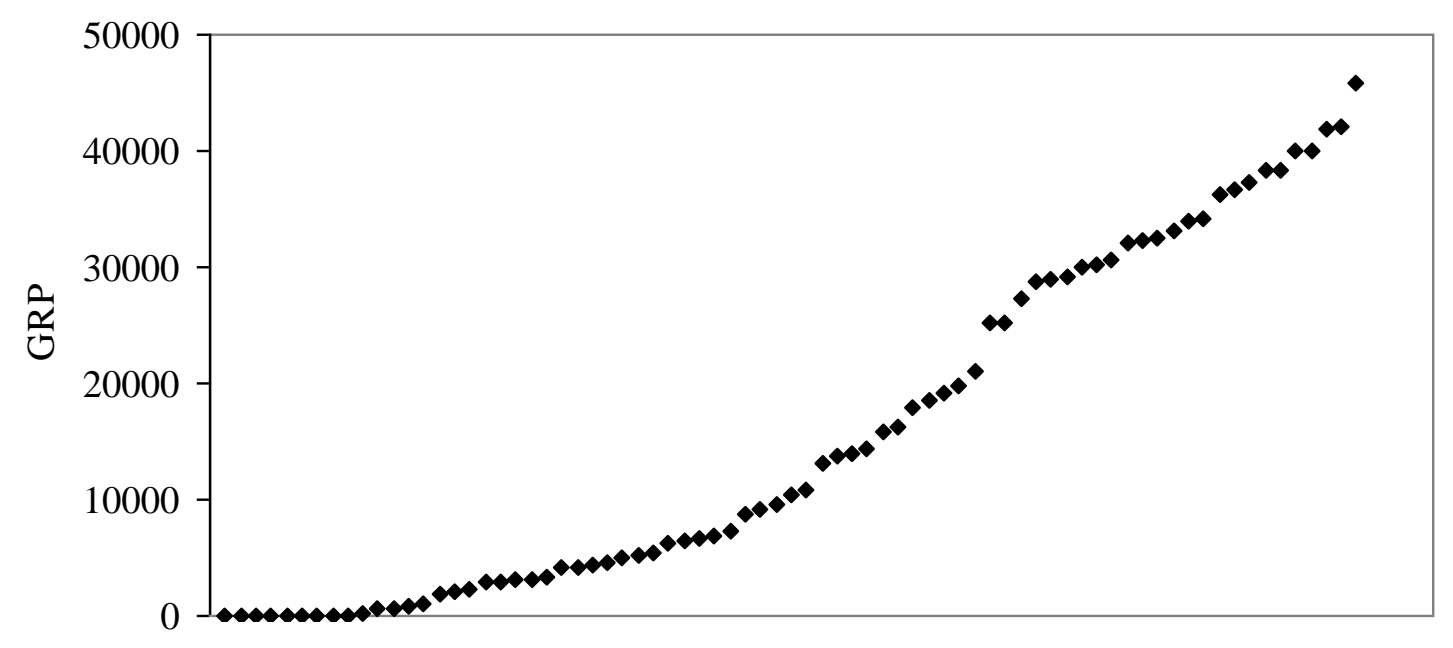

\section{Content Analysis of Campaign Advertising}

To link the emotional content of advertising to the appraisals of NES respondents, I need measures of emotional appeals in the ads. CMAG ads are not coded for emotion, only affective tone (positive, negative, mixed contrast). Thus, I need selection criteria to determine which ads to code and a coding scheme to measure those appeals myself.

Rather than winnowing down the 305 unique presidential ads aired in 2000 to a smaller subset, I keep all of those ads in my content analysis and GRP calculations. This includes all ads aired by Bush and Gore, failed primary candidates, the DNC and RNC,

\footnotetext{
${ }^{12}$ All but two counties in the nation are located entirely within one media market. No NES respondents live in either of those two split counties, so there is no error in matching respondents to markets.
} 
interest groups, and third-party candidates over the course of the calendar year starting with the first nomination contests in January. Limiting the analysis to ads by only certain candidates during a certain time period (e.g. Bush and Gore ads during the general election) may eliminate advertising that actually affects emotional appraisals. The on-line model (Lodge, McGraw, and Stroh 1989; McGraw, Lodge, and Stroh 1990) suggests that attitudes are the product of information processed in the past and incorporated into a summary running tally. Thus, how a voter feels about a candidate in November may be the integrated sum of all information received and processed over the course of the campaign. The details may be forgotten, but even information encountered early in the primaries may factor into emotional appraisals at the end of the campaign. Also, the NES asks if respondents have ever felt a certain emotion about a candidate, not whether that emotion is current or the product of recently encountered information. Memories of emotions, then, are valid reports give the question wording. ${ }^{13}$

CMAG records ad scripts and several screen shots, and compiles these into "storyboards." My coding is confined to the scripts. Advertising relies on multiple cues, including music, tone of voice, and visuals, to evoke emotions among viewers (Brader 2006; West 2001). Auditory components of the 305 ads are unavailable in the storyboards and most of the visuals are missing. There is also no readily available archive to obtain the full videos of the commercials. Thus, I cannot code for all audiovisual elements. Coding the limited screenshots would provide some sense of the visual cues viewers saw,

\footnotetext{
${ }^{13}$ I do not factor timing of ads into my analysis. With my aggregate measures, ads aired the day of a respondent interview count the same as ads from months prior. From an online perspective information encountered long before the interview date is integrated into current appraisals. Thus, I am not concerned about decay effects. I do, however, tailor the GRP measures to the date of the individual respondent interview as the emotion measures are in the pre-election wave. If a respondent is interviewed on October 15 , then, the GRP measures matched to that respondent only include ads aired in her market up to that date.
} 
but it would be an incomplete and perhaps biased picture of the full ad. Even if audiovisual elements were available, in all likelihood they would simply reinforce the emotional appeals already present in the ad scripts. Pictures and sound are critical to evoking emotion and it is a limitation of my study that I cannot capture them as part of the information context, but coding those elements would in reality provide very little new information about what emotional appeals were made in the ads.

My coding focuses on two questions. First, which candidate is the target of an appeal? The scripts are generally clear about what candidate is the focus of an appeal, and tend to name candidates specifically. Vague references such as "my opponent," "other candidates," or "the other guy" are actually rare in the storyboards. When they do appear, I use ad dates to determine the identity of the "other" candidate. Vague mentions in Gore primary ads are assumed to mean Bill Bradley, and vice verse for such references in Bradley ads. The same logic applies to Bush and John McCain in the Republican primary. Vague identifiers in Bush and Gore general election ads presumably refer to each other. No minor candidate ads in the Republican primary make vague references, and only one third party ad in the general election does so. ${ }^{14}$ The NES only assesses emotions toward Bush and Gore, so my presentation is limited to those candidates. However, I coded for appeals directed at all primary and general election candidates. ${ }^{15}$

Second, what emotion is an appeal trying to evoke? I coded appeals for various emotions common in the discrete tradition: anger, contempt, disgust, disappointment, excitement, fear, gratitude, hope, pride, resentment, shame, and sympathy. I excluded

\footnotetext{
${ }^{14}$ A Nader ad that aired very few times vaguely mentions other candidates whom I code as Bush and Gore.

${ }^{15}$ These include Democrat Bill Bradley and Republicans John McCain, Gary Bauer, Alan Keyes, and Steve Forbes. Also included are third-party candidates Pat Buchanan, Ralph Nader, and Harry Browne
} 
emotions not relevant for campaign advertising (e.g. guilt is a reaction to the self, so one cannot feel "guilty toward" a candidate). The NES only assesses anger, fear, hope, and pride toward the nominees, so I limit analyses to GRP measures of appeals using those emotions. Given my discrete framework I am mainly interested in whether appeals to a particular emotion elicit that feeling in voters. For example, the ability of anger directed at Gore to make voters angry at him is of more theoretical concern than whether other emotions also provoke that anger. At any rate, these four emotions account for over $90 \%$ of all emotional appeals in the 305 ads, a pattern Brader (2006) approximates in his content analysis, so excluding other emotions leaves out few appeals.

Table 3.1 defines the four emotions used in this analysis and provides examples of storyboard statements that appeal to them. The unit of analysis is the ad itself. Thus, I coded for the presence of an emotional appeal in the ad rather than breaking it into smaller statements. When a script included an emotional appeal toward a certain candidate, it received a score of 1 for the combination of that emotion and candidate. All non-present appeals were coded 0. An ad whose only appeal is hope directed at Bush, then, would receive a score of 1 for "Bush hope," but a 0 in all other categories.

Appendix C shows the coding instrument. Ads often appeal to multiple emotions. Contrast ads, for example, offer negative messages about one candidate, but positive messages about another. Thus, I did not limit the number of emotions to which an ad could appeal. Only 60 storyboards (19.7\%) appeal to just one emotion, so most make multiple appeals. I did not allow an ad to lack emotion. Each storyboard was coded for at least one emotional appeal, and almost all could be easily classified in one category. 
Table 3.1: Definitions of Coded Emotions

\begin{tabular}{|c|c|c|}
\hline Emotion & Definition & Example \\
\hline Anger & $\begin{array}{l}\text { Response to an offensive or } \\
\text { undesirable action in the } \\
\text { present or past that violates } \\
\text { social norms or values }\end{array}$ & $\begin{array}{l}\text { Bush Anger }(O A=.894 ; P i=.834) \text { : } \\
\text { "When George W. Bush first ran [for governor] } \\
\text { he promised not to cut our retirement fund. Then, } \\
\text { he went and raided it because he wanted to pay } \\
\text { for other things." } \\
\text { Gore Anger }(O A=.903 ; P i=.874) \text { : } \\
\text { "Under Clinton/Gore, prescription drug prices } \\
\text { have skyrocketed and nothing has been done." }\end{array}$ \\
\hline Fear & $\begin{array}{l}\text { Response to uncertainty } \\
\text { about the future status of } \\
\text { some object an individual } \\
\text { values }\end{array}$ & $\begin{array}{l}\text { Bush Fear }(O A=.956 ; P i=.932) \text { : } \\
\text { "Studies show that Bush's plan would lead to } \\
\text { benefit cuts and increase in the retirement age or } \\
\text { both." } \\
\text { Gore Fear }(O A=.958 ; P i=.941) \text { : } \\
\text { "Think what Justice Hillary Clinton or Charlie } \\
\text { Schumer would do to your gun rights. When Al } \\
\text { Gore's Supreme Court agrees with Al Gore's } \\
\text { Justice Department and bans ownership of } \\
\text { firearms, what freedom is next?" }\end{array}$ \\
\hline Hope & $\begin{array}{l}\text { Response to the belief that a } \\
\text { favorable outcome is } \\
\text { possible in the future }\end{array}$ & $\begin{array}{l}\text { Bush Hope }(O A=.989 ; P i=.978) \text { : } \\
\text { "The Bush education plan. Accountability. } \\
\text { Standards. And a fresh start for America." } \\
\text { Gore Hope }(O A=.951 ; P i=.946) \text { : } \\
\text { "Al Gore builds upon a foundation of fiscal } \\
\text { discipline. Pay down the nation's debt, protect } \\
\text { Social Security and Medicare, a } \$ 10,000 \text { a year } \\
\text { tax deduction for college tuition..." }\end{array}$ \\
\hline Pride & $\begin{array}{l}\text { Response to taking credit } \\
\text { for a valued or desirable } \\
\text { object or achievement }\end{array}$ & $\begin{array}{l}\text { Bush Pride }(O A=.918 ; P i=.890) \text { : } \\
\text { "George Bush is cleaning up Texas. The } \\
\text { Environmental Protection Agency reports that } \\
\text { Texas leads America in reducing toxic pollution." } \\
\text { Gore Pride }(O A=.888 ; P i=.872) \text { : } \\
\text { "He's taken on the worst polluters in America } \\
\text { and become a leading voice for clean air, clean } \\
\text { water, and the environment. Al Gore." }\end{array}$ \\
\hline
\end{tabular}


I recruited an assistant to recode all 305 ads for the purpose of calculating intercoder reliability. ${ }^{16}$ Table 3.1 reports observed agreement $(O A)$ and Scott's Pi (Pi). All coefficients exceed standard minimum levels (.8 for $O A, .7$ for $P i)$. Coder disagreements were resolved through discussion, and the consensus coding was used in analyses.

\section{Measures}

Emotion. The 2000 NES asks respondents, "Has (Bush/Gore), because of the kind of person he is or because of something he has done, ever made you feel (emotion)?" This is a yes/no question, and respondents saying "yes" answer a subsequent item measuring emotion frequency. For easier presentation, I report analyses on the dummy item, but the findings are comparable when the dependent variable is an ordinal frequency measure. Thus, the results are robust to changes in the form of the dependent variable. Less than $1 \%$ of respondents do not recognize the candidates, answer "don't know," or refuse to respond, so almost all responses are valid reports.

Gross Rating Points. Appeal codes $(1=$ appeal present, $0=$ appeal absent $)$ were entered into the dataset containing the unique ad airings, then multiplied by the GRP of each airing. Those products were then added to obtain eight GRP measures of emotional appeals by market: Bush anger (total GRP of ads containing anger appeals directed at Bush), Bush fear, Bush hope, Bush pride, Gore anger, Gore fear, Gore hope, and Gore pride. Figure 3.2 and 3.3 plot the total GRP of emotional appeals targeted at Bush and Gore respectively by media market. Similar to Figure 3.1, the emotional appeal GRP plots are heavily skewed with many markets receiving little to no advertising and others

\footnotetext{
${ }^{16}$ Thanks to Peter Bobkowski of the UNC School of Journalism and Mass Communication for his help.
} 
experiencing a relative deluge of ads. Again, I do not transform these distributions because the GRP values have actual meaning for market penetration.

Sophistication. Political sophistication is a factor score constructed from interest, knowledge, and attention. I use the standard 3-point NES political interest item and the 5point attention to campaign news measure. I construct an additive knowledge scale from four measures of recognition of major political figures (Trent Lott, William Rehnquist, Tony Blair, Janet Reno) and two measures about majority party control in the House and Senate. All three measures load onto one dimension in principal components analysis (eigenvalue $=1.944 ;$ loadings: attention $=.854$. interest $=.834$, knowledge $=.821) . \mathrm{I}$ combine these three indicators into a factor score that represents the underlying dimension of political sophistication $(M=0, S D=1)$.

Controls. I include the same controls used in the first chapter. Demographics include age, race $(1=$ white, $0=$ non-white $)$, sex $(1=$ female, $0=$ male $)$, education $(1=$ less than high school, 7 = graduate degree), and household income (as asked in 2000 and not the standardized cumulative NES measure; $1=$ less than $\$ 4,999,22=\$ 200,000$ and over). Also included are the standard 7 -point partisanship scale $(1=$ strong Democrat, $7=$ strong Republican $)$ and the standard 7-point ideology scale $(1=$ strong liberal, $7=$ strong conservative). Issue distance is again measured as the average squared deviation between the respondent's positions and the mean candidate placement position from the entire NES sample (Alvarez 1997). 
Figure 3.2: GRP of Emotional Advertising Directed toward Bush by Media Market
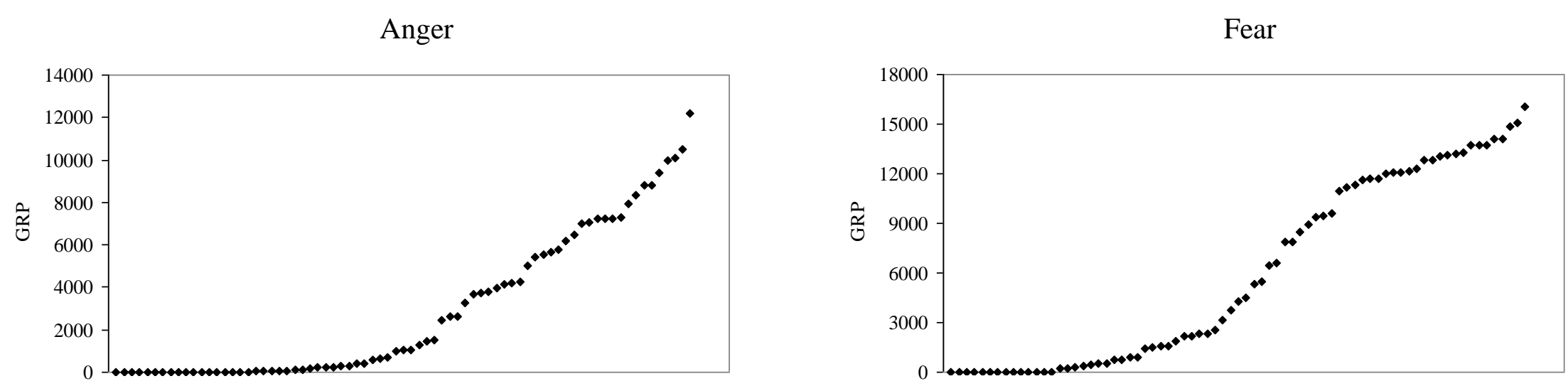

8
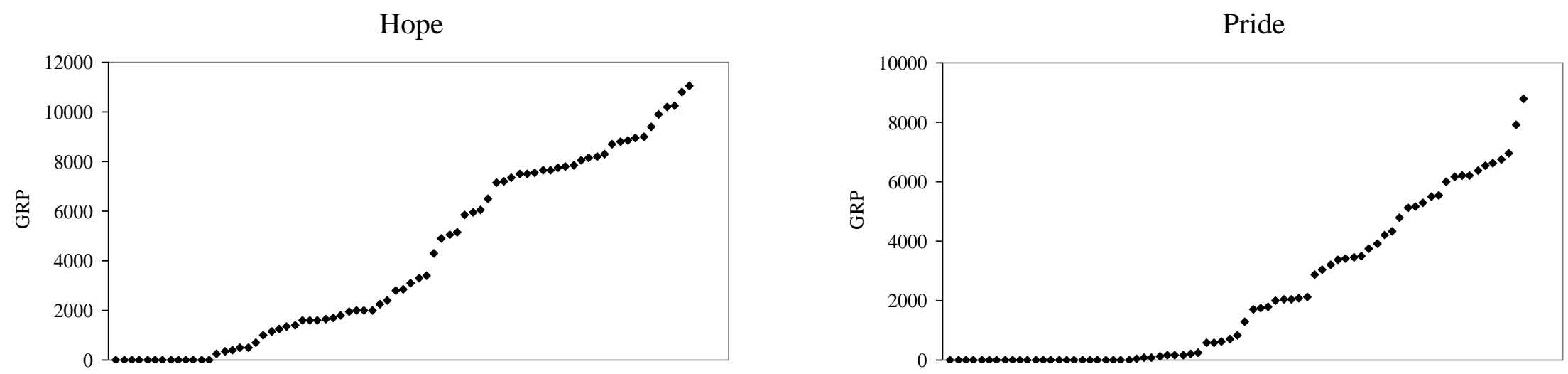
Figure 3.3: GRP of Emotional Advertising Directed toward Gore by Media Market
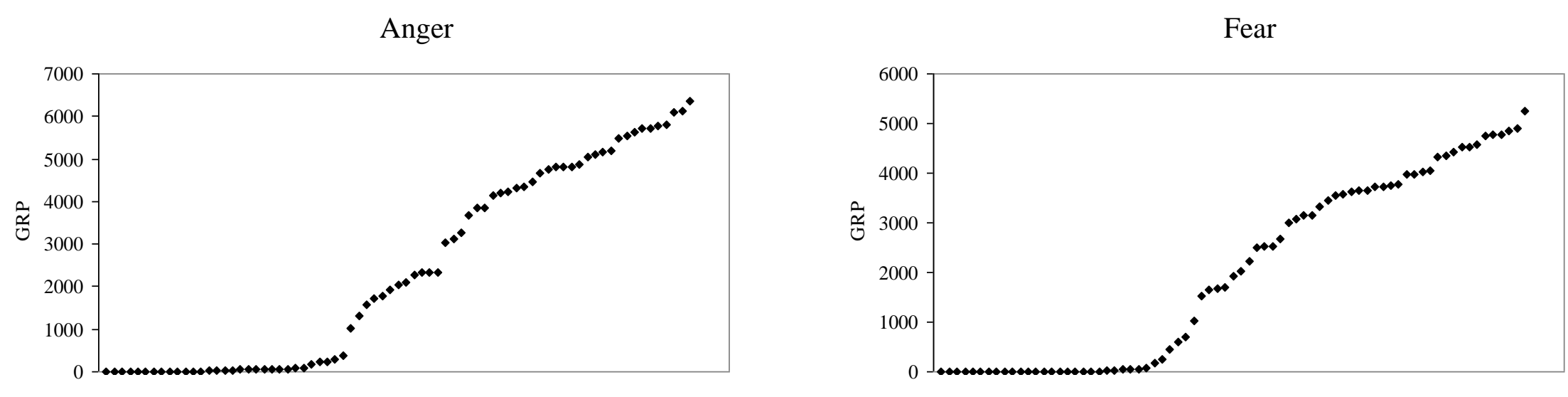

$\breve{o}$
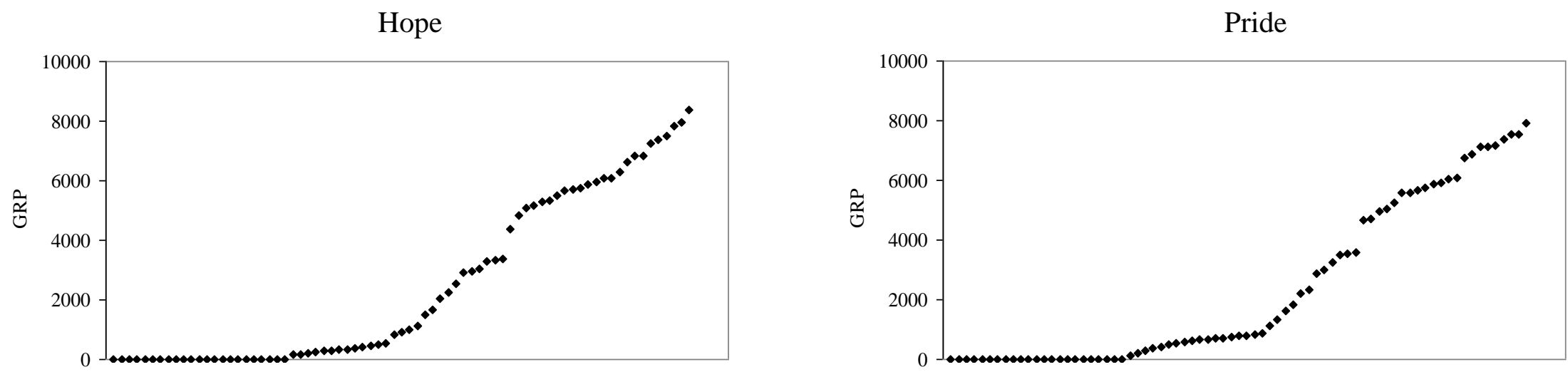


\section{Results}

\section{Direct Effects of Sophistication and Information Context}

Figure 3.4 shows the percentages of NES respondents living in tracked markets who report emotional responses to the candidates. Hope is the most common emotion for both nominees, with over $40 \%$ of the subsample reporting it for each. Fear, however, is the least common emotion. This pattern is similar to other NES samples from 1980 to 2004 . Hope tends to be the most frequent reported emotion for candidates, and fear the least common. All percentages here are below $50 \%$, so in no case does a majority of respondents feel any one emotion. This is the normal NES pattern for non-incumbents, including sitting or former vice presidents running for their own term, so the 2000 pattern is typical. Majorities often occur with appraisals of incumbents, except for with fear. Thus, emotion is more common when respondents are more familiar with a candidate.

Figure 3.4: Emotional Appraisals of Candidates, Respondents in Tracked Markets

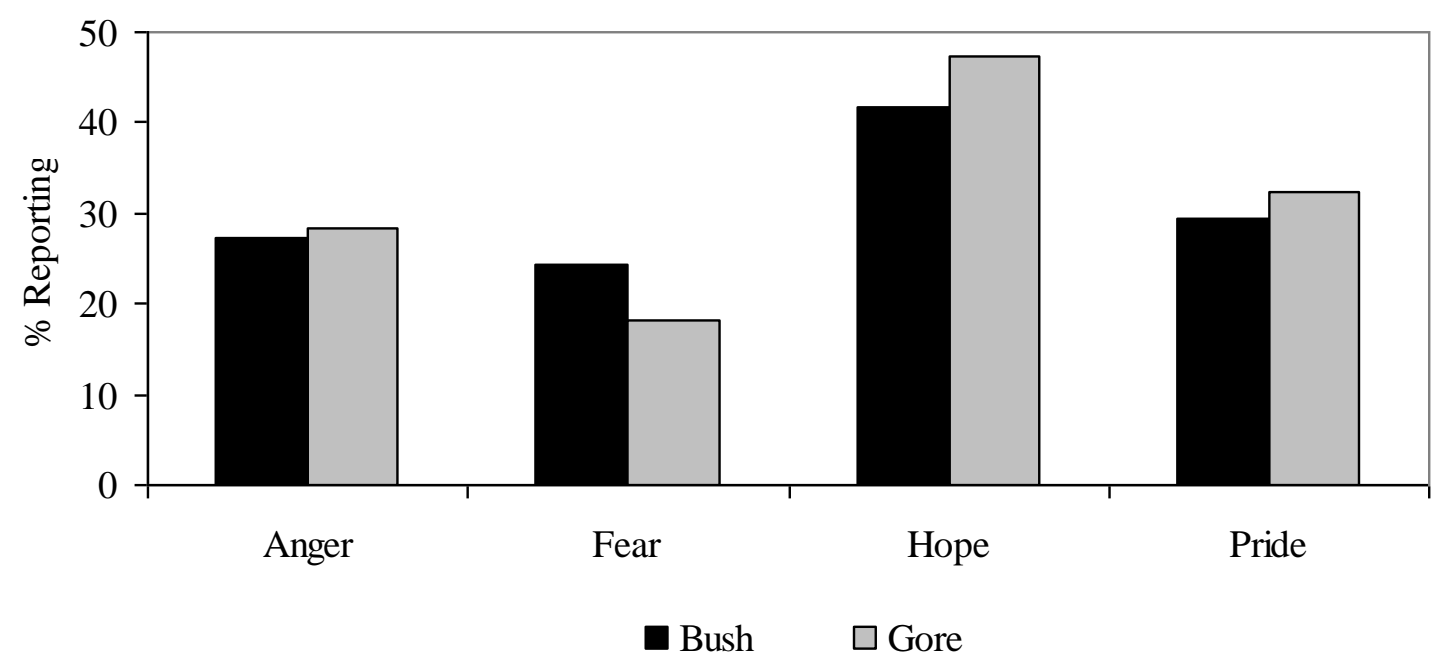


Table 3.2: Candidate Emotions, NES Respondents in 75 Largest Media Markets

\begin{tabular}{|c|c|c|c|c|c|c|c|c|}
\hline \multirow{4}{*}{ Sophistication } & \multicolumn{4}{|c|}{ Bush } & \multicolumn{4}{|c|}{ Gore } \\
\hline & Anger & Fear & Hope & Pride & Anger & Fear & Hope & Pride \\
\hline & $.395 * * *$ & $.514 * * *$ & $.207 *$ & $.462 * * *$ & $.622 * * *$ & $.479 * * *$ & $.366 * * *$ & $.341 * *$ \\
\hline & $(.102)$ & $(.105)$ & $(.097)$ & $(.103)$ & $(.102)$ & $(.117)$ & $(.097)$ & $(.098)$ \\
\hline \multirow[t]{2}{*}{ Partisanship } & $-.298 * * *$ & $-.217 * * *$ & $.473 * * *$ & $.351 * * *$ & $.307 * * *$ & $.315 * * *$ & $-.399 * * *$ & $-.352 * * *$ \\
\hline & $(.052)$ & $(.052)$ & $(.051)$ & $(.052)$ & $(.051)$ & $(.059)$ & $(.049)$ & $(.050)$ \\
\hline \multirow[t]{2}{*}{ Ideology } & $-.207 * *$ & $-.161 *$ & $.249 * *$ & $.289 * * *$ & .060 & .052 & $-.176^{*}$ & -.106 \\
\hline & $(.077)$ & $(.077)$ & $(.074)$ & $(.076)$ & $(.078)$ & $(.091)$ & $(.049)$ & $(.072)$ \\
\hline Issue & $.199 *$ & $.208^{*}$ & -.058 & .005 & .074 & $.339 * * *$ & $-.307 * * *$ & -.095 \\
\hline Distance & $(.084)$ & $(.085)$ & $(.087)$ & $(.092)$ & $(.081)$ & $(.089)$ & $(.075)$ & $(.086)$ \\
\hline \multirow[t]{2}{*}{ Age } & -.003 & $-.011+$ & .002 & -.002 & -.008 & -.005 & .004 & .001 \\
\hline & $(.006)$ & $(.006)$ & $(.005)$ & $(.006)$ & $(.005)$ & $(.006)$ & $(.005)$ & $(.005)$ \\
\hline \multirow[t]{2}{*}{ Education } & $.108+$ & .026 & -.071 & $-.119+$ & -.047 & -.106 & .045 & -.029 \\
\hline & $(.063)$ & $(.063)$ & $(.061)$ & $(.063)$ & $(.061)$ & $(.071)$ & $(.061)$ & $(.061)$ \\
\hline \multirow[t]{2}{*}{ Female } & -.126 & -.115 & .116 & .212 & -.105 & -.046 & -.004 & .219 \\
\hline & $(.175)$ & $(.175)$ & $(.171)$ & $(.175)$ & $(.165)$ & $(.192)$ & $(.167)$ & $(.167)$ \\
\hline \multirow[t]{2}{*}{ Income } & -.002 & -.002 & .002 & -.019 & .012 & .001 & .006 & -.020 \\
\hline & $(.024)$ & $(.025)$ & $(.024)$ & $(.024)$ & $(.023)$ & $(.026)$ & $(.024)$ & $(.024)$ \\
\hline \multirow[t]{2}{*}{ White } & .003 & -.112 & -.077 & -.262 & .239 & -.105 & .015 & .028 \\
\hline & $(.223)$ & $(.222)$ & $(.235)$ & $(.247)$ & $(.246)$ & $(.284)$ & $(.223)$ & $(.215)$ \\
\hline \multirow[t]{2}{*}{ Constant } & -.267 & .022 & $-2.084 * * *$ & $-2.121 * * *$ & $-1.757 * * *$ & $-2.536 * * *$ & $1.725 * * *$ & .697 \\
\hline & $(.573)$ & $(.574)$ & $(.564)$ & $(.588)$ & $(.472)$ & $(.555)$ & $(.459)$ & $(.457)$ \\
\hline LR & $162.52 * * *$ & $121.87 * * *$ & $259.84 * * *$ & 181.12 & $156.28 * * *$ & $152.61 * * *$ & $245.52 * * *$ & $138.57 * * *$ \\
\hline Pseudo- $\mathrm{R}^{2}$ & .161 & .125 & .227 & .175 & .147 & .176 & .213 & .132 \\
\hline $\mathrm{N}$ & \multicolumn{4}{|c|}{832} & \multicolumn{4}{|c|}{832} \\
\hline
\end{tabular}

Note. Entries are unstandardized logistic regression coefficients; standard errors in parentheses; cluster corrected standard errors are used with respondents clustered on media market; issue distance for the Bush emotions is the respondent issue distance from Bush; issue distance for the Gore emotions is the respondent distance from Gore $;+p<.1, * p<.05, * * p<.01, * * * p<.000$ 
Before introducing information context measures into the analysis, I first examine individual characteristics and how they predict emotion. Table 2 applies the same model used to predict emotions in the pooled NES in Chapter 2 to appraisals of Bush and Gore. ${ }^{17}$ Only respondents living in the 75 tracked media markets are included in this analysis so that the model is tested on the same portion of the NES sample used in later analyses. The results strongly support H1, the basic theory at the core of this dissertation. Political sophistication is positively related to emotional appraisals in all eight models.

Table 3.3 reports the direct effects of emotional appeals on appraisals of Bush and Gore. ${ }^{18}$ In seven of eight models, advertising employing a particular emotional theme significantly increases the likelihood that respondents will report feeling that emotion toward the targeted candidate. For example, an increase in GRP of anger appeals targeted at Bush in a market significantly increases the chance that respondents living there will feel angry at him, as see in the first column of estimates. The same is true of anger appeals directed at Gore, as demonstrated by the significant positive coefficient on anger GRP for reporting anger toward him. The sole exception is fear appeals directed at Gore which do not affect the intended emotion.

The pattern of significant direct effects for seven categories of emotional appeals on the emotions and candidates they target is strong support for the idea that citizens as a

\footnotetext{
${ }^{17}$ The 2000 NES sampled 1807 respondents, 1439 of which lived in markets tracked by CMAG. There is no way to obtain advertising data for the 368 lost cases. However, there are no significant differences in the emotion means between the full sample and the subset of 1439. Also, the model in Table 3.2 performs similarly on both sets of respondents, so losing those cases does not bias my results. Of the remaining 1439 cases, I lose 607 because of listwise deletion, largely due to missing income and ideology data. I have used AmeliaView to restore the full 1439 cases with multiple imputation, but the imputed data results are similar to those obtained using the 832 . Thus, I am confident that missing data do not significantly bias the results.

${ }^{18}$ My model specification assumes that appeals directed at one candidate do not predict emotions toward the other. Empirically, this assumption holds. Emotional appeals about one candidate are processed by respondents in relation to only that candidate. Given the low correlations of Bush and Gore emotions, this lack of effect indicates that emotions toward the two candidates are largely independent of one another.
} 
Table 3.3: Candidate Emotions, Individual Characteristics and Advertising GRPs

\begin{tabular}{|c|c|c|c|c|c|c|c|c|}
\hline \multirow{4}{*}{ Sophistication } & \multicolumn{4}{|c|}{ Bush } & \multicolumn{4}{|c|}{ Gore } \\
\hline & Anger & Fear & Hope & Pride & Anger & Fear & Hope & Pride \\
\hline & $.419 * * *$ & $.545 * * *$ & $.188^{*}$ & $.449 * * *$ & $.613 * * *$ & $.479 * * *$ & $.388 * *$ & $.348 * * *$ \\
\hline & (.099) & $(.093)$ & $(.090)$ & $(.097)$ & $(.087)$ & $(.126)$ & $(.112)$ & $(.091)$ \\
\hline \multirow[t]{2}{*}{ Partisanship } & $-.312 * * *$ & $-.231 * * *$ & $.484 * * *$ & $.359 * * *$ & $.309 * * *$ & $.318 * * *$ & $-.409 * * *$ & $-.366 * * *$ \\
\hline & $(.058)$ & $(.056)$ & $(.050)$ & $(.057)$ & $(.045)$ & $(.058)$ & $(.045)$ & $(.059)$ \\
\hline \multirow[t]{2}{*}{ Ideology } & $-.195 * *$ & $-.145^{*}$ & $.253 * * *$ & $.295 * * *$ & .061 & .052 & $-.170 *$ & -.105 \\
\hline & $(.064)$ & $(.056)$ & $(.068)$ & $(.072)$ & $(.088)$ & $(.095)$ & $(.069)$ & $(.070)$ \\
\hline Issue & $.209 *$ & $.226 * *$ & -.053 & .008 & .071 & $.332 * * *$ & $-.3000 * *$ & -.096 \\
\hline Distance & $(.083)$ & $(.079)$ & $(.105)$ & $(.107)$ & $(.096)$ & $(.079)$ & $(.092)$ & $(.082)$ \\
\hline \multirow{2}{*}{ Anger GRP } & $.186^{*}$ & .073 & -.129 & $-.266 * *$ & $.263 *$ & .069 & -.170 & $-.405^{*}$ \\
\hline & $(.091)$ & $(.088)$ & $(.124)$ & $(.092)$ & $(.126)$ & $(.151)$ & (.119) & $(.176)$ \\
\hline \multirow[t]{2}{*}{ Fear GRP } & .186 & $.239 *$ & $-.239 *$ & -.070 & .162 & .269 & $-.388^{*}$ & .059 \\
\hline & $(.136)$ & $(.115)$ & $(.096)$ & (.089) & $(.142)$ & $(.218)$ & (.195) & (.189) \\
\hline \multirow[t]{2}{*}{ Hope GRP } & -.089 & $-.463 * *$ & $.178 * *$ & .087 & -.120 & $-.401 *$ & $.399 *$ & -.074 \\
\hline & $(.095)$ & $(.157)$ & $(.065)$ & $(.119)$ & $(.112)$ & $(.192)$ & $(.191)$ & $(.189)$ \\
\hline \multirow[t]{2}{*}{ Pride GRP } & $-.297 *$ & .034 & .139 & $.181 * *$ & -.144 & -.145 & $.217+$ & $.368^{*}$ \\
\hline & $(.145)$ & $(.118)$ & $(.144)$ & $(.057)$ & $(.149)$ & $(.194)$ & $(.118)$ & $(.177)$ \\
\hline \multirow[t]{2}{*}{ Constant } & -.477 & -.369 & $-2.107 * *$ & $-2.092 * * *$ & $-1.867 * * *$ & $-2.501 * * *$ & $1.752 * * *$ & .713 \\
\hline & $(.611)$ & $(.577)$ & $(.622)$ & $(.458)$ & $(.533)$ & $(.613)$ & $(.422)$ & $(.583)$ \\
\hline LR & $281.48 * * *$ & $171.45^{* * *}$ & $242.50 * * *$ & $222.68 * * *$ & $233.83 * * *$ & $248.20 * * *$ & $311.18 * * *$ & $187.72 * * *$ \\
\hline Pseudo- $\mathrm{R}^{2}$ & .180 & .149 & .242 & .191 & .160 & .189 & .224 & .144 \\
\hline $\mathrm{F}(13,809)$ & $4.692 * * *$ & $5.711 * * *$ & $4.007 * * *$ & $4.005 * * *$ & $3.134 * * *$ & $3.246 * * *$ & $2.870 * *$ & $2.839 * *$ \\
\hline $\mathrm{N}$ & \multicolumn{4}{|c|}{832} & \multicolumn{4}{|c|}{832} \\
\hline
\end{tabular}


whole are responsive to the content of advertising. It is important that in no instance do the combination of anger and fear or hope and pride GRPs significantly affect the same emotions. Anger appeals increase the likelihood of feeling angry. Fear appeals do not. Likewise, fear appeals increase the chance of feeling afraid, but anger does not. The same is true of positive appraisals like hope and pride and positive emotional appeals. Thus, respondents are reacting to the specific discrete emotions that permeate their information contexts. Their emotions are not simple reactions to campaign positivity and negativity.

Whether ad makers consciously target specific discrete emotions is beside the point. Citizens react emotionally to ads as if those appeals are specially tailored. At some level, then, respondents are capable of processing the nuances of emotional appeals, and, as a result, become more likely to feel the targeted emotions as exposure to those appeals increases. This result bolsters the credibility of using a discrete framework to analyze advertising. Were the data to show broader positive and negative reactions, this would support a dimensional perspective such as affective intelligence. However, they do not.

Further supporting the discrete approach is the fact that in six models in Table 3.3 a second category of appeals significantly predicts appraisals, but in a negative direction. ${ }^{19}$ For example, hope GRPs targeting Bush decrease the chance that respondents in a market will fear him. The clear pattern in these negative results is time orientation. Fear and hope are both future-oriented emotions. Likewise, anger and pride both deal with the present or past. Thus, respondents again demonstrate their ability to see beyond pure affective tone. They correctly perceive the timing of discrete emotions, and emotional appeals which play to the same time orientation pull respondents in conflicting

\footnotetext{
${ }^{19}$ One of the exceptions to the two significant effects pattern actually supports the point made here. Fear appeals about Gore do not increase the chance that respondents will fear him, but hope appeals decrease that probability. Thus, anger at Gore is the only emotion that lacks a significant balancing effect.
} 
directions. Arguing that Bush will do terrible things should he win is more than offset by arguments that he will do wonderful things, as seen in the Bush hope coefficient that is nearly twice the size of the fear GRP estimate for feeling afraid of him. To the extent that advertising effects are mediated through emotional experiences, this result helps explain why advertising messages and campaign effects more generally appear to cancel each other out in many studies (Brady and Johnston 2006). Emotional tugs in campaign ads matter, but they mostly matter because they neutralize the advertising of the opposition.

\section{Sophistication as a Moderator of Responsiveness to Information Context}

Now I test $\mathrm{H} 2$ to determine whether sophistication conditions the effect of emotional appeals on candidate appraisals. Imagine a market where 4000 GRPs of anger appeals against Gore aired through the campaign, roughly the median of anger appeals targeting him. The average television viewer in this market saw an ad with an anger appeal forty times, but the number of appeals high sophisticates saw may be greater than forty whereas low sophisticates may have seen fewer. High sophisticates are paying more attention to politics, so perhaps they are watching more programming such as local and national news that is campaign related. Indeed, campaign ads tend to air heavily during news broadcasts (Franz et al. 2008). Thus, they see more ads because they are watching shows where campaign advertising is more concentrated. Low sophisticates are less tuned into news about the campaign, so their exposure may be lower than the average.

Exposure, however, is only part of the dynamic underlying the moderating role of sophistication. Even if high and low sophisticates see the same number of emotional appeals, those appeals may be more relevant to high sophisticates given their greater interest in and knowledge about politics. They likely understand those appeals better and 
are more motivated to care about and react to them. All things being equal, living in a market where more of these appeals are aired may reinforce the messages in those ads, but more so for high sophisticates who are naturally more engaged with the campaign. Thus, whether the true mechanism is exposure or some mixture of understanding and motivation, the indicators that comprise sophistication may interact to make the appraisals of high sophisticates more responsive to emotional appeals.

Tables 3.4 and 3.5 interact sophistication with GRPs to predict emotions toward Bush and Gore respectively. ${ }^{20}$ Five of the eight significant GRP coefficients for Bush emotions in Table 3.3 interact significantly with sophistication, as do three of the six significant Gore GRPs. Figures 3.5 and 3.6 plots these interactive relationships for Bush and Gore appraisals. Predicted probabilities are graphed at the GRP minimum (always 0), mean, and maximum values. Every plotted interaction shows the same pattern - political sophistication makes individuals more emotionally responsive to an increase in advertising GRPs appealing to specific emotional themes.

Panel A in Figure 3.5, for example, shows the interactive effect of sophistication and anger appeals directed at Bush on the probability that respondents are angry at him. The unmarked line plots the effect of sophistication in a market with zero GRPs of anger appeals. The least sophisticated respondents at $-2 S D$ on the factor score have only a $6.7 \%$ chance of being angry at Bush as compared to a $34.5 \%$ chance for the highest sophisticates at $+2 S D$. Thus, in an information context with no ad stimulus, the highest sophisticates are about six times as likely to experience anger as the lowest.

As anger GRPs targeting Bush increase, low and high sophisticates respond differently. Only respondents scoring at the sophistication mean and above demonstrate

\footnotetext{
${ }^{20}$ All interactions are the products of centered constituent terms.
} 
Table 3.4: Bush Emotions with Sophistication and Advertising Interactions

\begin{tabular}{|c|c|c|c|c|}
\hline & Anger & Fear & Hope & Pride \\
\hline \multirow[t]{2}{*}{ Sophistication } & $.498 * * *$ & $.682 * * *$ & $.351 * *$ & $.411 * *$ \\
\hline & $(.137)$ & $(.139)$ & $(.128)$ & $(.158)$ \\
\hline \multirow[t]{2}{*}{ Partisanship } & $-.315 * * *$ & $-.230 * * *$ & $.488 * * *$ & $.365 * * *$ \\
\hline & $(.060)$ & $(.056)$ & $(.049)$ & $(.058)$ \\
\hline \multirow[t]{2}{*}{ Ideology } & $-.194 * *$ & $-.139+$ & $.261 * * *$ & $.296 * * *$ \\
\hline & $(.064)$ & $(.072)$ & $(.069)$ & $(.072)$ \\
\hline \multirow[t]{2}{*}{ Issue Distance } & $.209 *$ & $.229 * *$ & -.048 & .009 \\
\hline & $(.083)$ & $(.081)$ & $(.106)$ & $(.108)$ \\
\hline \multirow[t]{2}{*}{ Anger GRP } & $.153^{*}$ & .089 & -.120 & $-.399 *$ \\
\hline & $(.074)$ & $(.117)$ & $(.127)$ & $(.177)$ \\
\hline Anger GRP X & $.105^{*}$ & .090 & -.095 & -.022 \\
\hline Sophistication & $(.046)$ & $(.116)$ & $(.117)$ & (.069) \\
\hline \multirow[t]{2}{*}{ Fear GRP } & .161 & $.109+$ & $-.170 *$ & -.059 \\
\hline & $(.146)$ & $(.063)$ & $(.071)$ & $(.111)$ \\
\hline Fear GRP X & -.067 & $.106 *$ & $-.107 * *$ & -.049 \\
\hline Sophistication & $(.179)$ & $(.049)$ & $(.039)$ & (.079) \\
\hline \multirow[t]{2}{*}{ Hope GRP } & -.064 & $-.397 *$ & $.175^{*}$ & -.071 \\
\hline & $(.104)$ & $(.193)$ & $(.070)$ & $(.175)$ \\
\hline Hope GRP X & -.076 & $.186+$ & $.107 * *$ & .082 \\
\hline Sophistication & $(.171)$ & (.107) & $(.036)$ & $(.101)$ \\
\hline \multirow[t]{2}{*}{ Pride GRP } & $-.260 *$ & -.027 & .123 & $-.296 *$ \\
\hline & $(.115)$ & $(.122)$ & $(.100)$ & $(.122)$ \\
\hline Pride GRP X & $-.099 *$ & .061 & .038 & .097 \\
\hline Sophistication & $(.040)$ & $(.105)$ & $(.073)$ & $(.110)$ \\
\hline \multirow[t]{2}{*}{ Constant } & -.488 & -.428 & $-2.170 * * *$ & $-2.085 * * *$ \\
\hline & $(.604)$ & $(.579)$ & (.619) & $(.449)$ \\
\hline LR & $306.60 * * *$ & $224.97 * * *$ & $263.16 * * *$ & $299.28 * * *$ \\
\hline Pseudo-R ${ }^{2}$ & .191 & .157 & .251 & .196 \\
\hline $\mathrm{F}(17,801)$ & $2.726 * * *$ & $1.903 *$ & $2.409 * *$ & 1.247 \\
\hline $\mathrm{N}$ & 832 & 832 & 832 & 832 \\
\hline
\end{tabular}

Note. Entries are unstandardized logistic regression coefficients; standard errors in parentheses; cluster corrected standard errors are used with respondents clustered on media market; demographic controls were also estimated but are not shown for space reasons (see Appendix D); original GRP coefficients are multiplied by 1000 to show the effect of a 1000 GRP change; $F$ represents improvement in fit over a model with advertising GRPs but no interactions with sophistication; $+\mathrm{p}<.1,{ }^{*} \mathrm{p}<.05, * * \mathrm{p}<.01,{ }^{* * *} \mathrm{p}<.001$ 
Figure 3.5: Predicted Probabilities of Bush Emotions with Sophistication and Advertising Interactions $\mathrm{X}$-Axis $=$ Sophistication, $\mathrm{Y}$-Axis $=$ Probability of Experiencing Emotion

A. Anger GRP Effect on Bush Anger

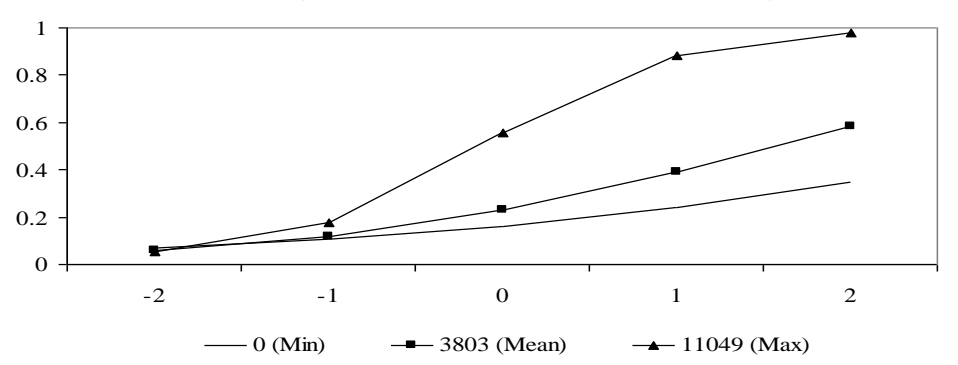

C. Fear GRP Effect on Bush Fear
B. Pride GRP Effect on Bush Anger

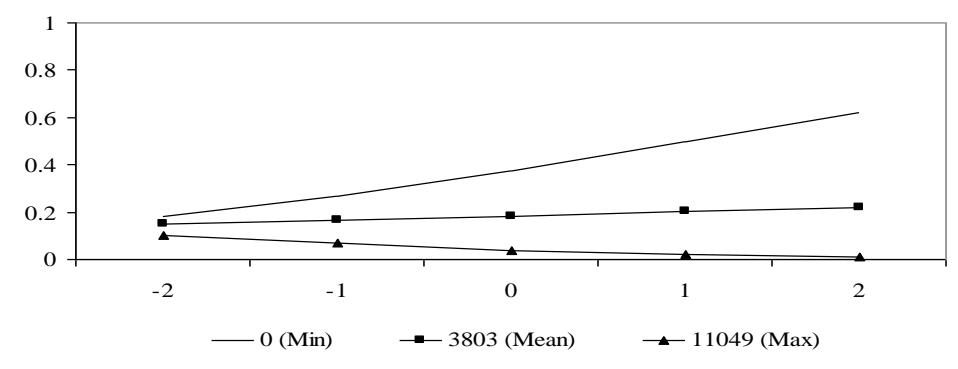

D. Fear GRP Effect on Bush Hope

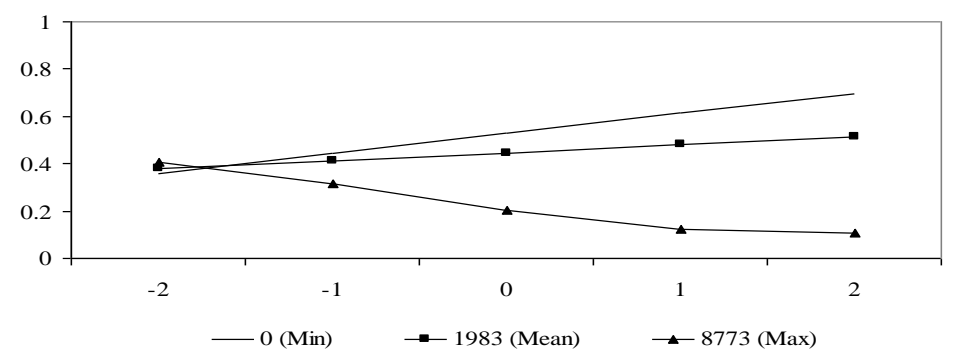

E. Hope GRP Effect on Bush Hope

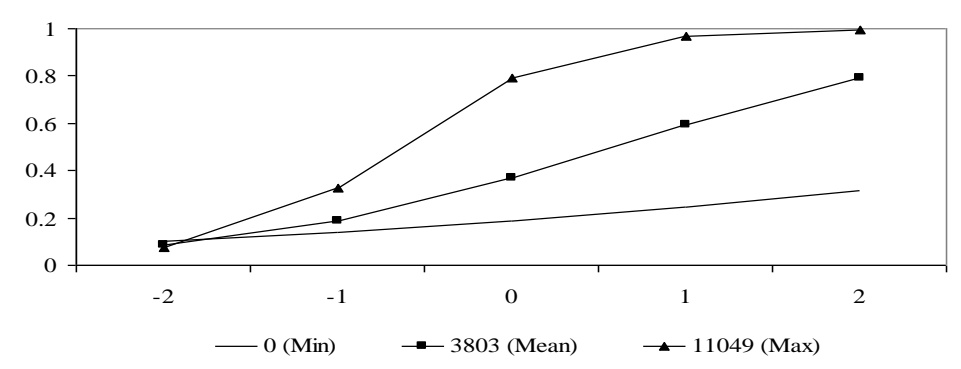


Table 3.5: Gore Emotions with Sophistication and Advertising Interactions

\begin{tabular}{|c|c|c|c|c|}
\hline & Anger & Fear & Hope & Pride \\
\hline Sophistication & $\begin{array}{l}.592 * * * \\
(.131)\end{array}$ & $\begin{array}{l}.346 * * \\
(.126)\end{array}$ & $\begin{array}{l}.378 * \\
(.151)\end{array}$ & $\begin{array}{l}.254^{*} \\
(.121)\end{array}$ \\
\hline Partisanship & $\begin{array}{c}313 * * * \\
(.048)\end{array}$ & $\begin{array}{c}.312 * * * \\
(.055)\end{array}$ & $\begin{array}{c}-.412 * * * \\
(.045)\end{array}$ & $\begin{array}{c}-.357 * * * \\
(.059)\end{array}$ \\
\hline Ideology & $\begin{array}{l}.063 \\
(.089)\end{array}$ & $\begin{array}{c}.054 \\
(.095)\end{array}$ & $\begin{array}{l}-.171 * \\
(.069)\end{array}$ & $\begin{array}{l}-.103 \\
(.071)\end{array}$ \\
\hline Issue Distance & $\begin{array}{l}.073 \\
(.097)\end{array}$ & $\begin{array}{l}.343))) \\
(.078)\end{array}$ & $\begin{array}{c}-.298 * * \\
(.090)\end{array}$ & $\begin{array}{l}-.099 \\
(.085)\end{array}$ \\
\hline Anger GRP & $\begin{array}{l}.218 \\
(.158)\end{array}$ & $\begin{array}{l}.071 \\
(.196)\end{array}$ & $\begin{array}{l}.196 \\
(.133)\end{array}$ & $\begin{array}{l}-.406^{*} \\
(.181)\end{array}$ \\
\hline $\begin{array}{l}\text { Anger GRP X } \\
\text { Sophistication }\end{array}$ & $\begin{array}{l}.339 * \\
(.137)\end{array}$ & $\begin{array}{l}.529 \\
(.407)\end{array}$ & $\begin{array}{l}-.166 \\
(.170)\end{array}$ & $\begin{array}{l}.049 \\
(.122)\end{array}$ \\
\hline Fear GRP & $\begin{array}{l}.210 \\
(.139)\end{array}$ & $\begin{array}{l}.238 \\
(.202)\end{array}$ & $\begin{array}{l}-.408^{*} \\
(.204)\end{array}$ & $\begin{array}{l}-.119 \\
(.199)\end{array}$ \\
\hline $\begin{array}{l}\text { Fear GRP X } \\
\text { Sophistication }\end{array}$ & $\begin{array}{l}.010 \\
(.158)\end{array}$ & $\begin{array}{l}-.425 \\
(.387)\end{array}$ & $\begin{array}{l}.056 \\
(.184)\end{array}$ & $\begin{array}{l}-.019 \\
(.143)\end{array}$ \\
\hline Hope GRP & $\begin{array}{l}-.096 \\
(.167)\end{array}$ & $\begin{array}{l}-.420+ \\
(.246)\end{array}$ & $\begin{array}{l}.412^{*} \\
(.196)\end{array}$ & $\begin{array}{l}.101 \\
(.199)\end{array}$ \\
\hline $\begin{array}{l}\text { Hope GRP X } \\
\text { Sophistication }\end{array}$ & $\begin{array}{l}-.080 \\
(.165)\end{array}$ & $\begin{array}{l}-.161 * \\
(.079)\end{array}$ & $\begin{array}{l}.195^{*} \\
(.092)\end{array}$ & $\begin{array}{l}.127 \\
(.132)\end{array}$ \\
\hline Pride GRP & $\begin{array}{l}-.266 \\
(.172)\end{array}$ & $\begin{array}{l}-.124 \\
(.127)\end{array}$ & $\begin{array}{l}.239+ \\
(.131)\end{array}$ & $\begin{array}{l}.365^{*} \\
(.149)\end{array}$ \\
\hline $\begin{array}{l}\text { Pride GRP X } \\
\text { Sophistication }\end{array}$ & $\begin{array}{c}-.253+ \\
(.131)\end{array}$ & $\begin{array}{c}.143 \\
(.212)\end{array}$ & $\begin{array}{l}-.052 \\
(.208)\end{array}$ & $\begin{array}{l}.115 \\
(.133)\end{array}$ \\
\hline Constant & $\begin{array}{c}-1.852 * * \\
(.545)\end{array}$ & $\begin{array}{c}-2.459 * * * \\
(.617)\end{array}$ & $\begin{array}{c}1.762 * * * \\
(.421)\end{array}$ & $\begin{array}{c}.713 \\
(.589)\end{array}$ \\
\hline LR & $282.94 * * *$ & $319.05 * * *$ & $389.07 * * *$ & $236.23 * * *$ \\
\hline Pseudo- $\mathrm{R}^{2}$ & .169 & .197 & .235 & .150 \\
\hline $\mathrm{F}(17,801)$ & $2.171 * *$ & $1.998 * *$ & $2.883 * * *$ & 1.415 \\
\hline $\mathrm{N}$ & 832 & 832 & 832 & 832 \\
\hline
\end{tabular}

Note. Entries are unstandardized logistic regression coefficients; standard errors in parentheses; cluster corrected standard errors are used with respondents clustered on media market; demographic controls were also estimated but are not shown for space reasons (see Appendix D); original GRP coefficients are multiplied by 1000 to show the effect of a 1000 GRP change; $F$ represents improvement in fit over a model with advertising GRPs but no interactions with sophistication; $+\mathrm{p}<.1,{ }^{*} \mathrm{p}<.05, * * \mathrm{p}<.01,{ }^{* * *} \mathrm{p}<.001$ 
Figure 3.6: Predicted Probabilities of Gore Emotions, Sophistication and Advertising Interactions

$\mathrm{X}$-Axis $=$ Sophistication, $\mathrm{Y}$-Axis $=$ Probability of Experiencing Emotion

A. Anger GRP Effect on Gore Anger

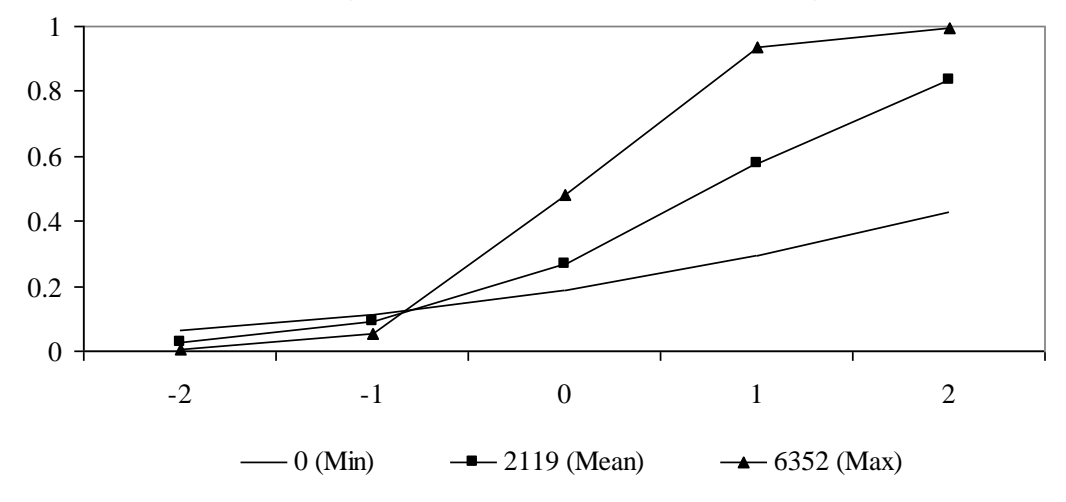

B. Hope GRP Effect on Gore Fear

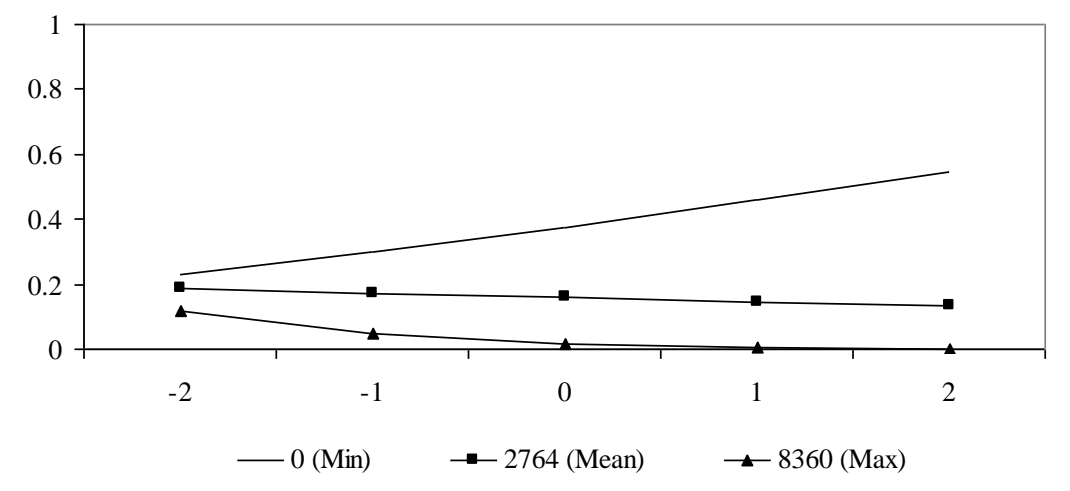

C. Hope GRP Effect on Gore Hope

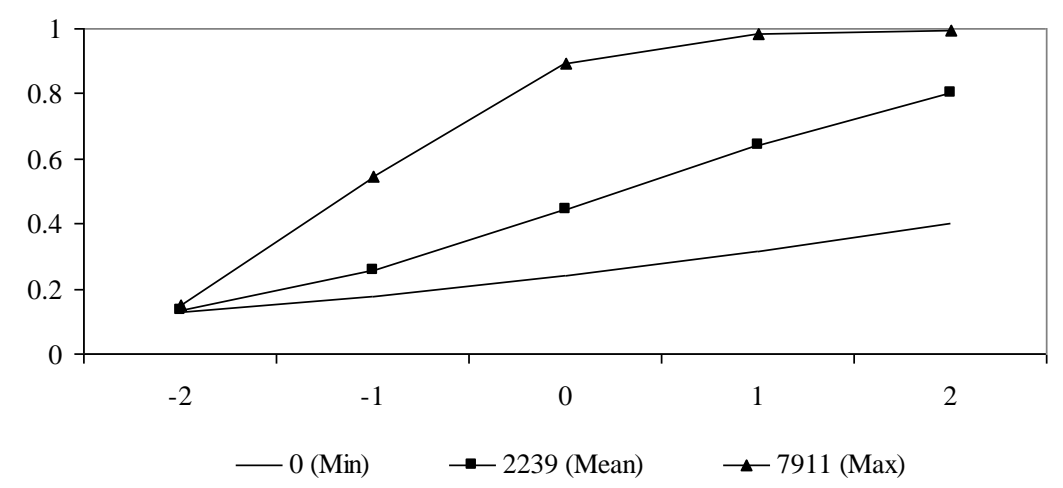


any increased tendency to get angry at Bush in response to an increase in ads with that emotional theme, though that responsiveness is greater as sophistication increases. The $7 \%$ increase between the min and the max of anger GRPs for respondents at $-1 S D$ is insignificant. The lowest sophisticates actually become $1.4 \%$ less likely to feel anger moving from 0 to 111 exposures, an insignificant change but one that fits with Brader's (2006) finding that low sophisticates withdraw slightly in response to emotional ads.

Panel B in Figure 3.5 plots the interaction of sophistication and pride appeals targeting Bush on the likelihood of being angry at him. The negative pride effect on anger is more pronounced among higher sophisticates. The unmarked line indicates a market with no pride appeals. In the absence of such messages, the highest sophisticates are about three times as likely to be angry at Bush as the lowest $(18.1 \%$ chance at $-2 S D$, $61.9 \%$ at $+2 S D)$. At the GRP mean, however, where average viewers see 38 pride ads, the probability for the highest sophisticates is cut by two-thirds to $22.1 \%$ while the lowest sophisticates show an insignificant decrease to $14.9 \%$. At the maximum value, roughly 115 pride exposures, depresses the probability for those at $+2 S D$ to only a $1.2 \%$ chance of being angry at Bush. Respondents at $-2 S D$ drop to a $10 \%$ chance, but this value is statistically indistinguishable from their $18.1 \%$ chance in a market with no pride appeals.

Thus, anger messages aimed at Bush increase the chance that respondents will be angry at him whereas pride messages decrease that probability. The effect of an increase in both types of appeals, however, varies by sophistication. Respondents scoring below the sophistication mean are, statistically speaking, relatively unresponsive to a change in ad exposures. Showing them more anger or pride appeals does not with any confidence change their appraisals. Those above the mean, however, are responding to changing ad 
GRPs, with the highest sophisticates being even more responsive than those at the mean. Overall, though, anger and pride appeals in this instance tend to cancel each other out at all levels of sophistication. The predicted effects in Table 3.5 may look large, but their real effects are rather small given the balance of anger and pride appeals about Bush in most markets. The ultimate effect of advertising on appraisals, then, is highly contingent upon the ratio of emotional appeals aired in any one market.

The pattern seen in the anger at Bush example repeats across all the significant interactions in Figures 3.5 and 3.6. High sophisticates are more emotionally responsive to information context than low sophisticates, at least when context is conceptualized as the emotional content of advertising. This interaction, however, is as much the product of high sophisticates being more responsive as it is low sophisticates being unresponsive. With few exceptions, respondents below the sophistication mean across all eight interactions are unmoved in response to emotional appeals, so it is the more informed and engaged respondents whose emotions are really shaped by advertising. Though only eight of the fourteen direct GRP effects in Table 3.3 interact significantly with sophistication, each of those interactions shows that sophistication enhances emotional responsiveness to advertising. Thus, these results strongly support H2. High sophisticates are both more emotional, and more emotionally responsive to their information contexts.

\section{Effects on Voting Behavior}

H3 posits that emotion will more strongly influence the political behavior of high sophisticates than. Thus, emotion and sophistication should interact significantly when modeling respondent behavior. With emotional appeals and appraisals of the candidates, the most logical action to examine is voting. In the next set of analyses, the dependent 
variable is presidential vote choice in the 2000 election ( $1=$ Gore vote, $0=$ Bush vote $)$. Before directly testing $\mathrm{H} 3$, however, I examine whether emotional appeals affect vote choice and whether sophistication moderates any such relationship. I have shown that sophistication moderates emotional responsiveness to advertising appeals. If the emotions of high sophisticates are more influenced by the messages in their information environments, might their votes also be more responsive to those same appeals?

Table 3.6 models voting with predictors for emotion GRPs. ${ }^{21}$ The first column regresses vote choice on appeals directly. Only three categories of appeals significantly shape voting. No Bush appeal categories factor into vote choice, but anger, hope, and pride messages targeted at Gore do. These three effects are all in the expected direction, with anger reducing the chance of a Gore vote and hope and pride increasing it. The second column interacts appeal GRP with sophistication. Only the effect of fear appeals directed at Bush varies by sophistication level. This one interaction shows that fear appeals sway the votes of high sophisticates more than those of low sophisticates, an important contrast to the critique that "fear mongering" ads irrationally sway the uninformed masses (Brader 2006). However, the key point is that fear is the only significant interaction. Emotional appeals may affect vote choice directly, but the magnitude of those effects is largely not contingent upon sophistication.

Table 3.7 also models vote choice, replacing advertising GRP with emotional appraisals of Bush and Gore. The first column tests direct emotion effects. Four emotions significantly shape voting behavior, all in the expected direction. Fear of Bush and hopefulness about Gore increase the likelihood that a respondent will vote for Gore. Hopefulness about Bush and anger at Gore make a Bush vote more likely.

\footnotetext{
${ }^{21}$ Of the 832 NES respondents in the emotion models, 197 did not vote, so the $\mathrm{N}$ is reduced.
} 
Table 3.6: Presidential Vote with Sophistication and Advertising Interactions

\begin{tabular}{|c|c|c|}
\hline & No Interactions & Interactions \\
\hline Sophistication & $.295(.191)$ & $.041(.429)$ \\
\hline Emotions Targeted at Bush: & & \\
\hline Anger GRP & $-.178(.244)$ & $-.048(.269)$ \\
\hline Fear GRP & $.189(.233)$ & $-.049(.252)$ \\
\hline Hope GRP & $.119(.173)$ & $.013(.216)$ \\
\hline Pride GRP & $.164(.195)$ & $.177(.207)$ \\
\hline Emotions Targeted at Gore: & & \\
\hline Anger GRP & $-.921(.383)^{*}$ & $-.812(.455)+$ \\
\hline Fear GRP & $.342(.332)$ & $.408(.369)$ \\
\hline Hope GRP & $-1.269(.298) * * *$ & $-1.384(.369) * * *$ \\
\hline Pride GRP & $1.406(.347) * * *$ & $1.629(.406)^{* * *}$ \\
\hline Bush Appeal Interactions: & & \\
\hline Anger GRP X Sophistication & & $-.390(.285)$ \\
\hline Fear GRP X Sophistication & & $.503(.218)^{*}$ \\
\hline Hope GRP X Sophistication & & $.038(.270)$ \\
\hline Pride GRP X Sophistication & & $.231(.281)$ \\
\hline Gore Appeal Interactions: & & \\
\hline Anger GRP X Sophistication & & $-.121(.454)$ \\
\hline Fear GRP X Sophistication & & $-.152(.217)$ \\
\hline Hope GRP X Sophistication & & $.318(.729)$ \\
\hline Pride GRP X Sophistication & & $-.432(.549)$ \\
\hline Controls: & & \\
\hline Ideology & $-.445(.158)^{* *}$ & $-.479(.156) * *$ \\
\hline Partisanship & $-1.022(.113) * * *$ & $-1.027(.112)^{* * *}$ \\
\hline Bush Issue Distance & $.794(.189)^{* * *}$ & $.781(.179)^{* * *}$ \\
\hline Gore Issue Distance & $-.653(.181) * * *$ & $-.669(.181)^{* * *}$ \\
\hline Constant & $3.257(1.254)^{* *}$ & $3.210(1.293)^{*}$ \\
\hline LR & $383.15^{* *}$ & $878.24 * * *$ \\
\hline Pseudo- $\mathrm{R}^{2}$ & .675 & .691 \\
\hline $\mathrm{F}(27,586)$ & & $3.812 * * *$ \\
\hline $\mathrm{N}$ & 635 & .635 \\
\hline
\end{tabular}

Note. Entries are unstandardized logistic regression coefficients; standard errors in parentheses; cluster corrected standard errors are used with respondents clustered on media market; demographic controls were also estimated (see Appendix E); GRP coefficients are multiplied by 1000 to show the effect of a 1000 GRP change; $F$ tests improvement in fit over model with no interactions; $+\mathrm{p}<.1, * \mathrm{p}<.05$, $* * \mathrm{p}<.01, * * * \mathrm{p}<.001$

The second column in Table 3.7 interacts emotion and sophistication. Three interactions are significant - fear of Bush, pride in Bush, and pride in Gore. The two 
original hope variables and anger at Gore remain significant after specifying the interaction terms, but sophistication does not moderate their effects.

Table 3.7: Presidential Vote with Sophistication and Emotion Interactions

\begin{tabular}{|c|c|c|}
\hline & No Interactions & Interactions \\
\hline Sophistication & $.198(.187)$ & $.488(.396)$ \\
\hline Bush Emotions: & & \\
\hline Anger & $-.135(.501)$ & $-.416(.455)$ \\
\hline Fear & $2.026(.539) * * *$ & $2.302(.519) * * *$ \\
\hline Hope & $-2.139(.473) * * *$ & $-2.346(.530) * * *$ \\
\hline Pride & $-.575(.595)$ & $-.326(.616)$ \\
\hline Gore Emotions: & & \\
\hline Anger & $-.964(.333) * *$ & $-1.290(.399)^{* *}$ \\
\hline Fear & $-.963(.638)$ & $-.782(.561)$ \\
\hline Hope & $2.160(.393) * * *$ & $2.244(.415) * * *$ \\
\hline Pride & $.798(.489)$ & $.890(.497)+$ \\
\hline Bush Emotion Interactions: & & \\
\hline Anger X Sophistication & & $-.279(.551)$ \\
\hline Fear X Sophistication & & $1.177(.515)^{*}$ \\
\hline Hope X Sophistication & & $-.508(.718)$ \\
\hline Pride X Sophistication & & $-1.456(.633)^{*}$ \\
\hline Gore Emotion Interactions: & & \\
\hline Anger X Sophistication & & $-.307(.749)$ \\
\hline Fear X Sophistication & & $-.499(.853)$ \\
\hline Hope X Sophistication & & $-.404(.597)$ \\
\hline Pride X Sophistication & & $1.316(.554) *$ \\
\hline Controls: & & \\
\hline Ideology & $-.260(.182)$ & $-.343(.191)+$ \\
\hline Partisanship & $-.809(.126)^{* * *}$ & $-.920(.134) * * *$ \\
\hline Bush Issue Distance & $.817(.315)^{*}$ & $.782(.327)^{*}$ \\
\hline Gore Issue Distance & $-.635(.220)^{* *}$ & $-.568(.248)^{*}$ \\
\hline Constant & $2.471(1.536)$ & $2.955(1.617)+$ \\
\hline LR & $337.70 * * *$ & $291.93 * * *$ \\
\hline Pseudo- $\mathrm{R}^{2}$ & .772 & .789 \\
\hline$F(27,586)$ & & $5.932 * * *$ \\
\hline $\mathrm{N}$ & 635 & 635 \\
\hline
\end{tabular}

Note. Entries are unstandardized logistic regression coefficients; standard errors in parentheses; cluster corrected standard errors are used with respondents clustered on media market; demographic controls were also estimated (see Appendix E); $F$ tests improvement in fit over model with no interactions; $+\mathrm{p}<.1, * \mathrm{p}<.05, * * \mathrm{p}<.01, * * * \mathrm{p}$ $<.001$ 
Figure 3.7 plots the significant interaction effects. In each case emotional appraisals are stronger influences on the vote choices of high sophisticates than those of low sophisticates. For example, holding other predictors at their means, respondents at -2 $S D$ on sophistication who are proud of Bush still have more than an $80 \%$ chance of voting for Gore even though this emotion should encourage a Bush vote. High sophisticates at $+2 S D$ who are also proud of Bush, however, only have about a $10 \%$ chance voting for Gore. Similar action biases are evident in the remaining two plots.

\section{Figure 3.7: Predicted Probability of Gore Vote, Sophistication and Emotion Interactions}

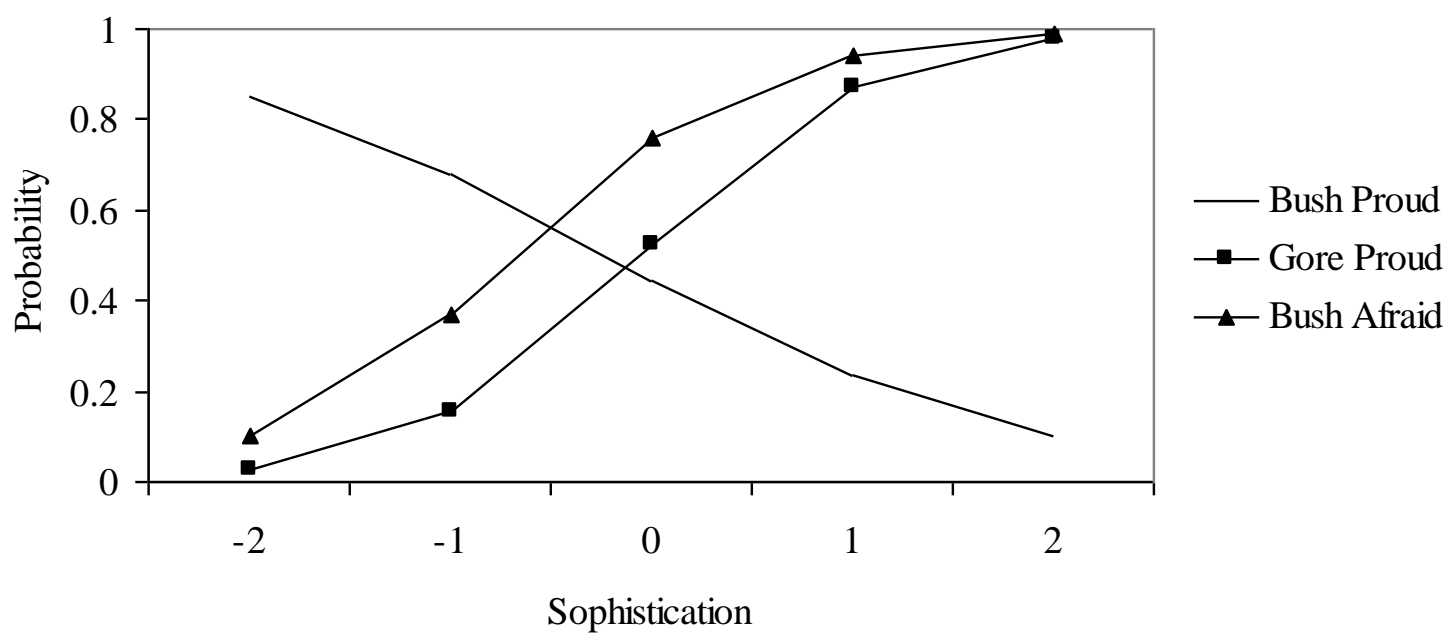

Thus, the action tendencies emotions induce are most evident in the voting of more sophisticated respondents, strongly supporting $\mathrm{H} 3$ that sophistication enables either the understanding or the motivation to translate emotion into political action. These results also show that emotional cues interact with sophistication to affect vote choice, but only indirectly. By and large, sophistication does not directly condition the effect of advertising on voting. Ad appeals, however, make certain emotions more or less likely, 
particularly for high sophisticates. Sophistication then moderates the effects of those emotions on voting about half of the time. Thus, the respondents whose voting is most influenced by emotions are highly sophisticated ones, but also ones living in markets with greater exposure to the campaign advertising that elicits those emotions in the first place. The voters least likely to act on emotion are lower sophisticates. However, campaign ads barely affect their appraisals, so the indirect interaction of ad appeals and sophistication is less powerful for the politically disengaged. ${ }^{22}$

\section{Sophistication as a Moderator in Policy Attitudes}

The student sample used to test emotion paradata in Chapter 2 allows me to test $\mathrm{H} 3$ in another context - the expression of policy attitudes. Table 3.8 adapts the latency ratio and response change models to predict Iraq War policy attitudes, but now incorporates emotional appraisals of the Iraq War and the interactions of those emotions with sophistication. Again, sophistication moderates the effect of emotion in a number of instances. Positive interaction signs indicate that high sophisticates who experience a particular emotion are more likely to agree with policy statements than low sophisticates who also feel that emotion. Negative signs mean that high sophisticates are more likely to disagree than similarly emotional low sophisticates.

Figure 3.8 plots two significant interactions. ${ }^{23}$ Panel A shows the interaction of anger at the US and sophistication for agreeing that "the US should send more troops to

\footnotetext{
${ }^{22}$ I replicated the analysis in Table 3.7 using the pooled 1980-2004 NES data used in Chapter 2. I find similar results in those data. Half of the pooled sophistication and emotion interactions are significant, with emotion being a stronger influence on the voting of high sophisticates in each instance. Thus, these interactive effects are not simply an artifact of some dynamic unique to the 2000 election.

${ }^{23}$ All interaction plots show similar patterns, so only two are plotted. The choice of interactions is arbitrary.
} 
Table 3.8: Emotion Effects on Iraq War Policy Attitudes

\begin{tabular}{|c|c|c|c|c|}
\hline & $\begin{array}{c}\text { Humanitarian } \\
\text { Aid }\end{array}$ & $\begin{array}{c}\text { Repair } \\
\text { Damage }\end{array}$ & $\begin{array}{c}\text { Keep } \\
\text { Troops }\end{array}$ & $\begin{array}{c}\text { Send } \\
\text { Troops }\end{array}$ \\
\hline Anger at Iraqis & $\begin{array}{c}.067 \\
(.263)\end{array}$ & $\begin{array}{c}.156 \\
(.257)\end{array}$ & $\begin{array}{c}.067 \\
(.263)\end{array}$ & $\begin{array}{c}.319 \\
(.285)\end{array}$ \\
\hline Anger at the US & $\begin{array}{l}.054 \\
(.389)\end{array}$ & $\begin{array}{l}-.418 \\
(.387)\end{array}$ & $\begin{array}{l}-.886+ \\
(.489)\end{array}$ & $\begin{array}{l}-.369 \\
(.413)\end{array}$ \\
\hline Guilt about US Actions & $\begin{array}{l}-.029 \\
(.348)\end{array}$ & $\begin{array}{l}.121 \\
(.356)\end{array}$ & $\begin{array}{l}-.258 \\
(.365)\end{array}$ & $\begin{array}{l}-.149 \\
(.349)\end{array}$ \\
\hline Sympathy for Iraqis & $\begin{array}{c}.921 \\
(.691)\end{array}$ & $\begin{array}{l}1.022 \\
(.686)\end{array}$ & $\begin{array}{c}.094 \\
(.561)\end{array}$ & $\begin{array}{l}.601 \\
(.635)\end{array}$ \\
\hline Sophistication & $\begin{array}{c}.749 * * * \\
(.119)\end{array}$ & $\begin{array}{c}.492 * * * \\
(.117)\end{array}$ & $\begin{array}{c}.891 * * * \\
(.125)\end{array}$ & $\begin{array}{c}-.341 * * \\
(.119)\end{array}$ \\
\hline Anger at Iraqis X Sophistication & $\begin{array}{c}.039 \\
(.273)\end{array}$ & $\begin{array}{c}-.863 * * \\
(.271)\end{array}$ & $\begin{array}{l}.441 \\
(.547)\end{array}$ & $\begin{array}{l}.884 * * \\
(.323)\end{array}$ \\
\hline Anger at US X Sophistication & $\begin{array}{c}.596 \\
(.438)\end{array}$ & $\begin{array}{l}.036 \\
(.444)\end{array}$ & $\begin{array}{l}-.655^{*} \\
(.269)\end{array}$ & $\begin{array}{c}-1.968 * * * \\
(.508)\end{array}$ \\
\hline Guilt X Sophistication & $\begin{array}{l}-.574 \\
(.368)\end{array}$ & $\begin{array}{l}.438 \\
(.376)\end{array}$ & $\begin{array}{c}-1.134 * * \\
(.428)\end{array}$ & $\begin{array}{l}-.093 \\
(.352)\end{array}$ \\
\hline Sympathy X Sophistication & $\begin{array}{l}1.831 * \\
(.751)\end{array}$ & $\begin{array}{l}1.787 * \\
(.834)\end{array}$ & $\begin{array}{l}1.669 * \\
(.655)\end{array}$ & $\begin{array}{l}-.237 \\
(.763)\end{array}$ \\
\hline Blame & $\begin{array}{c}.077 \\
(.127)\end{array}$ & $\begin{array}{l}.131 \\
(.127)\end{array}$ & $\begin{array}{l}-.281 * \\
(.125)\end{array}$ & $\begin{array}{l}-.049 \\
(.127)\end{array}$ \\
\hline Ideology & $\begin{array}{c}-.369 * * \\
(.137)\end{array}$ & $\begin{array}{l}-.274^{*} \\
(.133)\end{array}$ & $\begin{array}{c}.038 \\
(.133)\end{array}$ & $\begin{array}{l}.299 * \\
(.134)\end{array}$ \\
\hline Partisanship & $\begin{array}{l}.021 \\
(.109)\end{array}$ & $\begin{array}{c}.089 \\
(.107)\end{array}$ & $\begin{array}{l}.351 * * \\
(.101)\end{array}$ & $\begin{array}{l}.185+ \\
(.108)\end{array}$ \\
\hline$\tau_{1}$ & -4.439 & -3.415 & -1.139 & .741 \\
\hline$\tau_{2}$ & $\begin{array}{l}-2.444 \\
-1354\end{array}$ & $\begin{array}{r}-2.013 \\
-850\end{array}$ & $\begin{array}{r}.184 \\
1519\end{array}$ & $\begin{array}{l}2.325 \\
3854\end{array}$ \\
\hline $\begin{array}{l}\tau_{3} \\
\tau_{4}\end{array}$ & $\begin{array}{c}-1.354 \\
.681\end{array}$ & $\begin{array}{l}-.859 \\
1.496\end{array}$ & $\begin{array}{l}1.519 \\
3.342\end{array}$ & $\begin{array}{l}3.854 \\
6.098\end{array}$ \\
\hline LR & $76.25 * * *$ & $64.39 * * *$ & $177.73 * * *$ & $127.55^{* * *}$ \\
\hline Pseudo- $\mathrm{R}^{2}$ & .075 & .064 & .151 & .127 \\
\hline $\mathrm{F}(17,343 / 342)$ & $2.138 * *$ & $2.021 * *$ & $3.342 * * *$ & $3.743 * * *$ \\
\hline $\mathrm{N}$ & 374 & 373 & 374 & 374 \\
\hline
\end{tabular}

Note. Entries are unstandardized ordinal logistic regression coefficients; demographic controls were also estimates (see Appendix E); $F$ represents improvement in fit over the model with no interactions; $+\mathrm{p}<.1, * \mathrm{p}<.05, * * \mathrm{p}<.01, * * * \mathrm{p}<.001$

Iraq to fight the militia and terrorist organizations responsible for violence there." Respondents who feel angry at the US are more likely to disagree with sending troops, perhaps seeing this position as an appropriate remedy to some perceived wrong the US 
has committed. The effect of anger, however, is more pronounced among high sophisticates. Low sophisticates at -2 SD have a combined probability of $60.1 \%$ of choosing one of the two disagree categories as compared to an $81.6 \%$ chance for high sophisticates at $+2 S D$. Though disagreement with sending more troops is the dominant sentiment among angry respondents at all levels of sophistication, high sophisticates are more attracted to the extreme "disagree strongly" category than angry low sophisticates. Indeed, at the lowest levels of sophistication, angry respondents are just as likely to have no opinion on troops as they are to disagree strongly with sending more. However, among the highest sophisticates, the more extreme sentiment is the most likely.

Panel B plots the interaction of sympathy for the Iraqis and sophistication for agreeing that "the US should increase financial aid to Iraq to repair damage to infrastructure like roads and bridges caused by the US invasion." Sympathy, an emotion that motivates helping actions meant to alleviate the suffering of others (Haidt 2003), elicits agreement with the infrastructure statement, but it is a stronger influence on the attitudes of high sophisticates. The lowest sophisticates who feel sympathy have a $43 \%$ chance of agreeing with reparative aid, but only a $6.7 \%$ chance of strongly agreeing. In fact, "agree strongly" is the least likely choice of respondents at $-2 S D$. High sophisticates, however, are much more likely to agree with reparative aid as the highest sophisticates at $+2 S D$ have a combined probability of $87.1 \%$ of agreeing with the policy statement. Indeed, the most dramatic movement across the sophistication spectrum occurs in the "agree strongly" category. Thus, the finding that high sophisticates rely more upon emotion in their voting behavior replicates to attitude expression, so this relationship is robust across behavioral domains. 
Figure 3.8: Sophistication and Emotion Interactions for Policy Attitudes

A. Anger at the US and Sophistication Interaction for Sending More Troops

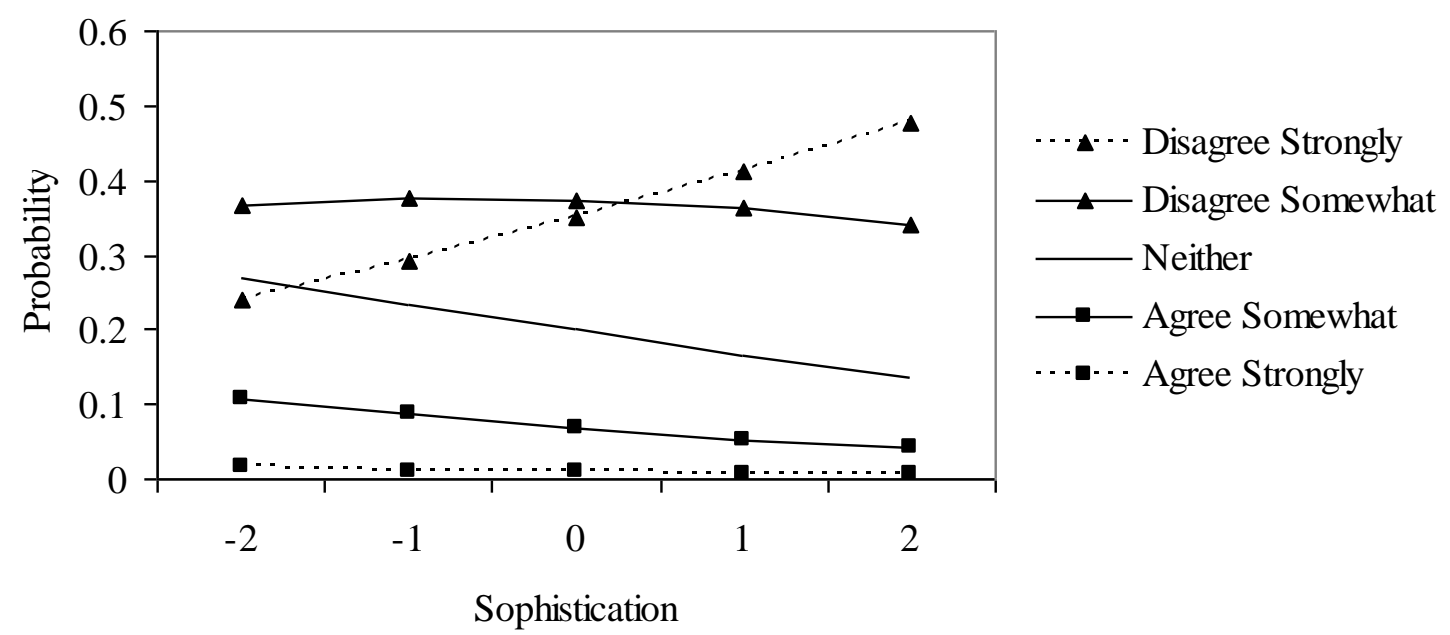

B. Sympathy for Iraqis and Sophistication Interaction for Repairing Infrastructure

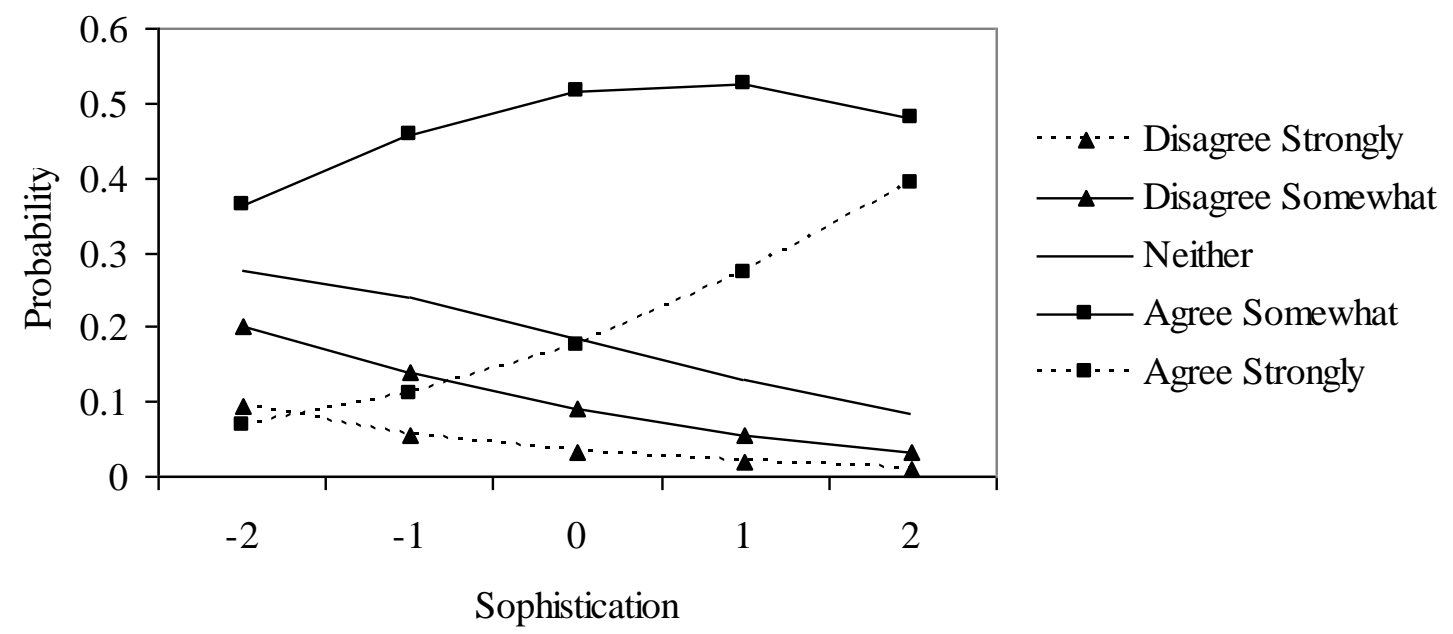

\section{Discussion}

In the previous chapter, I established that high political sophisticates are more likely to experience emotional reactions to politics than low sophisticates, and I rigorously tested that relationship through analysis of response latency and response change paradata. I can 
confidently say, then, that more sophisticated individuals are indeed more emotional about politics than lower sophisticates. In this chapter, I have pushed that relationship further by demonstrating a role for information context in eliciting emotion and by showing behavioral consequences for the sophistication-emotion relationship. High sophisticates are more emotionally responsive to politically-relevant emotional stimuli in the information environment around them. Emotion is also more likely to affect the behavior of high sophisticates than low sophisticates, a pattern demonstrated in both voting behavior and the expression of policy attitudes toward the Iraq War.

Overall, then, my analyses thus far show that high sophisticates are more emotional about political stimuli, more responsive to emotional cues in their information contexts, and more responsive to emotion action tendencies in their behavior. These findings powerfully undermine the traditional stereotype that emotion is a low sophistication phenomenon. It is not the least informed and least engaged citizens who are more likely to think about politics in emotional terms or whose behavior is more likely to be swayed by emotional whims. Rather, it is informed and engaged voters who exhibit these qualities. Emotion, then, is a product of knowing about and caring about politics, not ignorance of political life. These results are interesting on the surface, but, more importantly, we must rethink how we normatively view the role of emotion in democracy. Can emotion be irrational and dangerous if those citizens we value most for their engagement with politics are also the most emotional about it? I will return to this question in the conclusion of this dissertation.

This chapter has certain strengths and weaknesses that affect how it informs my dissertation. It is more useful than a simple survey analysis because the CMAG data offer 
the ability to conduct a quasi-experiment given the immense variation in ad exposure across markets. I can assert with confidence, then, that the information context results presented here are the product of more than mere correlation. That these results are discovered in a quasi-experimental design hints that the relationship between sophistication and emotion is a causal one. It is not just that high sophisticates happen to be more emotional about political stimuli. Their greater engagement with politics is likely causing that emotionality. That assertion would be stronger, however, with a truly randomized experimental manipulation, something I offer in the next chapter.

Campaign ads are just one way to conceptualize information context, and no one operationalization is inherently better than another as citizens encounter political information in many forms. The next chapter reconceptualizes context as print and television news, but finds similar results for how sophistication moderates emotional responsiveness. I also expand my inquiry into behavioral effects into learning, and show that high sophisticates are more susceptible to the learning biases that emotions induce. Thus, even though in this chapter I choose one type of context to examine, I replicate its findings in different settings and on different types of behavioral variables.

My coding scheme does ignore certain aspects of emotional appeals, including their strength, dominance of an appeal in an ad, and the number of appeals to the same emotion in an ad. If a fear message about Bush claims that he will do ten terrible things if he wins, that ad is coded the same as an ad that only makes one fear appeal. While some of these other characteristics may affect the likelihood of an emotional response, the GRP measures I construct based on the mere presence of an emotional appeal are not inherently flawed. They simply measure one aspect of the information environment. 
Lastly, the specific results presented here are almost assuredly in part an artifact of circumstances unique to the 2000 election. Were I to choose a different election, the distribution of ads and their emotional appeals might be different across and within markets. With different candidates or an election featuring an incumbent, the specific emotions that predict voting either directly or when interacted with sophistication might be different. I am confident in predicting, however, that the broad findings would be the same were I to replicate this analysis in a different year. High sophisticates would still be more emotional, more responsive to emotional appeals, and more swayed by emotion in their voting. The significance of particular emotions might change, but the conclusions would be the same. 


\title{
Chapter 4
}

\section{An Experimental Exploration of Emotional Cues in News Media}

\begin{abstract}
This chapter describes a randomized experiment of roughly 860 undergraduates that further tests the hypotheses advanced thus far in this dissertation. I reconceptualize information context as the news media, namely print and television news about illegal immigration. I argue that contexts which rely upon more emotional cues (specifically audiovisual stimuli and explicit emotional frames) to convey information will prompt both greater emotional responsiveness and higher levels of learning as a general rule, but that sophistication moderates the magnitudes of those contextual effects. I again demonstrate that high sophisticates are more emotional about political stimuli, and that emotion is a stronger influence on their behavior - operationalized here as learning from news stories - than that of low sophisticates. Thus, this chapter offers the most solid evidence yet that the relationship between sophistication and emotion is not merely correlational in nature, but causal. I then discuss the larger practical and theoretical implications of this chapter.
\end{abstract}


Analyses thus far demonstrate substantial support for the core theory of my dissertation. Political sophistication is indeed positively related to the experience of emotion in reaction to politics. Furthermore, high sophisticates are also more emotionally responsive to emotional appeals in the information contexts around them and more reliant upon emotion in their political actions and attitudes. This chapter provides further tests of my central hypotheses using a randomized experiment of undergraduates. Analyses this far have relied largely on cross-sectional data that provide little insight into causal processes, so a randomized experiment is useful for establishing causality between sophistication and emotion and for ruling out the possibility that an endogenous relationship between emotion and sophistication is influencing the results. I reconceptualize information context as print and video news about illegal immigration and again show that high sophisticates are more responsive to emotional cues in the media they consume. I also show again that emotion-induced action tendencies are a greater influence on the behavior of high sophisticates, but this time in learning behavior rather than voting or attitude expression.

\section{News Media as Information Context}

The news media represent another "context" in which ordinary citizens might encounter political information. The focus here is on the conventional news media, meaning television and print outlets, and how the emotional cues in these environments moderate the relationship between sophistication and emotion. Traditional media, despite declining consumption rates, are still where most Americans are exposed to political news, making them the most important source of political information for the average citizen (Kinder 
2003; Prior 2007). These media present information in different ways, however, employing various formats, modalities, and frames to engage consumers. For example, print news is limited to the visual modality with its reliance on words and pictures, but television news offers a wealth of visual and auditory cues. Even within a particular format there is variation in news presentation. Some media rely more on the traditional hard news style which emphasizes balanced facts and frames that place stories within the context of broader political issues, and where emotional angles are deemphasized (Baum 2003). Other outlets prefer the soft news style that emphasizes analysis of events, episodic frames, human interest angles, and the emotional side of stories.

Presentation style matters for the understanding of news because it affects information processing. One way in which media presentation style varies is in the use of different modalities, meaning various types of visual and audio stimuli. The brain naturally processes stimuli from multiple senses simultaneously. Humans understand and learn better when the information they are exposed to is rich in sensory stimuli, thereby more closely resembling normal brain functioning (Graber 1990, 2001, 2004; Lewis 1984; Pryluck 1976). News formats such as television, then, are more conducive to the ability of average citizens to engage with information and store it in long-term memory than less stimulating formats such as print. Many studies demonstrate that stimuli rich in visual and audio modalities enhance information processing capabilities by making both the encoding of information in long-term memory and the retrieval of that information easier (Berry and Brosius 1991; Crigler, Just, and Neuman 1994; Graber 2001; Gregory 1997; Lang and Friestad 1993; Messaris 1994; Nelson and Boynton 1997; Paivio 1979; Van Der Molen and Van Der Voort 2000; Woodall 1986). 
Similarly, news reported from clear emotional angles motivates engagement with information (Biocca 1991; Jamieson and Waldman 2003; McQuail 1997) in comparison to balanced or neutral hard news that consumers tend to find boring (Baum 2002, 2003; Brants 1998). Emotionally compelling slants facilitate learning from the media, a pattern that makes sense as we now know that emotion and cognition work together rather than against one another as humans reason (Sniderman et al. 1991; Damasio 1994; Marcus et al. 2000). Though there are normative concerns about the manipulation of emotion and the usage of audiovisuals in news (see Graber, 2001 for a review), these cues are on balance desirable if the goal of the media are to educate the public about politics.

Given that presentation style affects information processing, it is reasonable to posit that the way in which news is communicated moderates the relationship between political sophistication and emotion. News formats low on sensory and emotional stimuli

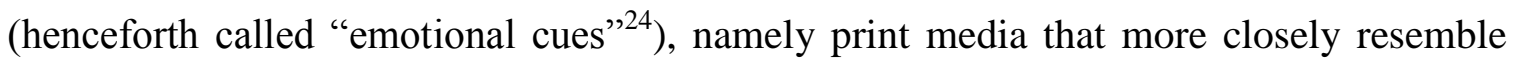
hard news, require greater cognitive effort and sophistication to engage with as they less closely resemble how the brain naturally functions (Grabe and Bucy 2009; Graber 2001, 2004). Contexts with more emotional cues are less cognitively demanding to understand and process. Thus, the ability to appraise information should be greater when more emotional cues are present in media. Consumers should be more likely to react emotionally to television news, for example, than to print news because of the presence of stimuli from audio and additional visual modalities (e.g. voices and their tone, sounds, music, etc.). Emotional responsiveness should also be greater to news presented with an emotional frame than to news that is neutral and lacking in a clear emotional angle.

\footnotetext{
${ }^{24}$ Brader (2006) also uses the term "emotional cues" to refer to stimuli that might trigger emotional responses. His study dealt with campaign advertising, specifically how audio and visual stimuli such as pictures, movement, music, sound, and voice elicit emotion among voters. I borrow the term from him.
} 


\section{Learning Effects}

Though media qualities may shape emotional appraisals, the product of the psyche's interacting with the information environment is learning (Graber 2001, 2004). Emotions affect learning as they motivate individuals to direct attention toward or away from stimuli that are relevant to the core relational themes of each particular emotion (Bower 1981; Leichtman, Cecci and Ornstein 1992; Nabi 1999, 2003). However, all emotions do not affect learning similarly. Fear focuses attention on threatening stimuli (e.g. Eysenck 1992; LeDoux 1996; MacLeod and Matthews 1988; Marcus and MacKuen 1993; Marcus et al. 2000). Fear deals with uncertainty, so humans are motivated to learn new information about threats to reduce that uncertainty. Fear induces greater central processing that makes the encoding of information into long-term memory easier (McGaugh and Cahill 2003).

Learning evidence is less clear with other emotions, notably anger. Dimensional perspectives posit that negative emotions universally heighten attention toward negative stimuli (e.g. Gray 1987; Watson et al. 1999), but other scholars have shown that anger affects action more than attention (Berenbaum, Fujita, and Pfenning 1995). Indeed, Valentino et al. (2008) find that anger actually depresses attention and learning. They posit that anger results from the certainty that an object violates values or norms, and that certainty does not require learning. Rather, it begs action over attention (Berkowitz 2003). Huddy et al. (2007) find a positive attention effect for anger, but further argue that anger produces biased learning processes rather than "objective" evaluation of incoming information about the aggravating object in question. 
Positive emotions do affect learning, but these effects are also inconsistent. Isbell et al. (2006) argue that happiness depresses systematic processing, thereby discouraging learning. However, enthusiasm, a dimension of emotion in the affective intelligence approach, encourages learning by eliciting information seeking behaviors (Marcus et al. 2000; Brader 2006). Moreover, beyond the distinction between positive and negative emotion, emotionality in general promotes greater cognitive engagement and learning (Civettini and Redlawsk 2009; Heuer and Reisberg 1992). Thus, particular emotions aside, the main point of the extant literature is that emotions motivate the direction of attention in ways that either inhibit or promote encoding of new information.

Emotion, then, plays a key role in learning. Therefore, if political sophistication and media context affect the experience of emotion, then the interaction of these three factors should ultimately shape how citizens learn from the media they consume. That is, media context and sophistication should together moderate the effect of emotion on learning. If media contexts with more emotional cues are easier to engage with and process, thereby eliciting greater emotionality, then learning should be greater in contexts where more cues are provided. Thus, news in video format should yield greater learning than the same news in print because of its usage of more audio and visual modalities. Likewise, news presented with a clear emotional frame should be easier for consumers to learn from than news that is more balanced and objective (consistent with Civettini and Redlawsk 2009, Heuer and Resiberg 1992).

However, regardless of the news format, I posit that sophistication moderates the effect of emotion on learning. Emotions affect learning because they motivate humans to alter how attentive they are to particular objects. Some emotions encourage greater 
attention to certain attitude objects with learning as a goal, but other emotions reduce the motivation to learn because those emotions are more action oriented. Given that high sophisticates are more interested in politics and more capable of engaging with political stimuli, they should be more susceptible to any learning biases of emotion. If an emotion encourages learning, then that effect should be most pronounced among the naturally more motivated high sophisticates who feel it. Likewise, if an emotion depresses learning, then learning should be lowest for high sophisticates who feel that emotion than for low sophisticates who also experience it.

\section{Hypotheses}

H1: Media formats with more emotional cues will elicit more emotion.

Thus, news in video format will elicit more emotion than news in print. News with an emotional tone will elicit more emotion than news framed in a balanced manner.

H2: Sophistication will positively affect emotional responsiveness regardless of media format.

Consistent with my prior theory and results, I expect that high sophisticates should be more likely to report emotional appraisals than low sophisticates regardless of the qualities that characterize the media participants consume. Thus, high sophisticates should always be more emotional even if contexts with more cueing are more effective at eliciting emotion across the sophistication spectrum than those with less cueing. 
H3: Media formats with more emotional cues will stimulate more learning than those with fewer such cues.

Thus, news in video will elicit more learning than news in print. News presented with an emotional tone will elicit more learning than news in a more balanced manner.

H4: Learning effects will be more pronounced among high sophisticates than among low sophisticates who experience the same emotion.

Sophistication and emotion will interact to affect learning. Thus, learning biases will be more evident among emotional high sophisticates. In this chapter I deal specifically with anger and sympathy. Specifically, I posit that angry high sophisticates should learn less from the media than angry low sophisticates as anger is an emotion that tends to depress learning. However, sympathetic high sophisticates should learn more than sympathetic low sophisticates as sympathy encourages engagement.

\section{Method}

Participants. Participants were 828 undergraduates enrolled in introductory political science classes at the University of North Carolina at Chapel Hill in spring of 2009. Students participated to fulfill a research requirement. They ranged from 18 to 30 years old $(M=19.982, S D=1.598$; see Appendix F for question wording and scaling), with a plurality being freshmen $(M=2.239, S D=1.057)$. Most students were female (62\%) and white (78\%; 10\% black, $4 \%$ Hispanic, $3 \%$ Asian), demographics that resemble the broader UNC population. The sample leaned Democratic $(M=3.391, S D=2.039$, and slightly liberal $(M=3.838, S D=2.058)$. 
Experimental Design. This experiment was a 2 X 3 design in which news format (print or video) and emotional tone (neutral, anger, sympathy) were manipulated. Thus, all stories in a particular condition were either read or watched (no combination thereof) and exuded a clear emotional frame. A seventh condition was a control with no stimulus. The seven conditions are hereafter referred to as: control, neutral print, neutral video, anger print, anger video, sympathy print, and sympathy video. Each treatment condition, except the control, contained three stories about illegal immigration. Participants in each condition either read or watched all three stories and completed the experiment in one sitting with no measures repeated over time, making this a between-subjects design as the critical comparisons are between subjects in different conditions rather than change within individual participants as a result of the stimuli.

Randomization. Students were randomly assigned to conditions using a random number generator. Before conducting any analyses, it was necessary to check that the randomization process worked in that participants did not vary significantly by condition on political sophistication, the key individual level variable in this study. As the final sophistication variable is a factor score with an artificial mean of 0 , difference of means tests are conducted on the three indicators of that variable: attention, interest, and a knowledge scale. These tests show no significant differences on any of the three indicators by condition [attention: ANOVA, $F(6,821)=.89, p<1$; Kruskal-Wallis, $\chi^{2}$ $(6)=4.542, p<1$; interest: $F(6,821)=.74, p<1 ; \chi^{2}(6)=3.333, p<1$; knowledge: $F(6$, $\left.821)=1.15, p<1 ; \chi^{2}(6)=7.029, p<1\right]$. Scheffe tests corroborate these results $(p<1$ for all pairwise comparisons of condition means on all three sophistication components). 
Procedure. The experiment was conducted using a web based survey program. Participants received individualized email invitations to access the study, and were allowed to take the experiment from locations of their choice as a lab setting might have exacerbated the already artificially high attention to stimuli that experiments introduce. Students in all seven conditions were administered the pre-test and the post-test, though the control post-test did not measure learning. Participants in the video conditions viewed the videos in random order through the survey program. The videos were hosted on my personal webspace so that the user comments, ads, and editorialized headlines common on YouTube videos were not visible to participants. Those in print conditions saw the print stories in random order. Latency timers were placed on the webpages containing stories so that those participants who did not watch or read the treatments could be dropped from final analyses $(\mathrm{N}=38)$. Final condition cell sizes ranged from 114 to 124 .

Stimuli. All stories were authentic local television news reports from various American media markets. Real television stories were preferred for greater construct validity of the reports in the video conditions. The stories were found on YouTube searching for "illegal immigration" stories, downloaded, and then edited to remove commercials and unrelated lead-ins.

Multiple stories to represent each tone were used to eliminate the confound of testing the design using just one story. Thus, unique story elements such as reporter race or sex, the specific aspect of illegal immigration at issue, or the location of the story ideally wash out as these elements vary within and between conditions, leaving the overarching emotional tone of the stories in each condition as the unifying element of the three that most stands out to participants. The stories in the neutral news condition all 
presented a mixture of positive and negative information about different aspects of illegal immigration, and lacked a clear emotional tone (see Appendices $\mathrm{G}-\mathrm{O}$ for the print versions of the nine stories). ${ }^{25}$ Anger stories depicted illegal immigrants engaging in activities that violate legal or social norms, actions that should elicit anger responses as that emotion deals with repudiation of norm violations (Haidt 2003). Sympathy stories portrayed illegal immigrants as suffering from hardships and wrongs, situations that should elicit sympathy as that emotion is a response to the suffering of others (Haidt 2003). Having two emotions allows generalization of the study beyond the context of one emotion, but anger and sympathy in particular were selected due to the ease of obtaining stories with those emotional slants.

Though I selected the television stories based on my perception of their emotional tones, I did rely on the judgments of three colleagues to help validate my groupings. All agreed that the three neutral stories presented a balance positive and negative information and lacked overt emotional frames. Likewise, all agreed that the three anger and three sympathy conditions carried their perceived emotional slants. The intensity of those emotional frames, however, also factored into my selection criteria. I selected neutral stories that were as cool and detached from the subject material as possible, whereas I selected anger and sympathy treatments that overtly featured moving visuals, editorial comments by reporters and anchors, and detectable emotional tones in the voices of the

\footnotetext{
${ }^{25}$ Neutral stories dealt with immigrant population growth, an ICE raid on a factory, and the costs of treating illegal immigrants in hospitals. Anger stories covered two illegal immigrants who murdered a teenage girl, illegal immigrants stealing Social Security numbers to commit fraud, and destruction of desert habitats that immigrants cause when infiltrating the US. Sympathy stories depicted the hardships of a girl whose mother was taken by ICE, the poverty of illegal immigrants, and the murder of an illegal immigrant in a hate crime. I have posted the videos on my YouTube channel (http://www.youtube.com/user/unc1693). YouTube management deleted the sympathy video about the murdered illegal immigrant from my channel homepage because its Associated Press copyright put me in violation of the YouTube user agreement. The original version is no longer available on the AP channel. The other eight videos are still viewable on my page.
} 
speakers. None of the three colleagues consulted labeled any of the stories in a condition as being noticeably more or less neutral or emotionally slanted than the others. Thus, though I relied on the expert judgment of compatriots to validate my groupings, there was an attempt to check my choice of treatment stories.

For the three print conditions, the video stories were transcribed verbatim, though verbal fillers and reporter sign offs were removed. The scripts were modified to resemble newspaper stories. Bylines and datelines were added with the same names and locations from the video versions. Quote attributions (e.g. "he said," "she said," etc.) were also added. No headlines were given to the print stories. Thus, the print condition conveys the same information spoken in the video conditions, but with modifications to make the stories resemble newspaper articles.

\section{Measures}

Experimental Variables. Two variables indicate the nature of emotional cues in the seven conditions. One variable represents presentation format $(1=$ control, $2=$ print, $3=$ video $)$. Another variable signifies emotional slant $(1=$ control, $2=$ neutral, $3=$ anger or sympathy). I combine the anger and sympathy conditions into the same value on this last variable because I have no theoretical interest in either the effect of anger in the sympathy conditions or the effect of sympathy in the anger conditions. Thus, I separate the anger and sympathy conditions in my analyses except when calculating difference of means tests. For example, when I model anger appraisals in Table X, only the five conditions representing the control, the two neutral conditions, and the two anger conditions are included in that analysis. 
Emotion. The post-test measured intensity of emotional reactions. Respondents were asked, "Does the illegal immigration situation make you feel (emotion)? If so, how (emotion) do you feel?" Responses ranged from 0 (no) to 4 (extremely). The post-test measured ten emotions: angry at illegal immigrants, angry at employers who hire illegal immigrants, sympathy toward illegal immigrants, guilt that the government has not done more to help illegal immigrants, afraid, proud, hopeful, disgusted at illegal immigrants, and disgusted at employers, and contempt toward illegal immigrants.

Learning. Treatment condition post-tests included nine items about information in the treatment stories. These included four fill-in-the-blank questions to measure cued recall and five multiple-choice items to tap recognition memory (Padilla-Walker and Poole 2002). Open-ended items were scored for correctness, then all nine items were combined into an additive learning scale $(0-9 ; \alpha$ calculated by condition and ranged from .716 to .865$)$.

Sophistication. Political sophistication is a factor score derived from principal component analysis $(M=0, S D=1)$. Three indicators of sophistication are used: attention to politics $(M=3.141, S D=.723)$, interest in politics $(M=2.356, S D=.614)$, and a political knowledge scale $(M=2.911, S D=1.487 ; \alpha=.821)$. Only one eigenvalue exceeds 1 (2.095), and all three indicators load strongly onto it (attention, .889; interest, .878 ; knowledge, .753). See Appendix F for question wordings.

Controls. Several controls were included in emotional reaction and learning models. These included ideology and partisanship (both measured as the traditional 7point NES scale), economic class, academic year as a proxy for the little age and education variance in the sample, and dummies for female and white (see Appendix F). 
Random assignment ensures that any systematic group differences on items that are not dependent variables are due to chance, but it is still necessary to control for these demographic and political characteristics if they can influence the dependent variables.

Manipulation Check. Difference of means tests were run on ordinal emotion items from the post-test. Emotions tested included anger (at illegal aliens, at employers who hire illegal immigrants), disgust (at illegal immigrants, at employers) sympathy (for illegal immigrants), fear (of illegal immigration), pride, guilt, and hope. Scheffe tests showed that the six treatment conditions significantly prompted several positive and negative emotions when compared to the control $(p<.05$ for all pairwise comparisons of the treatment conditions to the control for pride, disgust at illegal immigrants, and anger at employers who hire illegal immigrants; $p<1$ for all comparisons of treatment condition dyads for the same three emotions). As the control provided no stimulus, it is reasonable that a treatment of any kind might elicit a general emotional response about immigration, but not one that varies between the treatment conditions themselves if those particular emotions are not manipulated. Table 4.1 shows the means and standard deviations of the ten measured emotions by condition.

The conditions with anger and sympathy frames were effective at eliciting higher levels of only the intended emotions when compared to their respective neutral conditions. In the anger print condition, anger at illegal immigrants is the only emotion whose mean differs from the neutral print $(p<.001)$ condition, while the same is true when comparing the anger video to the neutral video condition $(p<.001)$. Likewise, sympathy for illegal immigrants is the only emotion with a significantly larger mean when comparing the sympathy print to the neutral print condition $(p<.001)$ and the 
Table 4.1: Means and Standard Deviations of Emotions by Condition

\begin{tabular}{|c|c|c|c|c|c|c|c|}
\hline & Control & $\begin{array}{c}\text { Neutral } \\
\text { Print }\end{array}$ & $\begin{array}{c}\text { Neutral } \\
\text { Video }\end{array}$ & $\begin{array}{c}\text { Anger } \\
\text { Print }\end{array}$ & $\begin{array}{l}\text { Anger } \\
\text { Video }\end{array}$ & $\begin{array}{c}\text { Sympathy } \\
\text { Print }\end{array}$ & $\begin{array}{c}\text { Sympathy } \\
\text { Video }\end{array}$ \\
\hline Anger at Illegal & 1.603 & 1.833 & 2.918 & 3.001 & 4.135 & .907 & 1.815 \\
\hline Aliens & $(.619)$ & $(.711)$ & (1.403) & (1.497) & $(1.843)$ & $(.422)$ & $(.615)$ \\
\hline Anger at & 1.189 & 1.716 & 1.600 & 1.718 & 1.675 & 1.585 & 1.596 \\
\hline Employers & $(.545)$ & $(.708)$ & $(.683)$ & $(.586)$ & $(.617)$ & $(.894)$ & $(.702)$ \\
\hline Disgust at Illegal & 1.509 & 2.088 & 2.075 & 2.266 & 2.233 & 2.004 & 2.119 \\
\hline Aliens & $(.863)$ & $(1.001)$ & $(.983)$ & $(1.141)$ & $(1.142)$ & $(1.016)$ & $(1.027)$ \\
\hline Disgust at & 2.162 & 2.226 & 2.280 & 2.259 & 2.282 & 2.108 & 2.248 \\
\hline Employers & $(1.098)$ & (1.099) & $(.988)$ & (1.107) & $(1.115)$ & $(1.059)$ & $(1.024)$ \\
\hline Fear of Illegal & 1.821 & 1.859 & 1.787 & 1.935 & 2.079 & 1.912 & 1.855 \\
\hline Immigration & $(.877)$ & $(.939)$ & $(.903)$ & $(.967)$ & $(.969)$ & $(.922)$ & $(.949)$ \\
\hline Hope & 1.778 & 1.859 & 1.787 & 1.815 & 1.758 & 1.950 & 1.752 \\
\hline & $(.799)$ & $(.840)$ & $(.784)$ & $(.878)$ & $(.663)$ & $(.787)$ & $(.729)$ \\
\hline Guilt & .553 & .619 & .615 & .581 & .539 & .683 & .532 \\
\hline & $(.178)$ & $(.223)$ & (.109) & $(.134)$ & $(.121)$ & $(.175)$ & $(.228)$ \\
\hline Pride & 1.019 & 1.518 & 1.418 & 1.492 & 1.544 & 1.600 & 1.559 \\
\hline & $(.573)$ & $(.707)$ & $(.666)$ & $(.738)$ & $(.777)$ & $(.824)$ & $(.636)$ \\
\hline Sympathy for & .813 & 1.117 & 2.233 & .509 & .816 & 1.975 & 3.428 \\
\hline Illegal Aliens & $(.372)$ & $(.473)$ & (1.069) & $(.228)$ & $(.301)$ & $(.519)$ & $(1.655)$ \\
\hline
\end{tabular}

Note. Entries include emotion means with standard deviations in parentheses 
sympathy video to the neutral video condition $(p<.001)$. These results show that the stimuli effectively elicited the intended emotions.

\section{Results}

\section{Eliciting Emotions toward Illegal Immigration}

H1 posits that media formats with more emotional cues, those that use more audiovisual modalities or clear emotional frames, will elicit greater emotion. I used one-way ANOVA and Kruskal-Wallis tests to evaluate the between-subjects relationship between emotion and experiment condition. The independent variable was a 7-point nominal item indicating the assigned experimental condition of the respondent. The two dependent variables, tested in separate analyses, are the 5-point strength of anger and sympathy toward illegal immigrants measures. Figure 4.1 shows the emotion means by condition. Main effects observed in difference of means tests for anger $[F(6,821)=18.1, p<.001$;

$\left.\chi^{2}(6)=63.723, p<.01\right]$ and sympathy $\left[F(6,821)=21.42, p<.001 ; \chi^{2}(6)=63.889, p<\right.$ $.001]$ show significant differences in reported emotion levels between conditions. The $\eta^{2}$ for anger and sympathy are .119 and .128 respectively, indicating a moderate relationship between the experimental conditions and respondent emotions as the manipulations account for a little over $10 \%$ of the overall variance in both dependent variables.

Scheffe tests were conducted to evaluate pairwise differences among the condition means. Scheffe tests provide very conservative difference tests between all possible condition dyads, reducing the possibility of Type-I error substantially compared 
to other post-hoc tests (Cohen et al. 2003). Let us first examine how the treatment conditions compare to the control. Neutral print means are slightly larger but statistically indistinguishable from the control (anger, $p<1$; sympathy, $p<1$ ). However, means for anger in the anger print condition $(p<.01)$ and sympathy in sympathy print $(p<.001)$ are significantly higher. Thus, neutral information in print is insufficient to stimulate greater emotion overall, but print paired with a clear emotional frame is more effective at eliciting a targeted emotion.

Figure 4.1: Emotion Means by Condition

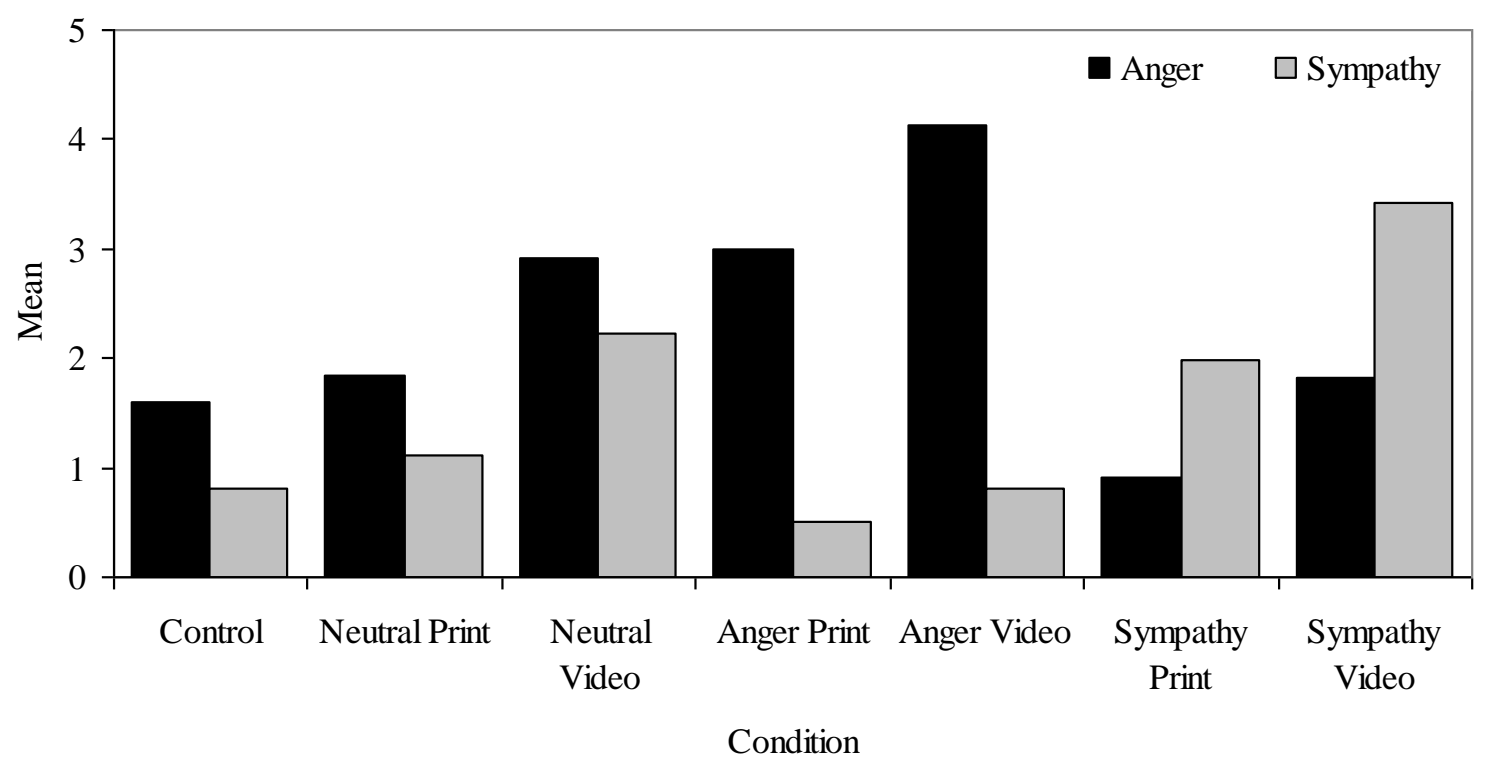

The neutral video condition elicits more of both anger $(p<.05)$ and sympathy $(p$ $<.001)$ than the control. The anger video effectively prompts only anger $(p<.001)$. The sympathy video condition only elicits sympathy $(p<.001)$. The presence of additional audiovisual cues, then, even paired with balanced information in the news content, 
stimulates multiple emotional appraisals. A video format is even more stimulating, however, when the information it conveys has a clear emotional slant.

When the control is no longer the baseline for comparison, significant betweengroup differences result from the presence of emotional cues in media stimuli. Compared to the neutral print condition, the neutral video stimulus elicits more anger $(p<.05)$ and sympathy $(p<.05)$. The anger video condition induces greater anger than the anger print condition $(p<.05)$, as does the sympathy video condition with sympathy when compared to the print $(p<.01)$. These results show a significant causal effect of audiovisual cues, but similar effects exist for emotional tone. Anger is greater in the anger print condition than the neutral print $(p<.001)$, and for anger video when compared to neutral video $(p<$ .001). The sympathy print condition elicits greater sympathy than the neutral print $(p<$ $.05)$, as does the sympathy video when compared to the neutral video $(p<.001)$.

These results support H1. Every condition except neutral print is more effective at eliciting the targeted emotions, demonstrating that news presentation format and the emotional tone of news content significantly shape emotional appraisals. Video formats are more emotionally provocative than print, and emotional frames consistently elicit greater emotion than neutral news. The greatest effect on emotion, however, occurs when the two types of emotional cues are paired, as the largest means are observed in the anger video and sympathy video conditions. These results show that information context plays an important causal role in shaping the emotional appraisals of news consumers.

Information context shapes emotional appraisals, but it is critical for my research to understand how sophistication interacts with that process. $\mathrm{H} 2$ posits that sophistication positively affects emotionality across conditions. Thus, the effect of sophistication in 
different conditions (sophistication $\mathrm{X}$ emotion condition $\mathrm{X}$ media condition) must be examined. Table 4.2 shows logistic regression results for dummy variables indicating the experience of anger and sympathy toward illegal immigrants. ${ }^{26}$ Significant conditional effects of sophistication and both condition dummies are evident when the other constituent terms are centered at their means. Interactions aside, high sophisticates are more likely to experience both anger and sympathy toward illegal immigrants than low sophisticates. However, consistent with $\mathrm{H} 1$, the data also indicate a role for news format. Exposure to video news rather than print or news with a clear emotional slant rather than a balanced tone makes emotional appraisals more likely. The two-way interactions are weaker with the only significant relationship being the moderating effect of sophistication on new format for anger appraisals.

The key result in Table 4.2, however, is the significant triple interaction of sophistication and the two experimental conditions. Thus, sophistication affects emotional appraisals, but its effect varies by condition. Figure 4.2 plots the predicted probabilities of feeling anger. The solid unmarked line in each box is the effect of sophistication in the control group. Different boxes compare the sophistication effect by media format or tone. Figure 4.3 shows the plots for sympathy appraisals. The pattern of results for both emotions is similar, so I limit my discussion to the anger plots.

Figure 4.2 shows that across all five conditions the sophistication plots slope significantly upward, supporting $\mathrm{H} 2$ that sophistication is positively related to emotional

\footnotetext{
${ }^{26}$ Results are similar when the dependent variable is ordinal emotion intensity, so the findings are robust to changes in the dependent variable form. The dummy is analyzed for ease of presentation. Emotion frequency vary by condition (control: $34.5 \%$ angry, $17.9 \%$ sympathetic; balanced print: $38.7 \%$ angry, 24.6\% sympathetic; balanced video: $61 \%$ angry, $48.4 \%$ sympathetic; anger print: $66.9 \%$ angry; anger video: $87.7 \%$ angry; sympathy print: $45.8 \%$ sympathetic; sympathy video: $81.8 \%$ sympathetic).
} 
Table 4.2: Immigration Emotions with Sophistication and Media Interactions

\begin{tabular}{|c|c|c|}
\hline & Anger & Sympathy \\
\hline Sophistication & $\begin{array}{c}.798 * * * \\
(.115)\end{array}$ & $\begin{array}{c}.705 * * * \\
(.111)\end{array}$ \\
\hline Emotion Condition & $\begin{array}{c}1.244 * * * \\
(.221)\end{array}$ & $\begin{array}{c}.912 * * * \\
(.211)\end{array}$ \\
\hline Media Condition & $\begin{array}{l}.533 * * \\
(.185)\end{array}$ & $\begin{array}{c}.801 * * * \\
(.158)\end{array}$ \\
\hline Sophistication X Emotion Condition & $\begin{array}{l}.428^{*} \\
(.172)\end{array}$ & $\begin{array}{c}.046 \\
(.223)\end{array}$ \\
\hline Sophistication X Media Condition & $\begin{array}{l}.529 * \\
(.213)\end{array}$ & $\begin{array}{l}.094 \\
(.172)\end{array}$ \\
\hline Emotion Condition X Media Condition & $\begin{array}{c}.501 \\
(.434)\end{array}$ & $\begin{array}{c}.247 \\
(.339)\end{array}$ \\
\hline Sophistication X Emotion Condition X Media Condition & $\begin{array}{l}.983^{*} \\
(.446)\end{array}$ & $\begin{array}{l}.823^{*} \\
(.373)\end{array}$ \\
\hline Ideology & $\begin{array}{c}.275^{* * * *} \\
(.074)\end{array}$ & $\begin{array}{l}-.043 \\
(.109)\end{array}$ \\
\hline Partisanship & $\begin{array}{c}.069 \\
(.074)\end{array}$ & $\begin{array}{c}-.398 * * * \\
(.107)\end{array}$ \\
\hline Economic Class & $\begin{array}{l}.226+ \\
(.131)\end{array}$ & $\begin{array}{c}-.441+ \\
(.254)\end{array}$ \\
\hline Female & $\begin{array}{c}.299 \\
(.246)\end{array}$ & $\begin{array}{l}.802 * \\
(.382)\end{array}$ \\
\hline White & $\begin{array}{l}.506^{*} \\
(.225)\end{array}$ & $\begin{array}{l}.562 * * \\
(.218)\end{array}$ \\
\hline Academic Year & $\begin{array}{l}-.279^{*} \\
(.113)\end{array}$ & $\begin{array}{l}.197 \\
(.189)\end{array}$ \\
\hline Constant & $\begin{array}{l}-.149 \\
(.535)\end{array}$ & $\begin{array}{c}-.629 * * * \\
(.105)\end{array}$ \\
\hline LR & $144.04 * * *$ & $128.87 * * *$ \\
\hline Pseudo- $\mathrm{R}^{2}$ & .177 & .165 \\
\hline $\mathrm{F}(13,560 / 559)$ & $2.438 * *$ & $2.051 *$ \\
\hline $\mathrm{N}$ & 591 & 590 \\
\hline
\end{tabular}

Note. Entries are unstandardized logistic regression coefficients; dependent variable is a dummy indicating that participant feels the emotion in question $(0=$ no emotion, 1 $=$ anger or sympathy toward illegal immigrants); interaction constituent terms were centered before making interaction terms; $F$ indicates improvement in fit over the model with no interactions; $+\mathrm{p}<.1,{ }^{*} \mathrm{p}<.05, * * \mathrm{p}<.01, * * * \mathrm{p}<.001$ 
Figure 4.2: Anger Predicted Probabilities, Sophistication Effect by Condition

$\mathrm{X}$-Axis $=$ Sophistication, Y-Axis $=$ Predicted Probability of Reporting Anger toward Illegal Immigrants

- Control $\quad \longrightarrow$ Neutral Print $\cdots \cdots$ Neutral Video $\quad \longrightarrow$ Anger Print $\quad \cdots \cdots$ Anger Video

A. Neutral Tone Conditions

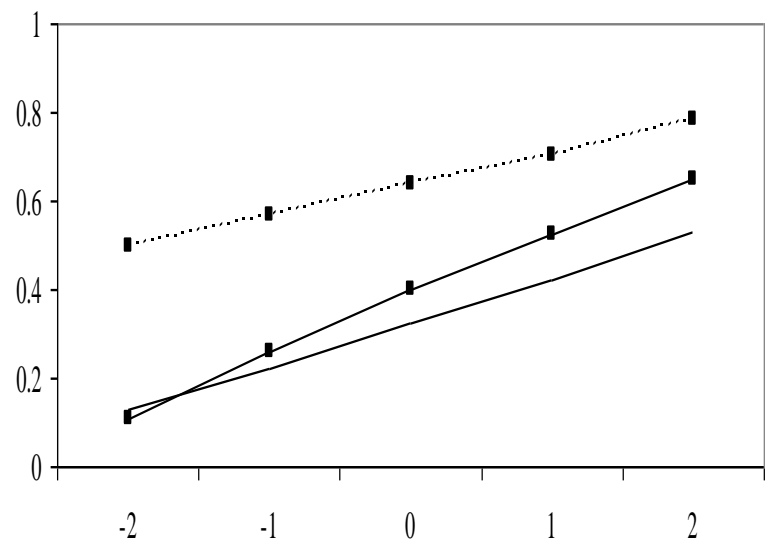

C. Print Conditions

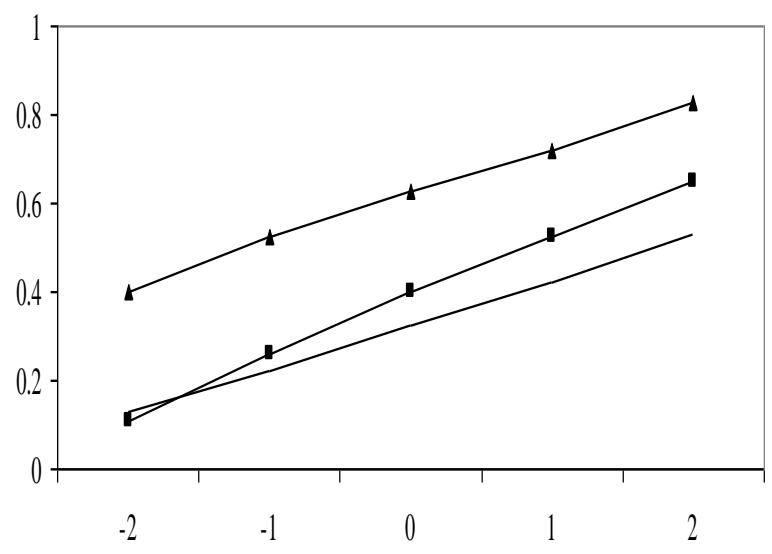

B. Anger Tone Conditions

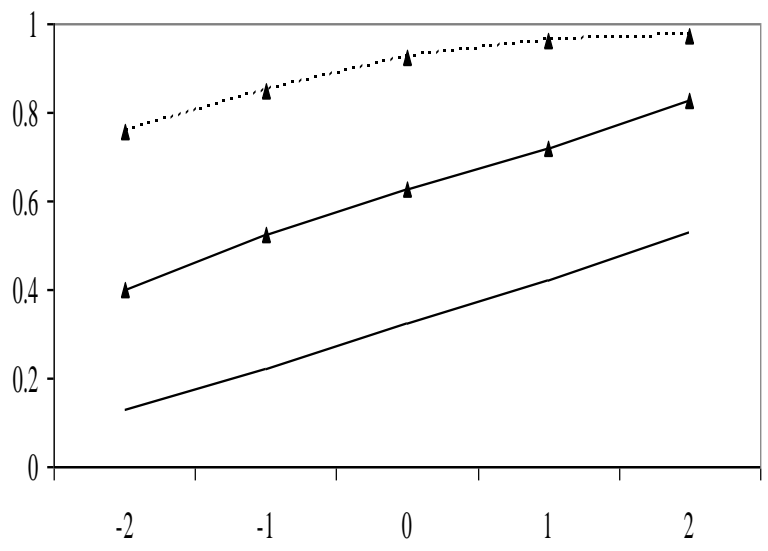

D. Video Conditions

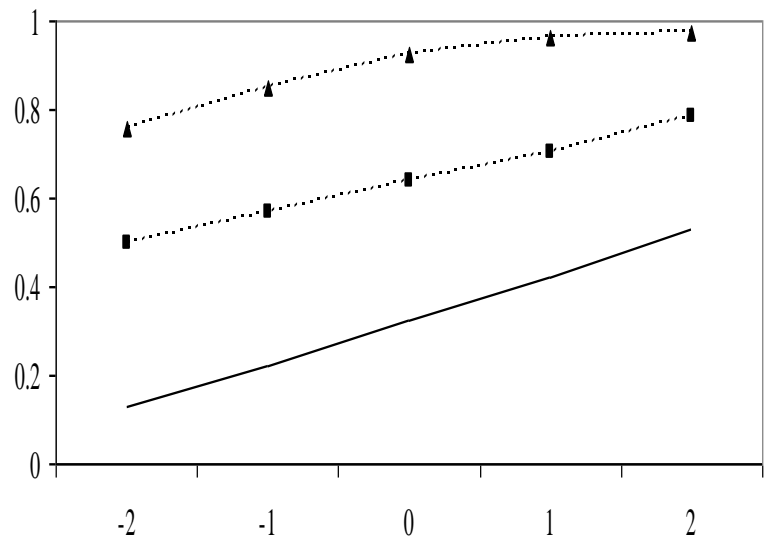


Figure 4.3: Sympathy Predicted Probabilities, Sophistication Effect by Condition

X-Axis $=$ Sophistication, Y-Axis $=$ Predicted Probability of Reporting Sympathy toward Illegal Immigrants

$\longrightarrow$ Control $\longrightarrow$ Neutral Print $\quad \cdots \cdots$ Neutral Video $\quad \longrightarrow$ Sympathy Print $\cdots \cdots$ Sympathy Video
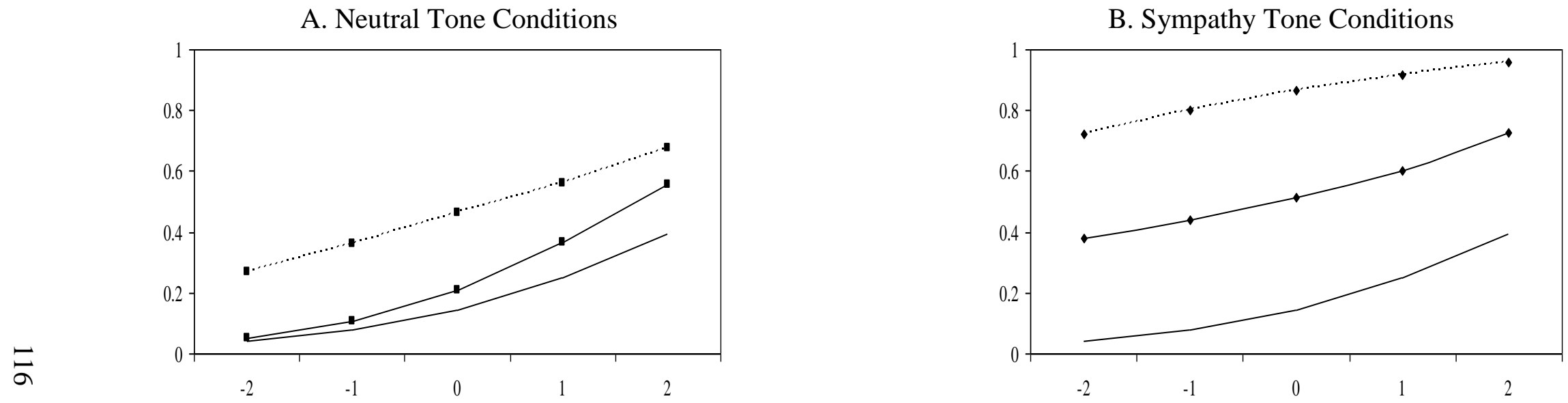

C. Print Conditions

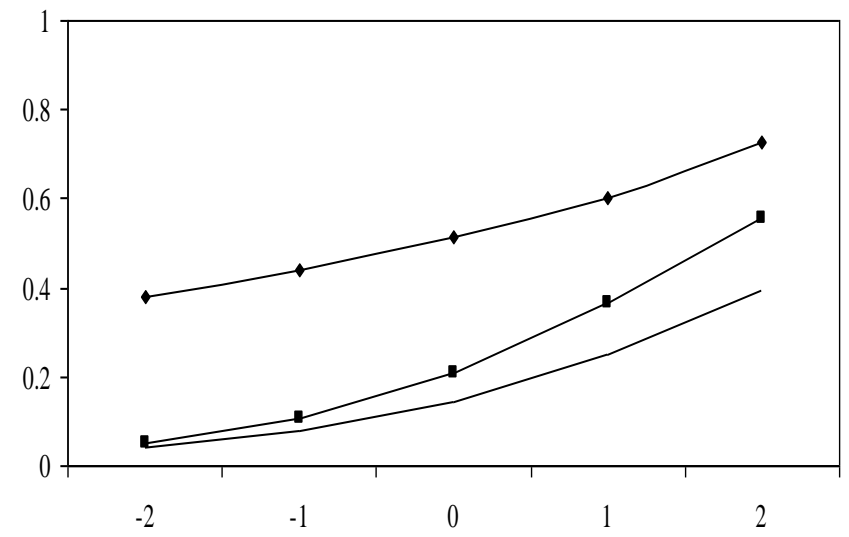

D. Video Conditions

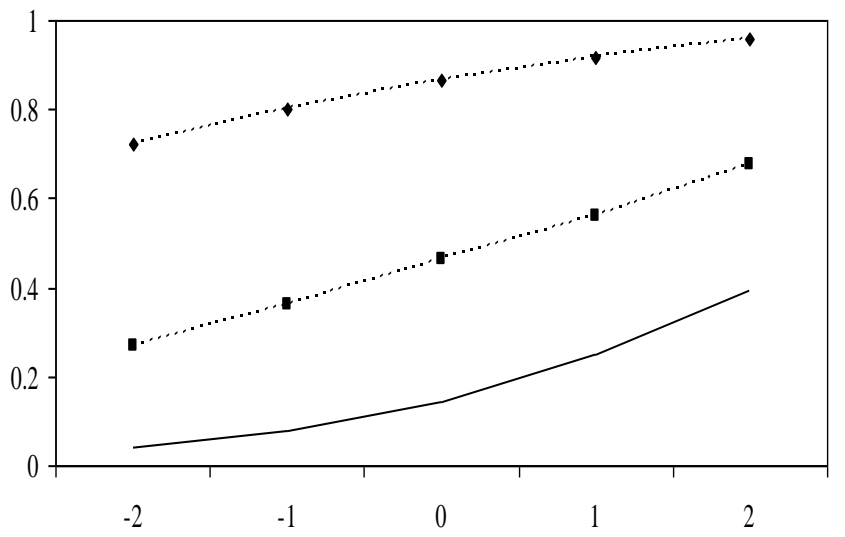


appraisals. Regardless of information context, high sophisticates are indeed more likely than low sophisticates to experience anger (and sympathy) toward illegal immigrants. In the control group, the lowest sophisticates at $-2 S D$ only have a $13 \%$ chance of reporting anger, whereas the highest sophisticates at $+2 S D$ have a $52.8 \%$ chance, a difference of 39.8 percentage points. In the absence of stimuli, this is a powerful sophistication effect.

Comparing treatment conditions in Figure 4.2, however, shows that media format can substantially moderate the effect of sophistication on emotion, shifting the location of the entire probability plot and its steepness. Panel A contrasts neutral video and print formats within the control. Compared to the control, the neutral print condition is generally ineffective at eliciting greater anger, though the 95\% confidence intervals (not shown) for the points at $+2 S D$ on sophistication in these conditions do not overlap. Thus, only the highest sophisticates respond with greater anger to information in the neutral print context, leaving lesser sophisticates incapable of engaging emotionally with the stimulus. Every point on the neutral video plot, however, differs from its respective point on the neutral print and control plots, indicating emotional responsiveness across the sophistication spectrum is greater in this condition.

A similar video format effect is seen in panel B where the two anger conditions are plotted. Again, every point on the anger video plot differs significantly from where similar sophisticates on the anger print and control plots are located. These results recall H1 that video formats elicit more emotion than print, an effect that is evident at every level of sophistication. The highest and the lowest sophisticates are better able to engage with news material presented in a video format and process it in a manner that facilitates 
anger appraisals. This universal effect of video does not necessarily replicate in print, however, at least when print news is presented in a neutral tone.

Panels $\mathrm{C}$ and $\mathrm{D}$ further support $\mathrm{H} 1$ as news with an emotional tone elicits greater emotion than either neutral news or the control. Again, this effect occurs across the sophistication spectrum. The entire anger print plot in panel C differs significantly from the neutral print and control. Whereas all but the most sophisticated participants were emotionally unresponsive to the neutral print prompt, the anger print condition elicits more anger at all sophistication levels. Print news, then, can be emotionally provocative, but only when that format has a clear emotional slant.

Likewise, every point on the anger video plot differs significantly from the neutral video and control plots. The power of emotional cues to elicit feelings is most evident in the anger video condition where the two types of cues - audiovisual and tone - are paired. Low sophisticates at $-2 S D$ on the sophistication factor score have a $75.6 \%$ chance of reporting anger as compared to $97.2 \%$ for participants at $+2 S D$, dramatic movement when compared to the control and other conditions with fewer cues.

Thus, $\mathrm{H} 1$ and $\mathrm{H} 2$ receive substantial support in this analysis. Media formats that employ more emotional cues are more effective at eliciting emotion among participants across the sophistication spectrum, as evidenced in both the difference of means tests and the anger plots where entire probability curves shift significantly upward when additional cueing is added to the media treatments. The sole exception is neutral news in print, a format whose limited cueing fails to emotionally engage all but the most sophisticated respondents as compared to no stimulus at all. This result hints that print media do little to engage citizens of even average sophistication, let alone low sophisticates. 
Sophistication, however positively affects the likelihood of emotional appraisals across conditions regardless of what cues are present. Absent any stimulus, high sophisticates are more emotional about immigration than low sophisticates, but that remains true in a low cue environment such as neutral print news and a high cue context that pairs video news with a clear emotional slant. However, the difference in likelihood of appraisal between the highest and lowest sophisticates does shrink as media employ more cues. The steepest slopes are observed in the control and neutral print conditions, but the shallowest is seen in the anger video condition. It appears that additional cueing enables the appraisals of low sophisticates more than those of high sophisticates.

This finding is intriguing only because it stands in contrast to the pattern observed in campaign advertising in Chapter 3 where low sophisticates were virtually unresponsive to large increases in advertising GRP. This could indicate a ceiling effect among high sophisticates. Perhaps they are already so capable of making appraisals that additional cues do little to aid them, but that would not explain the unresponsiveness of low sophisticates to campaign ads. Of course, it may simply be that campaign ads and news are so fundamentally different conceptualization of context that we should not reasonably expect to find the same emotional and behavioral patterns in both.

This pattern among low sophisticates might also result from the intensity of emotion in the stories or the extended length of exposure in viewing three news reports back-to-back. Neither of these, two aspects of information context are captured in the GRP measures that just reflect number of (typically) 30-second exposures. A third explanation might be that this comparatively greater responsiveness is an artifact of the experimental method. To complete the experiment, participants must force themselves to 
go through each webpage and at least satisfice their way through the survey, but even that minimum attention might amount to more attention than is normally devoted to advertising over the course of a campaign. The forced, artificial experiment might reveal what is actually a genuine response pattern, but it may not replicate to the real world because attention to stimuli such as campaign ads is not as fake and intentional. Uncovering the precise explanation for this result is beyond my scope in this experiment.

\section{Learning Effects}

Emotion also affects learning in ways that may be moderated by contextual and psychological factors. H3 posits that media formats with more emotional cues will stimulate greater learning. Video formats and media with clear emotional frames, then, should be more conducive to learning than print or news that is neutral in tone. To test H3 I first conducted one-way ANOVA and Kruskal-Wallis tests to evaluate the betweensubjects relationship for learning and experimental condition. I drop the control from analyses here as no stimulus was provided in that condition, so there was no information for participants to process and retain. The independent variable is a 7-point nominal item indicating experimental condition. The dependent variable is the 9-point learning scale.

Figure 4.4 shows the mean of the learning scale by condition. The difference of means tests indicate a significant main effect of condition on learning $[F(5,705)=28.92$, $\left.p<.001 ; \chi^{2}(5)=62.221, p<.001\right]$. The $\eta^{2}$ for learning is .167 , so the experimental treatment accounts for roughly $17 \%$ of the total variance in learning. Scheffe tests show significant differences within the three emotion groupings as the neutral $(p<.001)$, anger $(p<.05)$, and sympathy $(p<.001)$ video conditions all induce more learning than their 
print counterparts. Likewise, within media formats, the anger $(p<.001)$ and sympathy print $(p<.001)$ conditions both elicit significantly more learning than the neutral print stimulus, as do the anger $(p<.001)$ and sympathy $(p<.001)$ video conditions as compared to the neutral video group.

These results support $\mathrm{H} 3$. Media that are richer in emotional cues, those with video formats or emotional frames, are more conducive to learning than less evocative media. Indeed, the greatest learning occurs in those conditions, the anger and sympathy video groups, which take advantage of both types of emotional cueing, whereas the least learning occurs in the neutral print group where participants are exposed to the least emotional cueing. On average, then, the manner in which information is presented significantly affects learning.

If the interplay between sophistication and media format affects emotional appraisals, then it may also shape the learning that results from emotions. Formats with more emotional cues induce more learning than those with fewer cues, but $\mathrm{H} 4$ posits that, within these various conditions, sophistication and emotion interact so that learning effects are more pronounced among high sophisticates. The magnitude of that interaction, though, may vary depending upon emotional cueing. Thus, the quadruple interaction of sophistication, emotional experience, and the experimental conditions demands scrutiny (sophistication $\mathrm{X}$ anger/sympathy $\mathrm{X}$ emotion condition $\mathrm{X}$ media condition).

Table 4.3 shows poisson regression results for the learning count. A number of the lower-order effects are relevant to the hypotheses I test in this dissertation. The conditional effects of the interaction constituent terms show that each directly affects learning, albeit when the other terms are centered at their means, even though conditional 
Figure 4.4: Learning Means by Condition

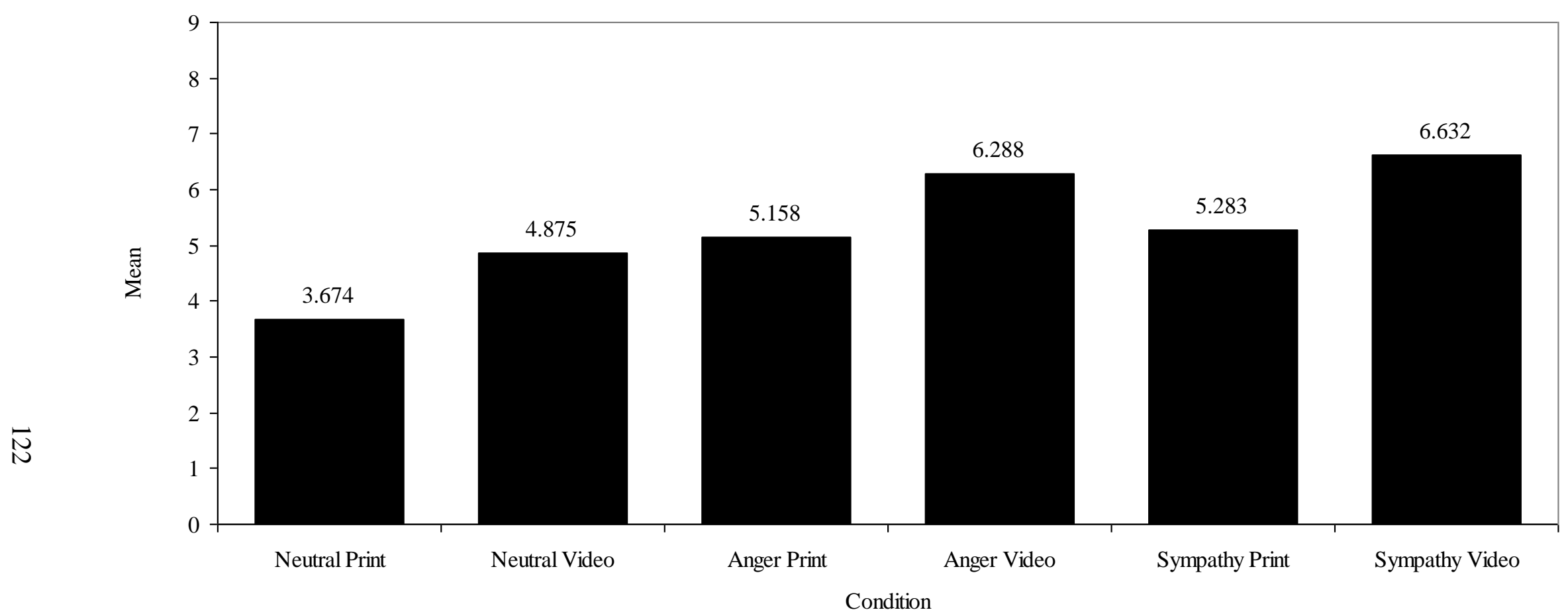


relationships exist. Sophistication, exposure to video news, and exposure to emotionally slanted news all independently stimulate learning, as hinted at in the tests of $\mathrm{H} 3$. Anger significantly depresses information retention, but sympathy enhances learning. The negative anger effect is consistent with Valentino et al. (2009), but little work suggests how sympathy might affect learning. Sympathy is a response to the suffering of others and elicits helping behavior to ameliorate that suffering (Haidt 2003). If sympathy promotes engaging others through behavior, it is reasonable that it also facilitates cognitive engagement though increased attention that leads to learning.

The key results in Table 4.3 are the significant quadruple interactions of sophistication, emotion, and the two condition dummies. Sophistication moderates the effect of emotion on learning such that the learning of high sophisticates is more influenced by emotion action tendencies. Thus, angry high sophisticates learn less than angry low sophisticates, but sympathetic high sophisticates learn more than sympathetic low sophisticates. To the extent that emotions motivate either engagement or disengagement with information encountered, Table 4.3 suggests that that motivation is greater for high sophisticates. They may be more interested in issues such as illegal immigration than low sophisticates and naturally more attentive to them, so those characteristics may dovetail with the greater engagement that sympathy seems to produce to motivate greater learning among high sophisticates. On the other hand, angry high sophisticates may care more about immigration, be more certain of their immigration attitudes, and feel they already know a great deal about the issue, perhaps explaining why the disengagement anger induces is more pronounced for them. 
Table 4.3: Learning Effects with Sophistication and Media Interactions

\begin{tabular}{|c|c|c|}
\hline & Anger & Sympathy \\
\hline Anger & $-.158(.059) * *$ & \\
\hline Sophistication & $.108(.022)^{* * *}$ & \\
\hline Emotion Condition & $.204(.057)^{* * *}$ & \\
\hline Media Condition & $.116(.052)^{*}$ & \\
\hline Anger X Sophistication & $-.194(.059)^{* *}$ & \\
\hline Anger X Emotion & $.296(.113)^{*}$ & \\
\hline Anger X Video & $-.199(.095) *$ & \\
\hline Sophistication X Emotion & $-.075(.043)+$ & \\
\hline Sophistication X Video & $-.079(.038)^{*}$ & \\
\hline Emotion X Media & $.021(.075)$ & \\
\hline Anger X Sophistication X Emotion & $-.15(.093)$ & \\
\hline Anger X Sophistication X Video & $-.227(.089) *$ & \\
\hline Anger X Emotion X Video & $.266(.71)^{* *}$ & \\
\hline Sophistication X Emotion X Video & $-.155(.076)^{*}$ & \\
\hline Anger X Sophistication X Emotion X Video & $-.314(.131)^{*}$ & \\
\hline Sympathy & & $.134(.042)^{* *}$ \\
\hline Sophistication & & $.225(.021) * * *$ \\
\hline Emotion Condition & & $.28(.042)^{* * *}$ \\
\hline Media Condition & & $.163(.041)^{* * *}$ \\
\hline Sympathy X Sophistication & & $.146(.052)^{* *}$ \\
\hline Sympathy X Emotion & & $.099(.099)$ \\
\hline Sympathy X Video & & $.021(.075)$ \\
\hline Sophistication X Emotion & & $.121(.048)^{*}$ \\
\hline Sophistication X Video & & $.174(.039) * * *$ \\
\hline Emotion X Media & & $.282(.076) * * *$ \\
\hline Sympathy X Sophistication X Emotion & & $.278(.076) * * *$ \\
\hline Sympathy X Sophistication X Video & & $.172(.088)^{*}$ \\
\hline Sympathy X Emotion X Video & & $.261(.169)$ \\
\hline Sophistication X Emotion X Video & & $.236(.086)^{* *}$ \\
\hline Sympathy X Sophistication X Emotion X Video & & $.378(.171)^{*}$ \\
\hline Ideology & $-.005(.011)$ & $-.006(.012)$ \\
\hline Partisanship & $-.002(.012)$ & $-.013(.013)$ \\
\hline Economic Class & $-.043(.024)+$ & $-.046(.025)+$ \\
\hline Female & $-.024(.044)$ & $-.011(.043)$ \\
\hline White & $.117(.057)^{*}$ & $.021(.057)$ \\
\hline Academic Year & $.061(.02)^{* *}$ & $.044(.019)^{*}$ \\
\hline Constant & $1.461(.022) * * *$ & $1.535(.028)^{* * *}$ \\
\hline LR & $198.93 * * *$ & $245.96 * * *$ \\
\hline Pseudo- $\mathrm{R}^{2}$ & .146 & .134 \\
\hline$F(21,443 / 442)$ & $1.689 *$ & $1.748 *$ \\
\hline $\mathrm{N}$ & 474 & 473 \\
\hline
\end{tabular}

Note. Entries are unstandardized poisson coefficients; dependent variable is a count of correct responses (0-9); interaction constituent terms are centered; F shows improvement in fit over the model with no interactions; $+\mathrm{p}<.1, * \mathrm{p}<.05, * * \mathrm{p}<.01, * * * \mathrm{p}<.001$ 
For example, Figure 4.5 plots predicted learning for the interaction of the experimental conditions, sophistication and the experience of anger toward illegal immigrants. In each condition, sophistication positively affects learning among participants who do not feel angry. Non-angry high sophisticates, thus, learn more from the treatment than non-angry low sophisticates. The sophistication effect among the nonangry mirrors Figure 4.5 in that learning is significantly higher at all points when comparing the two video conditions to their print counterparts, and when comparing the two anger conditions to the relevant neutral tone conditions.

Sophistication, however, negatively affects learning for angry participants across all conditions, but the learning plots show that the magnitude of that interaction is moderated by the emotional cues in media. In the neutral print condition, the least evocative context as it employs the fewest emotional cues, the learning curves for angry and non-angry participants only differ significantly among the highest sophisticates at +2 $S D$. Thus, anger depresses attention enough to affect learning only among the most sophisticated participants in this low cue situation. As media become more emotionally stimulating, however, the anger effect is amplified as less sophisticated participants begin to differ significantly from their non-angry counterparts. In the neutral video condition, learning is significantly lower among angry participants at $+1 S D$ and higher, and among those scoring at and above the mean in the anger print condition. In the anger video condition where audiovisual and explicit emotional framing are combined learning is significantly lower for participants scoring -1 SD and higher, leaving only the lowest sophisticates at $-2 S D$ unaffected. 
Figure 4.5: Learning Effect of Anger and Sophistication Interaction by Condition $\mathrm{X}$-Axis $=$ Political Sophistication, Y-Axis = Learning

— Not Angry $\quad \cdots \cdot$..... Angry
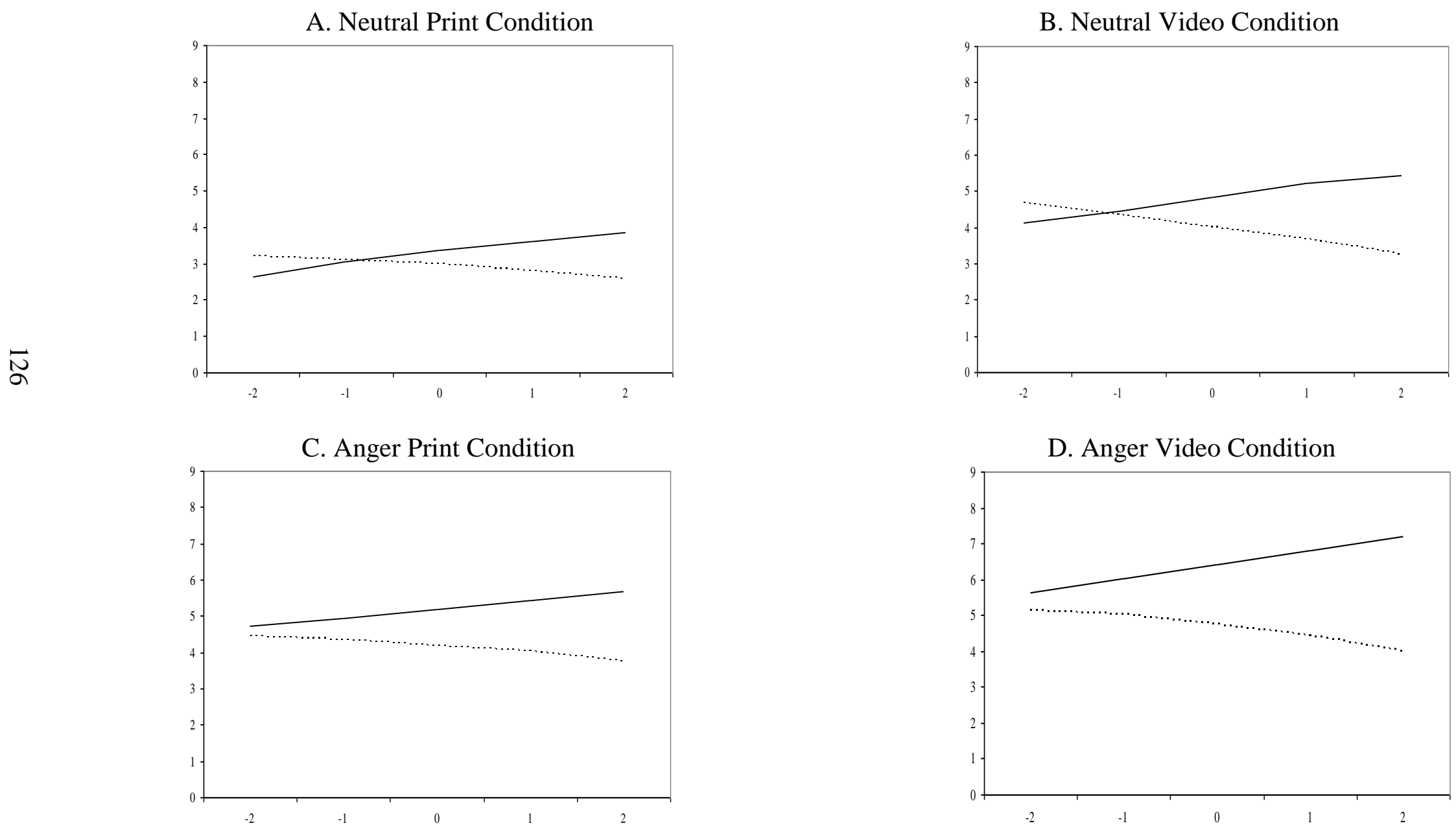

D. Anger Video Condition

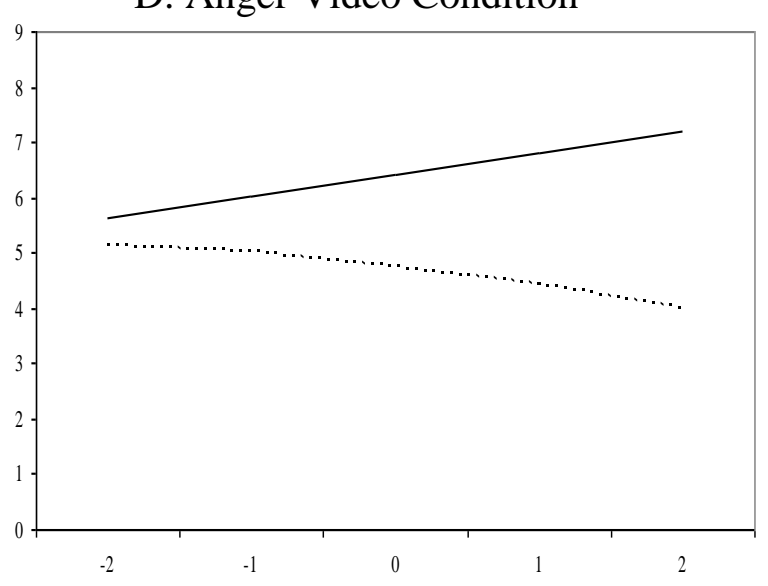


Figure 4.6: Learning Effect of Sympathy and Sophistication Interaction by Condition $\mathrm{X}$-Axis $=$ Political Sophistication, Y-Axis $=$ Learning

_ Not Sympathetic $\quad \cdots \cdots \cdot$. Sympathetic
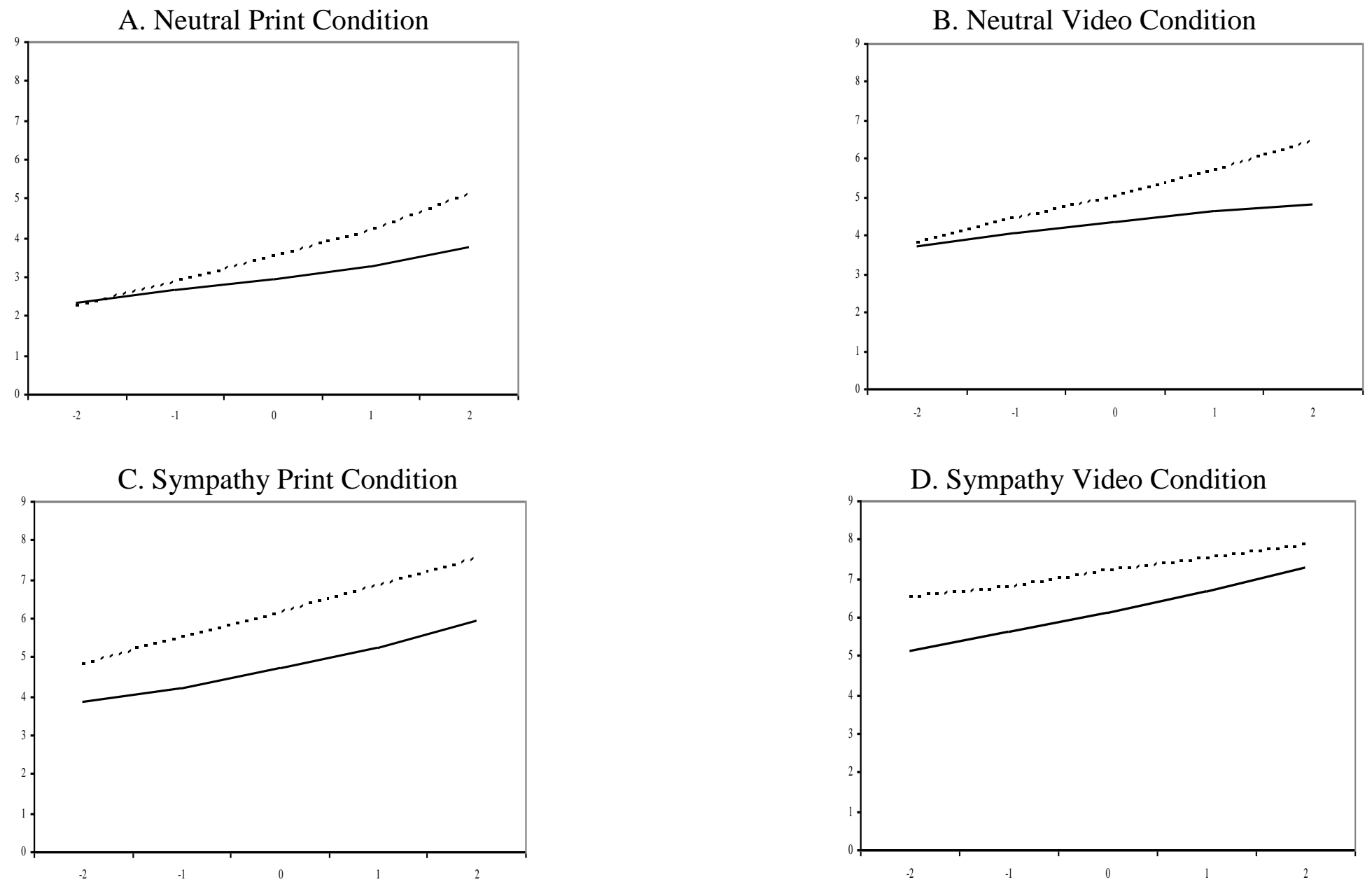

D. Sympathy Video Condition

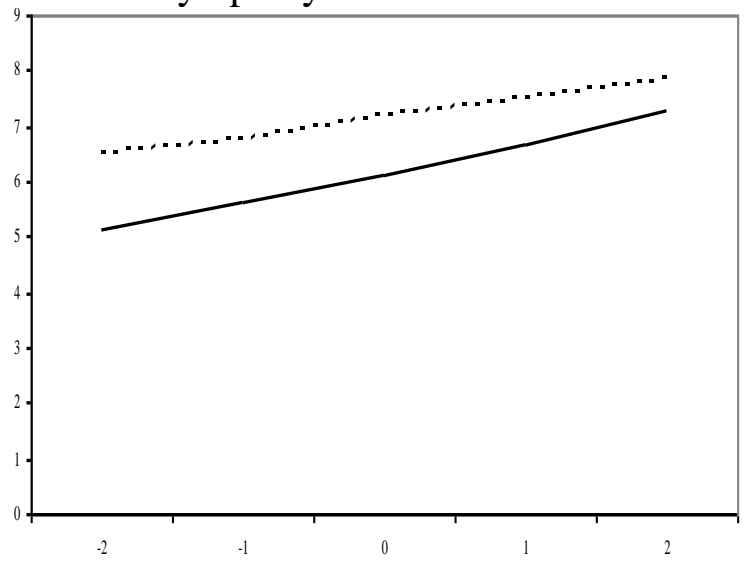


Figure 4.6 shows predicted learning for sophistication and sympathy interacted with the experimental conditions. Again, sophistication and media format jointly moderate the effect of emotion on learning. Sophistication among unsympathetic participants positively affects learning, but feeling sympathy further promotes learning. The magnitude of the sympathy effect, like anger, is heavily influenced by emotional cues. Only the highest sophisticates at $+2 S D$ in the neutral print condition learn significantly more than the unsympathetic. Those at $+1 S D$ and higher in the neutral video condition exhibit significant learning increases, as do those at $-1 S D$ and above in the anger print condition. The cue effect inverts in the sympathy video condition as participants scoring at the sophistication mean and below learn significantly more than the unsympathetic. High sophisticates here already score so highly on learning that it may be difficult for sympathy to focus their attention more than it already is on the stimuli.

The learning results support H4. For both anger and sympathy there is a powerful interaction between emotion and sophistication, but the magnitude of that interaction is moderated by the qualities of the media being consumed. Anger depresses attention to the stimuli, thereby decreasing learning. Sympathy, though, engages participants, drawing attention to the stories so that information encoding and recall is enhanced. These biases, however, are more pronounced among high sophisticates in almost every condition. Angry high sophisticates consistently learn less from the stimuli than angry low sophisticates, whereas sympathetic high sophisticates always learn more than sympathetic low sophisticates. In the least emotionally evocative contexts, however, emotion exclusively affects the learning of the highest sophisticates as compared to those who do not experience either anger or sympathy. As stimuli employ more emotional cues to 
engage participants, the less sophisticated begin to respond to their emotions through their learning patterns. Overall, then, this study shows that individual psychology and the qualities of media interact to shape how citizens respond to political stimuli, both in terms of their emotional appraisals and how they process information.

\section{Discussion}

This experiment suggests that the psyche and the qualities of information contexts interact to shape emotional responsiveness to political stimuli. On the psychological front, this chapter offers solid evidence that political sophistication is key to the experience of emotion. High sophisticates are more likely to feel emotion in response to illegal immigration than low sophisticates, a pattern found both in the absence of any stimuli and after participants are exposed to immigration news employing various modalities and tones. High sophisticates are not only more emotional about politics, but also more susceptible to the learning biases of emotion. Participants who feel anger toward illegal immigrants experience depressed learning levels, but that effect is most pronounced among the most sophisticated students in the sample. Sympathy, on the other hand, facilitates learning with its effect usually strongest among the highest sophisticates.

The experiment also shows how information contexts moderate the effects of both sophistication and emotion. Media contexts with more emotional cues are more effective at eliciting emotion from participants in general, but the degree of responsiveness for high and low sophisticates differs. High sophisticates are always more likely to feel anger or sympathy, even in conditions with more cueing. Likewise, media with more cues promote more learning in general, but those cues moderate the magnitude of emotional 
effects on learning. In low cue media, emotions tend to shape learning only among the most sophisticated participants, but, as media become more emotionally evocative by using more emotional cueing, less sophisticated participants begin to show those behavioral biases. Thus, all four hypotheses advanced here receive strong support.

This chapter further undermines the traditional view that emotion is a low sophistication phenomenon. This experiment reinforces the finding from previous chapters that high sophisticates, the most politically informed and engaged citizens, are actually more emotional about politics. High sophisticates report greater levels of emotion than low sophisticates in the absence of any stimuli, and continue to do so when prompted with emotionally compelling stories. Further, high sophisticates are more affected by the behavioral biases of emotion. These results shatter the stereotype of the unengaged and uninformed citizen who feels rather than thinks about politics, and whose behavior is driven by those feelings. Low sophisticates are certainly capable of making emotional appraisals about political stimuli, but they are less capable of doing so than their more sophisticated counterparts, and are less motivated to engage in behaviors that stem from emotional experiences.

This chapter is important in the larger picture of my dissertation because it is a randomized experiment from which I can draw some degree of causal inference. The positive relationship between sophistication and emotion consistently replicates in crosssectional contexts, but it is not possible to make explicit claims about causality from such data. The paradata in Chapter 2 treat the "one-shot" survey setting as an observable span of time in which I can analyze how respondent behavior in answering questions varies according to individual sophistication, but claiming causality from those patterns would 
be a stretch. Chapter 3 goes a step further in using a quasi-experiment where the advertising treatment varies by media market. While providing stronger clues about causal processes, quasi-experimental settings still leave considerable room for confounding factors to influence the observed results.

The experiment reported in this chapter, however, takes advantage of random assignment to rule out potential confounds. It also allows me to control the stimuli participants see, something I obviously cannot do with campaign ads from a decade ago. My results here provide the strongest evidence yet that sophistication is not just related to greater emotionality about politics, but causing or enabling those emotions in the first place. In the control condition there is no stimulus at all, yet high sophisticates are still more likely to be emotional about illegal immigration absent any prompting. Even in the NES setting there is the year-long stimulus of the campaign to which respondents react. That responsiveness of high sophisticates, however, replicates and becomes more pronounced as participants are exposed to more emotionally evocative media.

Causality is critical for my theory as it helps allay the concern of endogeneity between sophistication and emotion. The central claim of affective intelligence (Marcus et al. 2000) is the emotion promotes information seeking behavior. In other words, emotions induce learning, thereby making people more politically sophisticated. Indeed, given my learning results in this chapter, I can take no issue with the affective intelligence argument, and I readily admitted in Chapter 1 that the relationship between emotion and cognition is non-recursive. I will further admit that my results bolster the affective intelligence claim about information seeking. Marcus and his colleagues never test the effect of emotion on any measure that approximates learning as I do here. Instead, 
their analyses are normally limited to showing a relationship between emotion and attention to political campaigns. Thus, I specifically test the proposition that emotions make a more informed citizenry to which they allude but do not pursue.

However, this experiment, especially the control where no information that might provoke emotion is provided, shows that sophistication itself is a pre-cursor to emotion. Absent any stimulus or prior priming of illegal immigration, high sophisticates are more likely to report being emotional about the issue. When more evocative stimuli are provided, sophistication again is a key predictor of emotional appraisals in this controlled setting, and one that conditions how participants learn as a consequence of their emotions. Thus, though I in no way contradict the affective intelligence theory, I do demonstrate that the relationship between emotion and the qualities that indicate sophistication is a complex two-way street. Does emotion cause sophistication? Yes. Does sophistication cause emotion? Yes. In the real world these phenomena influence each other rather than one being the preeminent cause of the other.

The effects of the experimental treatments also beg reconsideration of how we normatively evaluate political communication. Many scholars have lamented the decline of traditional news media, particularly the hard news style once so common in print and television newscasts of decades past (e.g. Bennett 2003; Cook 2005; Hamilton 2004; Jones 2009; Norris 2000; Patterson 1994). Part of their critique is that modern news emphasizes flashy audiovisuals and emotional frames at the expense of the quality of reporting. The fear of many critics is that citizens will learn less about politics and government from more modern media formats, creating a politically impoverished citizenry. Grabe and Bucy (2009) refer to this fear as "the pomp and circumstance of 
print culture," a relic of times past when literacy was a supposed hallmark of an intelligent, thoughtful, and rational citizenry. If consumers of media cannot me made to read hard, objective, fact-based newspapers on a daily basis, the next best thing may be for them to watch informative public affairs programming that is the closest approximation in the television world. Certainly, the logic goes, average citizens will learn little or nothing from "fluff infotainment."

This study, however, suggests that those critiques may be overblown at best or unfounded at worst. Participants universally learn more when media take advantage of emotional cues. Indeed, the most learning occurs when media most resemble the flashy soft news format commonly derided in modern scholarship, and the least learning occurs when news most resembles the traditional type of reporting that many scholars idealize. Perhaps, then, modern media trends may actually create a more informed electorate for the very reasons they are attacked. Relying on more audiovisual modalities and emotional framing may do as much to engage and inform consumers as it does to entertain them. Humans are under a constant barrage of sensory stimuli. The brain is always monitoring the environment for stimuli that may induce emotion if cognitive or behavioral adaptation is necessary. The brain, then, is expert at multitasking, and may respond best to information that stimulates it as much as possible. All things equal, average citizens may just be hardwired to learn about politics better from Katie Couric and "if it bleeds, it leads" journalism than they are the New York Times or the PBS NewsHour.

Many scholars have shown that emotions have important effects on mass political behavior, and this experiment shows how the psyche and the external information context interact to moderate those processes. There is, however, room to improve upon this study. 
As with all student samples, the generalizability of these results is an open question, but public surveys rarely include the questions needed to replicate this study on a wider scale with a more representative sample. Also, context can be conceptualized in many ways. This experiment focuses solely on the news media, especially more traditional forms of communication such as print and television. It is reassuring that the general pattern of results reported here is similar to what was observed in the campaign advertising quasiexperiment in Chapter 3, but different types of contexts may function fundamentally differently. Whether the results would replicate in discussion networks or even other types of media formats is a question for further study. Nevertheless, this research, despite any limitations, sheds important light on the causal dynamics of emotion and provides strong support for the hypotheses I advance in this dissertation. 


\section{Chapter 5}

\section{Concluding Thoughts}

Ultimately, this dissertation asks us to reconsider how we think of the empirical and normative roles of emotion in politics. Beginning with the philosophers of Ancient Greece and Rome, theorists, social scientists, and popular political commentators have promulgated the idea that emotion is an undesirable contagion in the body politic. According to this view, emotion is wild and dangerous. It is the opposite of reason and, thus, irrational. It is a crutch that less informed and less engaged citizens rely upon rather than devoting the necessary effort to learn about politics and reason through political questions. In short, there is little desirable about emotion and humanity must strive to overcome or, at the very least, contain it.

Political science has begun to turn this negative view of emotion around, reframing emotion an important factor in political behavior and even a desirable element of democratic citizenship. My dissertation contributes to both of these arguments. As discussed in Chapter 1, most recent political science work on emotion deals with the direct effects of emotion on a variety of political behaviors. Thus, there is little doubt that emotions can powerfully influence voting, policy and political attitudes, learning, and myriad other behaviors. However, though it is invaluable, this literature gives little 
insight into how politics elicits emotion in the first place, and what factors might condition the behavioral effects of emotion. My dissertation begins to shed light on both those causal and conditional dynamics.

Throughout my dissertation I have argued that political sophistication enables individual emotional responsiveness to political stimuli. I have demonstrated and rigorously tested that relationship in cross-sectional data and have provided causal evidence from a randomized experiment that supports that theory. Thus, my central claim has held up quite robustly in multiple tests and in a variety of contexts. High political sophisticates are better at emotionally appraising politics than low sophisticates. They know more about politics, are more interested in it, and pay more attention to it. In sum, they understand political affairs better and are more engaged with the political world.

However, the causal side of emotion is about more than individual psychology. Citizens have the potential to tap into a wealth of political information that surrounds them at all times in different types of information contexts. Campaigns make themselves heard, but individuals can intentionally expose themselves to political information simply by turning on the television, opening the newspaper, or asking a friend about his or her view on the latest political story. Different contexts have different qualities, though. They vary in the amount of information available for consumption and the modalities they stimulate, as well as their familiarity, divisiveness, and myriad other factors.

I cannot operationalize context in all its forms in this one dissertation, nor can I tap into every possible quality that might vary across those contexts. Nevertheless, I have demonstrated that the qualities of two important political information contexts campaign advertising and the traditional news media - moderate how sophistication 
affects emotional appraisals. More emotionally evocative contexts are better at eliciting emotion in general and even certain behaviors such as learning. The emotions of high sophisticates are universally more responsive to political information in all its forms, but low sophisticates are better able to engage emotionally with some contexts than others. Thus, while sophistication and information context can shape emotional appraisals independent of one another, it is in their interaction that we can observe more powerful causal relationships that, indeed, more accurately reflect the reality of how citizens interact with their environments on a daily basis.

Though my dissertation pushes the boundaries of extant literature on emotion in politics by delving into questions of causality, it also encourages us to think harder about the effects of emotions. By and large scholars have been rightly concerned with uncovering the direct effects of emotion, but I have demonstrated in multiple analyses in my dissertation that political sophistication moderates the effect of emotion on behavior and attitudes. Contrary to the conventional academic and popular stereotype, it is not low sophisticates who are more prone to act on their emotions. Indeed, my analyses show that emotion often exerts little effect at all on the behaviors of the least engaged and informed citizens. Rather, it is high sophisticates, the citizens often idealized as the paragons of good democratic citizenship, who tend to act more on their emotions. Their feelings are stronger influences on the attitudes they express, the votes the cast, and how they learn from the information around them. High sophisticates understand better how to translate emotion into political action, and have the greater preexisting motivation and political interest to act upon their emotions. 
My results beg two important questions that stem from the traditional view of emotion. First, emotion has normally been seen as a detriment. From this point-of-view, it is a wild force that supposedly prevents the individual from engaging in the kind of rational thought and deliberation that characterize good citizenship. It needs taming so that education and careful reasoning can triumph. However, as my dissertation shows, if emotion is actually an outgrowth of knowledge about and engagement with the political world, is it really the undesirable element it has been painted to be? My results suggest that ignorance of and disinterest in political affairs do not breed emotional citizens. Rather, engagement and understanding promote not just thinking about politics, but feeling about it, as well. The emotional citizen is politically informed, engaged, interested, attentive, caring, and understanding - all the qualities that we normatively want citizens in a modern participatory democracy to possess. Individuals low in those qualities do not care enough or know enough about politics to feel much about it. Perhaps, then, emotions such as anger, fear, and hope are signs of the kind of engagement with politics that we value as a field. They are indicative of good, higher quality citizenship rather than a democracy of satisficers and dumbed-down sound bite politics.

Second, is emotional rational? Beginning with ancient scholars, Western culture has naturally paired the terms "emotion" and "irrational" both in and out of political contexts. The concerns that Marcus et al. (2000) document largely deal with philosophers who believed that passions take control of individuals and drive them to behaviors that are undesirable and counterproductive to society. Phrases such as "irrational anger," "irrational exuberance," and "get control of your emotions" are indicative of the sentiment that emotion is the opposite of reason and rationality. 
However, let us return to the core definition of what an emotion is - an appraisal that some object carries consequences for individual and group goals. If emotions occur because we feel that an object either threatens or enhances some goal or objective we desire, then the very definition of an emotion comports with the idea that rational behavior is goal-directed behavior. Emotion, then, depends on the ability to link stimuli to objectives, the consequence being that emotion promotes goal-seeking behavior. If the aggregation of fear is George W. Bush's reelection or the sum of hope is Barack Obama, perhaps these outcomes are the result of rational behavior stemming from some level of sophisticated thought. After all, it is high sophisticates who better understand politics and, presumably, their political desires who vote more on these emotions. Again, we must rethink how we stereotype emotion and begin to find a place for it in frameworks of rational action and behavior.

Overall, my dissertation has provided strong support for each hypothesis I have advanced in this research. High sophisticates are not only more emotional about politics, but more responsive to political stimuli and more prone to acting upon their feelings. This is not to say that low sophisticates are incapable of reacting emotionally to the political world. Rather, less informed and engaged citizens are simply less likely to be emotional about political affairs because they take do not understand politics as well and care less about it. When they do feel about politics, they are not as motivated as high sophisticates to act on those emotions, and, in some cases, may not understand how best to translate those feelings into action. As a result of this research, I would hope that interested scholars would also begin to rethink their assumptions about emotion, and push research in this area in other innovative and informative directions. 


\section{Appendix A \\ Iraq War Web Survey Questions}

\section{Sophistication Items}

1. Some people don't pay much attention to politics, and some people do. In general, how much attention do you pay to politics? $(1=$ none at all, $4=$ a lot $)$

2. Some people aren't very interested in politics, and some people are. In general, how interested are you in politics? $(1=$ none at all, $3=$ very much $)$

3. What job or political office does Harry Reid now hold?

4. What job or political office does Condoleezza Rice now hold?

5. If no one running for president receives a majority of electoral votes, who becomes responsible for choosing the President?

6. The Supreme Court has the power to declare laws unconstitutional. What is this power called?

7. Who was the first woman nominated for Vice President by a major political party?

\section{Iraq Emotions}

1. How often has the Iraq War made you feel angry toward the US/ angry toward the Iraqis/ guilty about the actions of the US/ sympathetic toward the Iraqis? $(0=$ never, 4 = very often)

\section{Iraq Blame}

1. In your opinion, who is responsible for the problems in Iraq? $(1=$ The Iraqis themselves are entirely to blame, $3=$ The Iraqis and the US are equally to blame, $5=$ The US is entirely to blame)

\section{Iraq Policy Items}

1. The US should increase financial aid to Iraq for humanitarian needs such as food, medicine, and shelter. ( $1=$ agree strongly, $5=$ disagree strongly $)$

2. The US should increase financial aid to Iraq to repair damage to infrastructure like roads and bridges caused by the US invasion.

3. The US should keep its troops in Iraq until the country is stable and secure enough to take care of itself.

4. The US should send more troops to Iraq to fight the militia and terrorist organizations responsible for violence there.

\section{Controls}

1. What is your academic year? $(1=$ freshman, $4=$ senior $)$

2. What is your gender?

3. What term best describes your race?

4. Which of the following best describes your religious preference?

5. Are you presently a member of the military?

6. What term best describes your political party affiliation? $(1=$ strong Democrat, 7 $=$ strong Republican) 
7. One way that people talk about politics in America is in terms of conservative, moderate, and liberal. Where would you place yourself on this scale? $(1=$ very liberal, 7 = very conservative) 


\section{Appendix B}

Media Markets Tracked by CMAG in 2000

\begin{tabular}{|l|c|l|c|}
\hline Market & Code & Market & Code \\
\hline Albany-Schenectady-Troy & 1 & Miami-Ft. Lauderdale & 39 \\
\hline Albuquerque-Santa Fe & 2 & Milwaukee & 40 \\
\hline Atlanta & 3 & Minneapolis-St. Paul & 41 \\
\hline Austin & 4 & Mobile-Pensacola & 42 \\
\hline Baltimore & 5 & Nashville & 43 \\
\hline Birmingham-Anniston-Tuscaloosa & 6 & New Orleans & 44 \\
\hline Boston-Manchester & 7 & New York City & 45 \\
\hline Buffalo & 8 & Norfolk-Portsmouth-Newport News & 46 \\
\hline Charleston-Huntington & 9 & Oklahoma City & 47 \\
\hline Charlotte & 10 & Omaha & 48 \\
\hline Chicago & 11 & Orlando-Daytona Beach-Melbourne & 49 \\
\hline Cincinnati & 12 & Philadelphia & 50 \\
\hline Cleveland-Akron-Canton & 13 & Phoenix-Prescott & 51 \\
\hline Columbus & 14 & Pittsburgh & 52 \\
\hline Dallas-Ft. Worth & 15 & Portland-Auburn & 53 \\
\hline Dayton & 16 & Portland, OR & 54 \\
\hline Denver & 17 & Providence-New Bedford & 55 \\
\hline Des Moines-Ames & 18 & Raleigh-Durham-Fayetteville & 56 \\
\hline Detroit & 19 & Richmond-Petersburg & 57 \\
\hline Flint-Saginaw-Bay City & 20 & Roanoke-Lynchburg & 58 \\
\hline Fresno-Visalia & 21 & Rochester & 59 \\
\hline Grand Rapids-Kalamazoo-Battle Creek & 22 & Sacramento-Stockton-Modesto & 60 \\
\hline Green Bay-Appleton & 23 & Salt Lake City & 61 \\
\hline Greensboro-High Pt.-Winston Salem & 24 & San Antonio & 62 \\
\hline Greenville-Spartanburg-Asheville & 25 & San Diego & 63 \\
\hline Harrisburg-Lancaster-Lebanon-York & 26 & San Francisco-Oakland-San Jose & 64 \\
\hline Hartford-New Haven & 27 & Seattle-Tacoma & 65 \\
\hline Houston & 28 & Spokane & 66 \\
\hline Indianapolis & 29 & St. Louis & 67 \\
\hline Jacksonville-Brunswick & 30 & Syracuse & 68 \\
\hline Kansas City & 31 & Tampa-St. Petersburg-Sarasota & 69 \\
\hline Knoxville & 32 & Toledo & 70 \\
\hline Las Vegas & 33 & Tulsa & 71 \\
\hline Lexington & 34 & Washington, DC-Hagerstown & 72 \\
\hline Little Rock-Pine Bluff & 35 & West Palm Beach-Ft. Pierce & 73 \\
\hline Los Angeles & 36 & Wichita-Hutchinson & 74 \\
\hline Louisville & 37 & Wilkes-Barre-Scranton & 75 \\
\hline Memphis & 38 & & \\
\hline & & & \\
\hline
\end{tabular}




\section{Appendix C \\ Storyboard Coding Instrument}

Coder:

Ad Name:

Determine whether an emotional appeal is present in the ad. Use the emotion definitions as a guideline for determining whether an appeal pertains to a certain emotion or not. If an appeal exists anywhere in the ad, place a " 1 " in the box that matches that emotion to the candidate who is the target of the appeal. Code all other appeals " 0 " for not being present in the storyboard.

\begin{tabular}{|c|c|c|c|c|}
\hline Emotion & Bush & McCain & Bradley & Gore \\
\hline Anger & & & & \\
\hline Contempt & & & & \\
\hline Disgust & & & & \\
\hline Disappointm & & & & \\
\hline Excitement & & & & \\
\hline Fear & & & & \\
\hline Gratitude & & & & \\
\hline Hope & & & & \\
\hline Pride & & & & \\
\hline Resentment & & & & \\
\hline Shame & & & & \\
\hline Sympathy & & & & \\
\hline
\end{tabular}




\section{Appendix D}

Demographic Controls, Tables 3.3 - 3.5

\begin{tabular}{|c|c|c|c|c|c|c|c|c|}
\hline \multicolumn{9}{|c|}{ Table 3.3} \\
\hline \multirow[b]{3}{*}{ Age } & \multicolumn{4}{|c|}{ Bush } & \multicolumn{4}{|c|}{ Gore } \\
\hline & Anger & Fear & Hope & Pride & Anger & Fear & Hope & Pride \\
\hline & $\begin{array}{l}-.004 \\
(.005)\end{array}$ & $\begin{array}{c}-.012+ \\
(.006)\end{array}$ & $\begin{array}{c}.003 \\
(.007)\end{array}$ & $\begin{array}{l}-.002 \\
(.008)\end{array}$ & $\begin{array}{l}-.009+ \\
(.0005)\end{array}$ & $\begin{array}{l}-.005 \\
(.007)\end{array}$ & $\begin{array}{c}.004 \\
(.005)\end{array}$ & $\begin{array}{c}.001 \\
(.006)\end{array}$ \\
\hline \multirow[t]{2}{*}{ Education } & $.119^{*}$ & .041 & -.075 & $-.125^{*}$ & -.037 & -.112 & .037 & -.032 \\
\hline & $(.058)$ & $(.071)$ & $(.060)$ & $(.063)$ & $(.059)$ & $(.077)$ & $(.079)$ & $(.056)$ \\
\hline \multirow[t]{2}{*}{ Female } & -.105 & -.072 & .116 & .203 & -.084 & -.081 & -.001 & .193 \\
\hline & $(.191)$ & $(.166)$ & $(.176)$ & $(.155)$ & $(.148)$ & $(.179)$ & $(.164)$ & $(.159)$ \\
\hline \multirow[t]{2}{*}{ Income } & -.003 & .002 & .006 & -.017 & .012 & .004 & .002 & -.020 \\
\hline & $(.026)$ & $(.024)$ & $(.029)$ & $(.027)$ & $(.024)$ & (.029) & $(.029)$ & $(.023)$ \\
\hline \multirow[t]{2}{*}{ White } & .013 & -.154 & -.126 & -.304 & .211 & -.123 & .058 & .027 \\
\hline & $(.191)$ & $(.185)$ & $(.227)$ & $(.255)$ & $(.251)$ & $(.285)$ & $(.194)$ & $(.223)$ \\
\hline & & & & & & & & \\
\hline \multirow[t]{2}{*}{ Age } & -.004 & $-.011+$ & .003 & -.002 & $-.008+$ & -.006 & .004 & .001 \\
\hline & $(.005)$ & $(.006)$ & $(.007)$ & $(.008)$ & $(.005)$ & $(.006)$ & $(.005)$ & $(.006)$ \\
\hline \multirow[t]{2}{*}{ Education } & $.117^{*}$ & .038 & -.078 & $-.126^{*}$ & -.045 & -.115 & .039 & -.029 \\
\hline & $(.057)$ & $(.071)$ & $(.060)$ & $(.062)$ & $(.059)$ & $(.079)$ & $(.079)$ & $(.057)$ \\
\hline \multirow[t]{2}{*}{ Female } & -.103 & -.071 & .109 & .207 & -.095 & -.062 & .004 & .193 \\
\hline & (.189) & (.169) & $(.173)$ & $(.154)$ & $(.147)$ & $(.181)$ & $(.165)$ & $(.159)$ \\
\hline \multirow[t]{2}{*}{ Income } & -.004 & .001 & .007 & -.019 & .014 & -.003 & .002 & -.021 \\
\hline & $(.027)$ & $(.024)$ & $(.029)$ & $(.028)$ & $(.024)$ & $(.031)$ & $(.029)$ & $(.023)$ \\
\hline \multirow[t]{2}{*}{ White } & .027 & -.157 & -.122 & -.311 & .205 & -.104 & .049 & .027 \\
\hline & $(.193)$ & $(.182)$ & $(.234)$ & $(.264)$ & $(.256)$ & $(.291)$ & $(.197)$ & $(.222)$ \\
\hline
\end{tabular}


Appendix E

Demographic Controls, Tables 3.6 - 3.8

\begin{tabular}{|c|c|c|c|c|c|c|c|c|}
\hline \multirow[b]{3}{*}{$\begin{array}{c}\text { Academic } \\
\text { Year }\end{array}$} & \multicolumn{2}{|c|}{ Table 3.6} & \multicolumn{2}{|c|}{ Table 2.7} & \multicolumn{4}{|c|}{ Table 3.8} \\
\hline & $\begin{array}{c}\text { No } \\
\text { Interactions }\end{array}$ & Interactions & $\begin{array}{c}\text { No } \\
\text { Interactions }\end{array}$ & Interactions & $\begin{array}{c}\text { Humanitarian } \\
\text { Aid } \\
\end{array}$ & $\begin{array}{c}\text { Repair } \\
\text { Damage }\end{array}$ & $\begin{array}{c}\text { Keep } \\
\text { Troops } \\
\end{array}$ & $\begin{array}{c}\text { Send } \\
\text { Troops }\end{array}$ \\
\hline & N/A & N/A & N/A & N/A & $\begin{array}{c}.058 \\
(.104)\end{array}$ & $\begin{array}{c}.047 \\
(.103)\end{array}$ & $\begin{array}{l}.003 \\
(.102)\end{array}$ & $\begin{array}{c}.029 \\
(.103)\end{array}$ \\
\hline Age & $\begin{array}{l}.012 \\
(.013)\end{array}$ & $\begin{array}{c}.013 \\
(.014)\end{array}$ & $\begin{array}{l}-.001 \\
(.015)\end{array}$ & $\begin{array}{l}-.004 \\
(.016)\end{array}$ & N/A & N/A & N/A & N/A \\
\hline $\begin{array}{c}\text { Economic } \\
\text { Class }\end{array}$ & N/A & N/A & N/A & N/A & $\begin{array}{c}.053 \\
(.128)\end{array}$ & $\begin{array}{c}.021 \\
(.129)\end{array}$ & $\begin{array}{l}.069 \\
(.124)\end{array}$ & $\begin{array}{l}.00002 \\
.132)\end{array}$ \\
\hline Education & $\begin{array}{l}.155 \\
(.129)\end{array}$ & $\begin{array}{l}.187 \\
(.138)\end{array}$ & $\begin{array}{c}.366 \\
(.153)^{*}\end{array}$ & $\begin{array}{c}.372 \\
(.167)^{*}\end{array}$ & N/A & N/A & N/A & N/A \\
\hline Female & $\begin{array}{c}.090 \\
(.297)\end{array}$ & $\begin{array}{c}.089 \\
(.314)\end{array}$ & $\begin{array}{c}.335 \\
(.405)\end{array}$ & $\begin{array}{l}-.333 \\
(.387)\end{array}$ & $\begin{array}{c}.235 \\
(.219)\end{array}$ & $\begin{array}{l}-.021 \\
(.218)\end{array}$ & $\begin{array}{l}-.392+ \\
(.213)\end{array}$ & $\begin{array}{l}-.439^{*} \\
(.204)\end{array}$ \\
\hline Income & $\begin{array}{l}-.072 \\
(.048)\end{array}$ & $\begin{array}{l}-.062 \\
(.049)\end{array}$ & $\begin{array}{c}-.132 \\
(.049)^{* *}\end{array}$ & $\begin{array}{l}-.125 \\
(.055)^{*}\end{array}$ & N/A & N/A & N/A & N/A \\
\hline White & $\begin{array}{l}-.061 \\
(.485)\end{array}$ & $\begin{array}{l}-.058 \\
(.522)\end{array}$ & $\begin{array}{l}-.443 \\
(.612)\end{array}$ & $\begin{array}{l}-.294 \\
(.601)\end{array}$ & $\begin{array}{l}-.386 \\
(.258)\end{array}$ & $\begin{array}{l}.104 \\
(.257)\end{array}$ & $\begin{array}{l}.623^{*} \\
(.259)\end{array}$ & $\begin{array}{l}-.007 \\
(.262)\end{array}$ \\
\hline
\end{tabular}




\section{Appendix F Experiment Question Wording}

\section{Sophistication Items}

1. Some people don't pay much attention to politics, and some people do. In general, how much attention do you pay to politics? $(1=$ none at all, $4=$ a lot $)$

2. Some people aren't very interested in politics, and some people are. In general, how interested are you in politics? $(1=$ none at all, $3=$ very much $)$

3. What job or political office does Harry Reid now hold?

4. What job or political office does Ben Bernanke now hold?

5. If no one running for president receives a majority of electoral votes, who becomes responsible for choosing the President?

6. The Supreme Court has the power to declare laws unconstitutional. What is this power called?

7. Who was the first woman nominated for Vice President by a major political party?

\section{Illegal Immigration Emotions}

1. Does the illegal immigration situation make you feel (emotion)? If so, how (emotion) do you feel? $(0=$ no, $4=$ extremely)

Learning Items: Neutral Conditions ( $C=$ Closed-Ended, $O=$ Open-Ended)

1. How many illegal immigrants of Hispanic origin are estimated to live in North Carolina? (C)

2. What percentage of the Duplin County population is Hispanic? (O)

3. How many temporary worker visas does the United States government issue each year? $(\mathrm{O})$

4. What was the main problem facing the UCSD burn center? (C)

5. What is UCSD planning to do to get paid for treating the illegal burn victims? (O)

6. Under what conditions do hospitals have to treat uninsured patients? (C)

7. What agency conducted the immigration raid in Houston? (O)

8. How did law enforcement find out that Action Rags USA might be employing illegal immigrants? $(\mathrm{O})$

9. What did the family member of a suspected illegal immigrant say as a defense for the arrested workers? (C)

Learning Items: Anger Conditions $(C=$ Closed-Ended, $O=$ Open-Ended $)$

1. What government agency took custody of the two illegal immigrants accused of murdering Dani Countryman? (C)

2. How long had the two illegal immigrants accused of murdering Dani Countryman been in the United States? (C)

3. What is an immigration detainer? $(\mathrm{O})$

4. How many Utah children are estimated to be victims of Social Security theft by illegal immigrants each year? (C)

5. What benefits do illegal immigrants get from having fake Social Security cards? (O) 
6. How much does a fake Social Security card cost on average? (O)

7. What do you call a location in the desert where illegal immigrants wait for human smugglers to pick them up? (C)

8. Why doesn't Arizona clean up the litter and pollution caused by illegal immigrants in the Arizona desert? (O)

9. What threat do abandoned vehicles pose to the desert ecosystem? (C)

\section{Learning Items: Sympathy Conditions $(C=$ Closed-Ended, $O=$ Open-Ended $)$}

1. What government agency seized Anna Herrera's mother and aunt? (C)

2. What is the name of the organization that Anna Herrera's teachers and friends started? (C)

3. What is the purpose of the organization that Anna Herrera's teachers and friends started? (O)

4. What has the decrease in employment been for illegal immigrants in Los Angeles as a result of the current recession? (C)

5. In what way has the current recession mainly affected the countries that illegal immigrants come from? (C)

6. Why don't some illegal immigrants like Manuel Barajas go home rather than stay in the United States with little change of finding work? (O)

7. Why has the New York City Police Department's hate crimes unit become involved in the murder of the illegal immigrant in New York City? (O)

8. How much is the case reward for information leading to the arrest of the men who murdered the illegal immigrant in New York City? (O)

9. Which country did the murdered illegal immigrant in New York City come from? (C)

\section{Controls}

1. What is your academic year? $(1=$ freshman, $4=$ senior $)$

2. What is your gender?

3. What term best describes your race?

4. What term best describes your immediate family's economic status $(1=$ working class, 5 = upper class)?

5. What term best describes your political party affiliation? $(1=$ strong Democrat, 7 = strong Republican)

6. One way that people talk about politics in America is in terms of conservative, moderate, and liberal. Where would you place yourself on this scale? $(1=$ very liberal, 7 = very conservative) 


\title{
Appendix G Neutral Story \#1
}

\author{
By Dave Jordan \\ Staff Writer \\ Wilmington Morning Star \\ Thursday, March 26, 2009
}

The challenges of illegal immigration are a concern for communities across North Carolina as the Hispanic population in the state surges. The US Census estimates 600,000 to 700,000 Hispanics are in North Carolina, and 300,000 to 400,000 are illegal. As we continue our investigation on illegal immigration, we take you to one county here in Eastern Carolina that has the highest percentage of Hispanics in the state, and based on the state numbers and research by the Pew Hispanic Center, half are likely illegal.

Alejandro Mendez came to the United States from Mexico twenty year ago as a migrant worker looking for economic freedom. "We had to start looking for something else, like, you know, to make a good life for my family, for everybody," Mendez said. Today, he's a US citizen and owns a restaurant in Warsaw in Duplin County. "I feel pretty good because, you know, we got a lot of benefits for the Mexican citizens," he continued.

Mendez is part of the changing face of Duplin County, the kind of ground zero in the surge of Hispanic immigrants, both legal and illegal. US Census figures show $20 \%$ of the population in Duplin County is Hispanic, the highest in the state. The state average is around $7 \%$.

And the increase in Warsaw is evident with the new businesses popping up. Jason Burrell is the Warsaw town manager. "We've had a good track record with the Hispanic businesses that have come here. They seem to flourish and they seem to do well," Burrell stated.

Research shows in North Carolina, Hispanics both legal and illegal make quite an economic contribution, about $\$ 9$ billion a year. Other research shows any revenue is offset by the costs of paying for services for those who are undocumented. And that's what has people in towns like Warsaw and so many others concerned about their communities. "We do see it changing. Sometimes it's not for the better," said Pearl West, a Warsaw resident.

Win Batton is the Warsaw mayor. "Many of them are certainly making a contribution in providing needed workforce, but, at the same time, if they're here illegally, uhh, in many cases they're not paying taxes other than what they have to pay on the food they buy," he said.

Alejandro says everyone who works in his restaurant is legal. He makes sure of it with proper paperwork. "We have to ask them for the social security. To pull it up on the computer," he explained. And it's that kind of business Warsaw officials say they want 
more of. "We want people that are legal. If they're not legal, we want them to go back, and get their status straight, and c'mon back and be a good productive citizen. Uhh, that way we can all benefit," Mayor Batton said. The town has even held workshops for people who may not be here legally, showing them how to correct the situation.

Anita Villeda of Beaufort County, whose boyfriend is illegal, says the 300,000 to 400,000 undocumented workers in the state are needed. "Mexicans are hard workers, and everybody knows that," she said. "They work for the tobacco, and, you know, in the fields in the hot weather. What other people won't do." And in the process, some say, keep costs down for many products, goods, and services Americans use. Others contend the undocumented workers keep wages down, and that's why US citizens don't want the jobs.

They're all issues being felt in this historic town of Warsaw, over 150 years old, now dealing with the growing pains of a new population explosion, and the challenges of illegal immigration." I think that it's something they have to work to fix, you know. The system needs to be fixed," Mendez said. One of the fixes employers are seeking is more foreign temporary worker visas. That would allow people to legally enter the United States to work, but not stay here permanently. Right now the United States gives out 66,000 per year for the entire county. 


\section{Appendix $\mathbf{H}$ Neutral Story \#2}

By Ed Lenderman

Staff Writer

San Diego Union Tribune

Thursday, March 26, 2009

The story of local wildfires doesn't just involve the firefighting and the property destruction. Of the 18 people lying in the University of California at San Diego (UCSD) medical center's burn unit today, 11 are illegal immigrants with no apparent health coverage.

The raging Harris Fire started along the border, so it was perhaps inevitable that among the burn victims would be illegal immigrants. Fifteen illegal immigrants in all have been victims of the fire, and 4 were found dead. The 11 injured are in UCSD medical center's acclaimed burn unit. Four are in critical condition.

"Here at UCSD we're the only regional burn unit in San Diego," explained Dr. Tom McAfee, physician-in-chief at UCSD. "We always look for ways to get reimbursed for the care we provide. And for patients that are undocumented, they often will not qualify for the usual programs, the usual safety net programs, that the county provides, or that the state provides through the MediCal program. So in many cases these patients won't have any sponsorship, and we won't recover any of the costs of the care we're providing."

Because of the severity of the injuries of the 11 illegals, the medical center is looking at a potential loss of hundreds of thousands of dollars. "Our philosophy here and the law is that a patient who comes through our doors and has an acute medical problem, we treat those patients without regard to the color of their skin, their religion, or their ability to pay," Dr. McAfee stated. "And we will continue to care for patients in our hospital until they are ready to be discharged or transferred to another facility."

But therein lies another cost issue. The nature of severe burns virtually requires long term care, months and perhaps years of treatment. "What often happens for us is that when a patient has reached a point where they really don't require acute hospitalization, but they could be transferred to either a rehabilitation facility or a skilled nursing facility, our experience is that those facilities won't accept those patients because, like us, they require reimbursement to keep their doors open," Dr. McAfee said. You would think the state and local governments would chip in here, but Dr. McAfee says that certainly hasn't been the case in the past. That doesn't mean UCSD isn't going to try this time around, and that includes seeking reimbursement from the government of Mexico.

"So we will be pursuing getting reimbursement through the Mexican government," Dr. McAfee stated. "We'll be going to the federal authorities. I'll be in Washington, D.C., on Monday meeting with our congressman and you can be sure I'll be talking about this issue, as well." 


\title{
Appendix I \\ Neutral Story \#3
}

\author{
By Ford Atkinson \\ Staff Writer \\ Houston Chronicle \\ Thursday, March 26, 2009
}

Immigration officers carried out a raid at an export business in southeast Houston this morning. They say they were working on a tip that illegal immigrants were employed at Action Rags USA.

It was a very, very strange morning at the clothing plant. It wasn't what people anticipated. But after a huge immigration raid, business was brought to a halt. Federal immigration agents began raiding a clothing rag exporting plant about 7 o'clock this morning.

Immigration officials said the raid came after a year-long investigation into reports that Action Rags USA employed illegal immigrants. "What you need to understand is that work site enforcement, particularly investigations involving work site enforcement are phased in approach," explained Agent Greg Palmore, an Immigration and Customs Enforcement (ICE) spokesman. "It takes various steps to get to the prosecution stage."

By early morning vans transported the immigrants away from the plant. As the raid progressed, family members of the suspected illegals arrived hoping to find out where their relatives would be taken. Family members we talked with thought the raid was unjustified. "They ain't really doing nothing bad, you know. They're working, you know," said Luis Patio, a nephew of a suspected illegal immigrant. "They ain't hurting no one, you know. They're here to make money." At least one of the detained workers was released to her family after proving she was a legal resident.

Investigation of Action Rags USA is not over. "What will happen here is we'll collect as much information as we can, and follow the information where it takes us," Agent Palmore stated. Officials have not yet said exactly how many immigrants they have taken into custody in the raid. We presume from observing the scene that it may be in the dozens, but those numbers cannot be confirmed. We also don't know what countries they come from. We expect to learn that at a 2 o'clock news conference tomorrow afternoon. 


\title{
Appendix J \\ Anger Story \#1
}

\author{
By Anna Songh \\ Staff Writer \\ Milwaukee Journal Sentinel \\ Thursday, March 26, 2009
}

Immigration and Customs Enforcement (ICE) officials have confirmed that two men accused of murdering a teenage girl in Milwaukee are in the United States illegally. ICE released a statement this morning saying that two cousins accused of the murder have admitted to authorities they illegally crossed into the US from Mexico six months ago.

A spokeswoman for ICE tells us Alejandro Rivera Gamboa and Gilberto Ariano Gamboa are both on ICE detainers. That means whenever their criminal case wraps up, whether or not they are convicted, they would immediately be put in the custody of immigration officials and begin the deportation process. However, that process, which can take a few months, does not begin until after the criminal case concludes. The cousins were arraigned yesterday.

It's been just over a week now since 15-year-old Dani Countryman died. Meanwhile we are learning about some of the evidence authorities are using to connect these two men to the crime. According to court documents, a bloody shoe print on Dani's chest matched a shoe belonging to one of the suspects, Alejandro Rivera Gamboa. Also in the document, Alejandro told detectives his cousin, Gilberto Ariano Gamboa, was lying on top of Dani when she screamed for help, so Alejandro stepped on her throat until she stopped moving.

Dani's family praised the police for their work and says these men deserve the toughest punishment. "I'm for the death penalty and, uhh, as far as I'm concerned, that's what should happen to them," said Carl Barton, Dani's great-uncle. "You know, they've taken her life, and why should they be alive?"

The two suspects reportedly met Dani at a party the night before she died. Witnesses say they gave her beer and were grabbing Dani and other women inappropriately. Prior to this morning's confirmation from immigration officials, we only knew the men were on ICE holds, which does not automatically mean they are in the US illegally. The spokeswoman said that can mean that someone has a green card, but has committed a crime and is being investigated for deportation. But, again, these two men apparently admitted coming into the country illegally six months ago. 


\section{Appendix K \\ Anger Story \#2}

By Robert Walz

Staff Writer

Salt Lake Tribune

Thursday, March 26, 2009

An illegal immigrant might have your child's social security number right now and is using it to get a job in the United States, and maybe even obtain credit cards. That's rather frightening to think about.

The Utah Attorney General plans to start sending letters out to parents to let them know that someone may have stolen their child's identity. The letters will tell parents how to find out if someone is using their child's number and why kids are the most likely targets for social security identity theft.

Children receive a social security card at birth, but don't usually use it until they get a job. But according to Utah Attorney General Mark Shurtleff, kids and thousands of others in the State of Utah are the victims of an underground social security scam that puts their identifications into the hands of illegal immigrants. "The numbers are pretty staggering," Shurtleff said. "There are a lot of social security numbers out there of people in this state that have been compromised by someone."

The high number of illegal immigrants coming into Utah helped created a lucrative underground counterfeiting business where crooks can sale a fake social security card for $\$ 150$ each. "It's hard to catch them," Shurtleff explained. "They move around a lot. As soon as you get some information on them, they move. There are more of them than you probably think."

Adults usually find out about the identity theft because it shows up on their credit reports, but most people never think about their kids' accounts until they grow up and get a job. "The worst time to find out about that is when they're 18. They go to get a car loan. They go to get student loans. They go to do something important, and then they find out that their credit history is wrecked," Attorney General Shurtleff said.

Investigators don't know exactly how many illegal immigrants are currently using the social security numbers of Utah children. The number could exceed 20,000, according to estimates, though. You can check out your social security account and your child's account by going to the Social Security Administration webpage. If you fill in your information, a printed report of any activity about the number will come in the mail in about four weeks.

In some cases an illegal immigrant had used a child's social security number for years without anyone knowing. "It's the gateway to everything that one needs to establish themselves in this country," Shurtleff said. The attorney general's office plans to send out 
100 copies of this letter to parents in the state of Utah this week. They anticipate they'll be sending out many, many more. 


\section{Appendix L Anger Story \#3}

By Rebecca Thomas

Staff Writer

Arizona Republic

Thursday, March 26, 2009

Though we hear a lot about illegal immigration, rarely do we hear about how it affects the environment. Human smugglers and illegal immigrants, though, are turning the southern Arizona desert into a wasteland.

The vast Sonora desert looks serene and clean, until you look closer. "There are thousands of these lay up spots, all across southern Arizona," border patrol agent Mike Scioli explained. These sites are the result of human smuggling. Foot guides lead immigrants from the border to lay up sites in the southern Arizona dessert. "What they'll do is they'll either wait for another foot guide to take them further north, or they're waiting for vehicles to pick them up to carry them into the city of Phoenix."

While they wait, illegal immigrants litter. Empty water bottles, plastic jugs, aluminum cans, shoes, clothes, you name it. "The dessert looks harsh. It looks tough, but in fact it's pretty delicate. And there are a lot of creatures that live out there," said environmentalist Rob Smith of the Sierra Club. Smith explained that animals can eat or get caught in plastic bags which can be deadly. Smugglers abandon vehicles that can contaminate the soil and groundwater if it leaks oil or other fluids. Plastic bottles and aluminum cans aren't biodegradable, so they can stick around for decades.

We visited one particular lay up site about 25 minutes southeast of Chandler. At this time there isn't legislation in place to clean these areas up. The dirty work is left to concerned citizens who volunteer.

"This is part of the much larger problem of immigration reform which ultimately needs Congress to act on, or this is just one more symptom," said Republican State Representative Ward Nichols. He has seen the devastation from these lay up sites first hand in the wildlife refuges along the border. "It was one of the most shocking things I've ever seen."

Nichols says right now the state doesn't have the money to clean up lay up sites, and it won't until the border is secure and foot traffic has stopped. "I believe at that point we can say, ok, we're going to get in and we're going to actively clean these areas up," Representative Nichols stated. "We're going to actively continue to patrol them, and let the environment come back. Let the wildlife come back in the area." Until then, lay up sites will continue to grow, endangering our fragile desert ecosystem. 


\section{Appendix M \\ Sympathy Story \#1}

\section{By Phil Hamilton \\ Staff Writer \\ Los Angeles Times}

Thursday, March 26, 2009

Like most days, Anne Herrera comes straight home after school. But instead of hanging out with friends and doing typical teen things, these days she's doing the cooking, paying the bills, helping her younger cousins with their homework, and then going to work herself. That's because Anna's mother and aunt were taken away by Immigration and Customs Enforcement (ICE) agents in the middle of the night last week for being undocumented immigrants.

"I was so used to coming home from work, or just from school, or just from anywhere, and going into my mom's room and telling her I'm here, or giving her a goodnight kiss," Annie cried. "And it's hard to know that she's no longer in her room."

Anna says even with her grandmother trying to help out, all of the children are having a hard time. "It's been hard for me concentrating on work because sometimes I think about my mom, and how she might be doing over there. Sad without us being there with her."

Anna's mother and aunt are being held at a detention center in Los Angeles. In the meantime, her teachers and classmates have been trying to help raise money to hire an attorney. "My teacher, you know, opened an account, and we started a small organization called the United Family Fund," Anna said. "And we're raising money just to help children whose parents have been taken away to pay for, umm, legal help."

Anna knows many people won't have sympathy for her family's ordeal, seeing the issue as simple as you're legal or illegal. "No, it's not that simple," she stated. "I mean, I might not understand about politics or everything that's going on, but it's not that simple. There are families who are being split up. Little kids are being left without their parents, without their moms."

She is devastated that her mother will not see her graduate high school in three weeks, something she had always dreamed of. "She did so much and she worked so hard, and it is very, very, very hard. And, you know, I'm so proud of my mom, and I know I want her to be proud of me." One of Anna's teachers set up a bank account through Washington Mutual called the United Families Fund to try and help local families dealing with immigration issues. 


\section{Appendix N \\ Sympathy Story \#2}

By Thelma Guiterrez

Staff Writer

Los Angeles Times

Thursday, March 26, 2009

On the corner of a busy Los Angeles intersection, day laborers gather and wait for work. Manuel Barajas arrived at 6 AM. So did Pedro Pablo, and about 100 others. Nine hours later they are still waiting.

Manuel, who says he's in the country illegally, says he's desperate because he was two small children to feed in Mexico City, rent to pay here, and he hasn't worked more than three days in the last year. His brother helps to support him. He says he wants to go home, but can't even afford a ticket.

When asked if they're having similar problems, the men at the day laborer center all raise their hands. Jeronimo Salguero, director of the day laborer center, says employment has fallen off by as much as $75 \%$ this past year. "They come to the office and say, 'Jeronimo, please help me. I want to go back to my country.",

Pedro Pablo, also undocumented, is one of them. He says he's out of money and can't even afford rent, which is $\$ 117$ a month. He took us to his one bedroom apartment that he shares with seven other workers. They sleep on the floor in the barren and unfurnished apartment, but each of them has their space. Pablo sleeps in the corner next to the coat closet with no pillow or blanket, but he does have a picture of his family. Pablo says he supports a wife and five sons in Guatemala, but he hasn't been able to send any money home for four months. And that weighs heavily on him.

Professor Abel Valenzuela of the University of California at Los Angles explains, "You're seeing fewer immigrants from all over the world who are here in the United States sending fewer resources back home, right from where they come from. This can have a really, really big impact on those countries that are most vulnerable economically speaking."

Pablo has decided to leave. The Guatemalan consulate gave him a one way bus ticket home. He takes with him a duffel bag, and an unfulfilled dream to make it in America. Until then, he goes back to the corner to wait for work. He says when he returns to his family empty-handed, he will ask for forgiveness. 


\section{Appendix 0 \\ Sympathy Story \#3}

By Chris Jones

Staff Writer

New York Times

Thursday, March 26, 2009

Authorities in New York are out looking for three people they say launched a vicious attack on an Ecuadorian immigrant on a street corner in Brooklyn, leaving him braindead. The 31-year-old victim was walking with his brother early Sunday morning, when witnesses and the police say the assailants began shouting anti-gay and anti-Hispanic slurs, then beat him with a baseball bat.

Local leaders quickly denounced the murder. "Let us stand together and let us denounce in no uncertain terms these acts of violence," the Reverend Herb Daughtry said in a statement. Police in New York are investigating the case as a homicide, and have also gotten the city's hate crimes task force involved.

Authorities haven't named any suspects, and are asking for help in locating a livery cab driver. Fernando Mateo of Hispanics Across America released a statement, saying, "We believe that he has information that could help the police department in solving this issue." The police are also offering a $\$ 22,000$ reward for any information leading to the arrest and conviction of the attackers. 


\section{Bibliography}

Abelson, Robert P., Donald R. Kinder, Mark D. Peters, and Susan T. Fiske. 1982. "Affective and Semantic Components in Political Person Perception." Journal of Personality and Social Psychology 42: 619-630.

Alvarez, R. Michael. 1997. Information and Elections. Ann Arbor: University of Michigan Press.

Anderson, John R. 1983. The Architecture of Cognition. Cambridge: Harvard University Press.

Ansolabehere, Stephen and Shanto Iyengar. 1995. Going Negative: How Political Ads Shrink and Polarize the Electorate. New York: The Free Press.

Aristotle. 1954. Rhetoric. Translation W. R. Roberts. New York: Modern Library.

Arkes, Hadley P. 1993. "Can Emotion Supply the Place of Reason?" In Reconsidering the Democratic Public, ed. George E. Marcus and Russell L. Hanson. University Park: Penn State University Press, pp. 287-305.

Arnold, Magda B. 1950. "An Excitatory Theory of Emotion.” In Feelings and Emotions, ed. M. L. Reymert. The Mooseheart Symposium. New York: McGraw-Hill.

Arnold, Magda B. 1960. Emotion and Personality. New York: Columbia University Press.

Bargh, James A. 1997. "The Automaticity of Everyday Life." In Advances in Social Cognition, ed. Robert S. Wyer. Mahwah: Erlbaum, pp. 1-61.

Bargh, John A. and Tanya L. 2000. "The Mind in the Middle: A Practical Guide to Priming and Automaticity Research." In Handbook of Research Methods in Social and Personality Psychology, ed. Harry T. Reis and Charles M. Judd. New York: Cambridge University Press, pp. 253-285.

Bartels, Larry M. 1996. "Uninformed Votes: Information Effects in Presidential Elections." American Journal of Political Science 40:194-230.

Bassili, John N. and Joseph F. Fletcher. 1991. "Response-Time Measurement in Survey Research: A Method for CATI and a New Look at Nonattitudes." Public Opinion Quarterly 55: 331-346.

Baum, Matthew A. 2002. "Sex, Lies and War: How Soft News Brings Foreign Policy to the Inattentive Public." American Political Science Review 96: 91-109. 
Baum, Matthew A. 2003. Soft News Goes to War: Public Opinion and American Foreign Policy in the New Media Age. Princeton: Princeton University Press.

Beck, Aaron T. 1976. Cognitive Therapy and the Emotional Disorders. New York: International Universities Press.

Bennett, W. Lance. 2003. "The Burglar Alarm that Just Keeps Ringing: A Response to Zaller." Political Communication 20: 131-138.

Berelson, Bernard R., Paul F. Lazarsfeld and William N. McPhee. 1954. Voting. Chicago: University of Chicago Press.

Berenbaum, Howard, Franl Fujita, and Joyce Pfenning. 1995. "Consistency, Specificity, and Correlates of Negative Emotions." Journal of Personality and Social Psychology 68: 342-252.

Berkowitz, Leonard. 2003. "Affect, Aggression, and Antisocial Behavior." In The Handbook of Affective Sciences, ed. Richard J. Davidson, Klaus R. Scherer, and H. Hill Goldsmith. Oxford: Oxford University Press, pp. 804-823.

Berry, Charles and Hans-Bernd Brosius. 1991. "On the Multiple Effects of Visual Format on TV News Learning." Applied Cognitive Psychology 5: 519-528.

Biocca, Frank. 1991. "The Role of Communication Codes in Political Ads.” In Television and Political Advertising: Signs, Codes, and Images, ed. Frank Biocca. Hillsdale: Erlbaum.

Bower, Gordon H. 1981. "Mood and Memory.” American Psychologist 36: 129-148.

Brader, Ted. 2006. Campaigning for Hearts and Minds: How Emotional Appeals in Political Ads Work. Chicago: University of Chicago Press.

Brady, Henry E. and Richard Johnston, eds. 2006. Capturing Campaign Effects. Ann Arbor: University of Michigan Press.

Brady, Henry E. and Paul M. Sniderman. 1985. "Attitude Attribution: A Group Basis for Political Reasoning.” American Political Science Review 79:1061-1078.

Brants, Kees. 1998. "Who's Afraid of Infotainment?" European Journal of Communication 13: 315-335.

Brians, Craig Leonard and Martin O. Wattenberg. 1996. "Campaign Issue Knowledge and Salience: Comparing Reception from TV Commercials, TV News and Newspapers." American Journal of Political Science 40: 172-193. 
Cacioppo, John T. and Gary G. Berntson. 1994. "Relationship between Attitudes and Evaluative Space: A Critical Review, with Emphasis on the Separability of Positive and Negative Substrates." Psychology Bulletin 115: 401-423.

Cacioppo, John T. and Gary G. Berntson. 1999. "The Affect System: Architecture and Operating Characteristics." Current Directions in Psychological Science 8: 133137.

Cacioppo, John T., Wendi K. Gardner, and Gary G. Berntson. 1997. "Beyond Bipolar Conceptualizations and Measures of Attitudes and Evaluative Space." Personality and Social Psychology Review 1: 3-25.

Cacioppo, John T., Wendi K. Gardner, and Gary G. Berntson. 1999. "The Affect System has Parallel and Integrative Processing Components: Form Follows Function." Journal of Personality and Social Psychology 76: 839-855.

Campbell, Angus, Philip E. Converse, Warren E. Miller and Donald E. Stokes. 1960. The American Voter. Chicago: University of Chicago Press.

Campbell, David E. 2006. "Religious 'Threat' in Contemporary Presidential Elections." Journal of Politics 68: 104-115.

Carmines, Edward G. and James H. Kuklinski. 1990. "Incentives, Opportunities, and the Logic of Public Opinion in American Political Representation." In Information and Democratic Processes, ed. John Ferejohn and James Kuklinski. UrbanaChampaign: University of Illinois Press.

Carsey, Thomas M. 2001. Campaign Dynamics: The Race for Governor. Ann Arbor: University of Michigan Press.

Cassino, Dan and Milton Lodge. 2007. "The Primacy of Affect in Political Evaluations." In The Affect Effect: Dynamics of Emotion in Political Thinking and Behavior, ed. W. Russell Neuman, George E. Marcus, Ann N. Crigler, and Michael MacKuen. Chicago: The University of Chicago Press.

Christianson, Sven-Ake and Elisabeth Engelberg. 1999. "Memory and Emotion: The MS Estonia Ferry Disaster.” Memory 7: 471-482.

Civettini, Andrew J.W. and David P. Redlawsk. 2009. "Voters, Emotions, and Memory." Political Psychology 30: 125-151.

Clarke, Simon, Paul Hoggett, and Simon Thompson. 2006. "The Study of Emotion: An Introduction." In Emotion, Politics, and Society, ed. Simon Clarke, Paul Hoggett, and Simon Thompson. New York: Palgrave Macmillan. 
Clore, Gerald L. 1994. "Why Emotions Require Cognition." In The Nature of Emotion: Fundamental Questions, ed. Paul Ekman and Richard J. Davidson. New York: Oxford University Press, pp. 181-191.

Clore, Gerald L. and Andrew Ortony. 2000. "Cognition in Emotion: Always, Sometimes, or Never?" In Cognitive Neuroscience of Emotion, ed. Richard D. Lane and Lynn Nadel. New York: Oxford University Press.

Cohen, Jacob, Patricia Cohen, Stephen G. West, and Leona S. Aiken. 2003. Applied Multiple Regression/Correlation Analysis for the Behavioral Sciences, $3^{\text {rd }}$ ed. Mahwah: Lawrence Erlbaum.

Collins, Allan M. and Elizabeth F. Loftus. 1975. "A Spreading Activation Theory of Semantic Memory." Psychological Review 82: 407-428.

Collins, Allan M. and M. Ross Qullian. "Retrieval Time from Semantic Memory." Journal of Verbal Learning and Verbal Memory 8: 240-247.

Conover, Pamela Johnston and Stanley Feldman. 1986. "Emotional Reactions to the Economy: I'm Mad as Hell and I'm Not Going to Take it Anymore." American Journal of Political Science 30: 50-78.

Converse, Philip E. 1962. "Information Flow and the Stability of Partisan Attitudes." Public Opinion Quarterly 26: 578-599.

Converse, Philip E. 1964. "The Nature of Belief Systems in Mass Publics." In Ideology and Discontent, ed. David E. Apter. New York: Free Press.

Converse, Philip E. 1990. "Popular Representation and the Distribution of Information." In Information and Democratic Processes, ed. John Ferejohn and James Kuklinski. Urbana: University of Illinois Press, pp. 367-288.

Cook, Timothy E. 2005. Governing with the News: The News Media as a Political Institution. Chicago: University of Chicago Press.

Corteen, Raymond S. and B Wood. 1972. "Autonomic Responses to Shock-Associated Words in Unattended Channel." Journal of Experimental Psychology 94: 308313.

Crigler, Ann N., Marion Just, and W. Russell Neuman. 1994. "Interpreting Visual versus Audio Messages in Television News." Journal of Communication 44: 132-149.

Damasio, Antonio. 1994. Descartes' Error: Emotion, Reason, and the Human Brain. New York: Harper Collins. 
Damasio, Antonio. 1999. The Feelings of What Happens: Body and Emotion in the Making of Consciousness. New York: Harvest Books.

Davidson, Richard J. 1994. "On Emotion, Mood and Related Affective Constructs." In The Nature of Emotion: Fundamental Questions, ed. Paul Ekman and Richard J. Davidson. New York: Oxford University Press.

Davidson, Richard J., Paul Ekman, Clifford D. Saron, Joseph A. Senulis, and Wallace V. Friesen. 1990. "Approach-Withdrawal and Cerebral Asymmetry: Emotional Expression and Brain Physiology I." Journal of Personality and Social Psychology 58: 330-341.

Delli Carpini, Michael X. and Scott Keeter. 1996. What Americans Know about Politics and Why It Matters. New Haven: Yale University Press.

Dolan, Kathleen A. and Thomas M. Holbrook. 2001. "Knowing Versus Caring: The Role of Affect and Cognition in Political Perceptions." Political Psychology 22: 27-44.

Druckman, Jamie. 2003 "The Power of Television Images: The First Kennedy-Nixon Debate Revisited." The Journal of Politics 65: 559-571.

Edwards, Kari. 1990. "The Interplay of Affect and Cognition in Attitude Formation and Change." Journal of Personality and Social Psychology 59: 202-216.

Ekman, Paul. 1982. Emotion in the Human Face. New York: Cambridge University Press.

Ekman, Paul. 1994. "Moods, emotions, and traits." In The Nature of Emotion: Fundamental Questions, ed. Paul Ekman and Richard J. Davidson. New York: Oxford University Press, pp. 56-58.

Ellsworth, Phoebe C. 1991. "Some Implications of Cognitive Appraisal Theories of Emotion." In International Review of Research on Emotion, ed. K.T. Strongman. New York: Wiley, pp 143-161.

Ellsworth, Phoebe C. 1994. "Levels of Thought and Levels of Emotion." In The Nature of Emotion: Fundamental Questions, ed. Paul Ekman and Richard J. Davidson. New York: Oxford University Press, pp. 192-196.

Eysenck, Michael W. and Angela Byrne. 1992. "Anxiety and Susceptibility to Distraction." Personality and Individual Differences 13: 793-798.

Fabrigar, Leandre R., Pennt S. Visser, and Michael W. Browne. 1997."Conceptual and Methodological Issues in Testing the Circumplex Structure in Data in Personality and Social Psychology." Personality and Social Psychology Review 1: 184-203. 
Fazio, Russell H. 1990. "A Practical Guide to the Use of Response Latency in Social Psychological Research.” In Review of Personality and Social Psychology, ed. Clyde Hendrick and Margaret S. Clark. Newbury Park: Sage, pp. 74-97.

Fazio, Russell H, Martha C. Powell, and Paul M. Herr. 1983. "Toward a Process Model of the Attitude-Behavior Relation: Accessing One's Attitude upon Mere Observation of the Attitude Object." Journal of Personality and Social Psychology 44: 723-735.

Fazio, Russell H. and Carol J. Williams. 1986. "Attitude Accessibility as a Moderator of the Attitude-Perception and Attitude-Behavior Relations: An Investigation of the 1984 Presidential Election." Journal of Personality and Social Psychology 51: 505-514.

Fiske, Susan T., Donald R. Kinder and W. Michael Larter. 1983. "The Novice and the Expert: Knowledge-Based Strategies in Political Cognition." Journal of Experimental Social Psychology 19:381-400.

Fiske, Susan T. and Shelley E. Taylor. 1991. Social Cognition. New York: McGraw-Hill.

Franz, Michael M., Paul B. Freedman, Kenneth M. Goldstein, and Travis N. Ridout. 2008. Campaign Advertising and American Democracy. Philadelphia: Temple University Press.

Freedman, Paul, Michael M. Franz, and Kenneth Goldstein. 2004. "Campaign Advertising and Democratic Citizenship." American Journal of Political Science 48: 723-741.

Freud, Sigmund. 1915. "Instincts and Their Vicissitudes." In Sigmund Freud: Collected Papers, Volume 4, ed. E. Jones. New York: Basic Books, pp. 60-83.

Fricker, Scott, Mirta Galesic, Roger Tourangeau, and Ting Yan. 2005. "An Experimental Comparison of Web and Telephone Surveys." Public Opinion Quarterly 69: 370392.

Frijda, Nico H. 1986. The Emotions. Cambridge: Cambridge University Press.

Frijda, Nico H. 1994. "Emotions Require Cognitions, Even If Simple Ones." In The Nature of Emotion: Fundamental Questions, ed. Paul Ekman and Richard J. Davidson. New York: Oxford University Press, pp. 187-202.

Forgas, Joseph P. 1995. "Mood and Judgment: The Affect Infusion Model (AIM)." Psychological Bulletin 117: 39-66.

Geer, John G. 2006. In Defense of Negativity: Attack Ads in Presidential Campaigns. Chicago: University of Chicago Press. 
Gelman, Andrew, and Gary King. 1993. "Why Are American Presidential Polls So Variable When Vote Are So Predictable?" British Journal of Political Science 23: 409-451.

Glaser, Jack M. 1994. "Back to the Black Belt: Racial Environment and White Racial Attitudes in the South." Journal of Politics 56: 21-41.

Goren, Paul. 1997. "Gut-Level Emotions and the Presidential Vote." American Politics Research 25: 203-229.

Grabe, Maria Elizabeth and Erik Page Bucy. 2009. Image Bite Politics: News and the Visual Framing of Elections. Oxford: Oxford University Press.

Graber, Doris A. 1994. "Why Voters Fail Information Tests: Can the Hurdles Be Overcome?" Political Communication 11: 331-346.

Graber, Doris A. 2001. Processing Politics: Learning from Television in the Internet Age. Chicago: University of Chicago Press.

Graber, Doris A. 2004. "Mediated Politics and Citizenship in the Twenty-First Century." Annual Review of Psychology 55: 545-571.

Gray, Elizabeth and David Watson. 2001. "Emotion, Mood and Temperament: Similarities, Differences and a Synthesis." In Emotions at Work: Theory, Research and Applications in Management, ed. Roy L. Payne and Cary L. Cooper. West Sussex: Wiley.

Gray, Elizabeth K. and David Watson. 2007. "Assessing Positive and Negative Affect via Self-Report." In Handbook of Emotion Elicitation and Assessment, ed. James A. Coan and John J.B. Allen. Oxford: Oxford University Press.

Gray, Jeffrey A. 1987. The Psychology of Fear and Stress. Cambridge: Cambridge University Press.

Greene, Steven. 2002. "The Socio-Psychological Measurement of Partisanship." Political Behavior 24: 171-197.

Gregory, Richard L. 1997. Eye and Brain: The Psychology of Seeing. Princeton: Princeton University Press.

Haidt, John. 2003. "The Moral Emotions." In The Handbook of Affective Sciences, ed. Richard J. Davidson, Klaus R. Scherer, and H. Hill Goldsmith. Oxford: Oxford University Press, pp. 871-890.

Hamilton, James T. 2004. All the News That's Fit to Sell: How the Market Transforms Information into News. Princeton: Princeton University Press. 
Hamm, Alfons O., Harald T. Schupp, and Almut I. Weike. 2003. "Motivational Organization of Emotions: Autonomic Changes, Cortical Responses, and Reflex Modulation." In The Handbook of Affective Sciences, ed. Richard J. Davidson, Klaus R. Scherer, and H. Hill Goldsmith. Oxford: Oxford University Press.

Heerwegh, Dirk. 2003. "Explaining Response Latencies and Changing Answers Using Client-Side Paradata from a Web Survey." Social Science Computer Review 21: 360-373.

Heuer, Friderike and Daniel Reisberg. 1992. "Flashbulbs and Memory for Detail from Emotional Events." In Affect and Accuracy in Recall: The Problem of "Flashbulb" Memories, ed. Eugene Winograd and Ulric Neisser. New York: Cambridge University Press, pp. 162-190.

Hitchon, Jacqueline C. and ChingChing Chang. 1995. "Effects of Gender Schematic Processing on the Reception of Political Commercials for Men and Women Candidates." Communication Research 22: 430-458.

Hobbes, Thomas. 1968. Leviathan. London: Penguin Books.

Huckfeldt, Robert, Paul E. Johnson, and John Sprague. 2004. Political Disagreement: The Survival of Diverse Opinions within Communication Networks. Cambridge: Cambridge University Press.

Huckfeldt, Robert and John Sprague. 1995. Citizens, Politics and Social Communication: Information and Influence in an Election Campaign. Cambridge: Cambridge University Press.

Huddy, Leonie, Stanley Feldman, and Erin Cassese. 2007. "On the Distinct Political Effects of Anxiety and Anger." In The Affect Effect: Dynamics of Emotion in Political Thinking and Behavior, ed. W. Russell Neuman, George E. Marcus, Ann N. Crigler, and Michael MacKuen. Chicago: The University of Chicago Press.

Huddy, Leonie, Stanley Feldman, Charles Taber, and Gallya Lahav. 2005. "Threat, Anxiety, and Support of Antiterrorism Policies." American Journal of Political Science 49: 593-608.

Huddy, Leonie, Jeffrey M. Jones, and Richard E. Chard. 2001. "Compassionate Politics: Support for Old-Age Programs Among the Non-Elderly." Political Psychology 22: 443-471.

Hume, David. 1975. Enquiries Concerning Human Understanding and Concerning the Principles of Morals, $3^{\text {rd }}$ ed. Oxford: Clarendon Press.

Isbell, Linda M., Victor C. Ottati, and Kathleeen C. Burns. 2006. "Affect and Politics: Effects on Judgment, Processing, and Information Seeking." In Feeling Politics: 
Emotion in Political Information Processing, ed. David P. Redlawsk. New York: Palgrave Macmillan.

Isen, Alice M, Thomas E. Shalker, Margaret Clark, and Lynn Karp. 1978. "Affect, Accessibility of Material in Memory, and Behavior: A Cognitive Loop?" Journal of Personality and Social Psychology 36: 1-12.

Jamieson, Kathleen Hall. 1996. Packaging the Presidency: A History and Criticism of Presidential Campaign Advertising. Oxford: Oxford University Press.

Jamieson, Kathleen Hall and Paul Waldman. 2003. The Press Effect: Politicians, Journalists, and the Stories that Shape the Political World. New York: Oxford University Press.

Jervis, Richard. "Political Implications of Loss Aversion." Political Psychology 13: 187204.

Johnson, Eric J. and Amos Tversky. 1983. "Affect, Generalization, and The Perception of Risk." Journal of Personality and Social Psychology 45: 20-31.

Jones, Alex. 2009. Losing the News. Oxford: Oxford University Press.

Just, Marion R., Ann N. Crigler, and Lori Wallach. 1990. "Thirty Seconds or Thirty Minutes: What Viewers Learn from Spot Advertisements and Candidate Debates." Journal of Communication 40: 120-133.

Kahneman, Daniel and Amos Tversky. 1979. "Prospect Theory: An Analysis of Decision Under Risk.” Econometrica 47: 263-291.

Kaid, Lynda Lee. 1991. "Ethical Dimensions of Political Advertising." In Ethical Dimensions of Political Communication, ed. Robert E. Denton, Jr. New York: Praeger, pp. 145-199.

Kaid, Lynda Lee and Anne Johnston. 1991. "Negative versus Positive Television Advertising in U.S. Presidential Campaigns, 1960-1988." Journal of Communication 41: 53-64.

Kam, Cindy D. 2006. "Political Campaigns and Open-Minded Thinking." Journal of Politics 68: 931-45.

Kern, Montague. 1989. 30-Second Politics: Political Advertising in the Eighties. New York: Praeger.

Key, V.O. 1949. Southern Politics in State and Nation. Knoxville: The University of Tennessee Press. 
Kinder, Donald R. 2003. "Communication and Politics in the Age of Information." In Oxford Handbook of Political Psychology, ed. Leonie Huddy, Robert Jervis, and David O. Sears. New York: Oxford University Press, pp. 357-393.

Kitayama, Shinobu. 1991. "Impairment of Perception by Positive and Negative Affect." Cognition and Emotion 5: 255-274.

Krosnick, John A. 1991. "Response Strategies for Coping with the Cognitive Demands of Attitude Measures in Surveys." Applied Cognitive Psychology 5: 213-236.

Krosnick, John A. and Duane F. Alwin. 1987. "An Evaluation of A Cognitive Theory of Response-Order Effects in Survey Measurement." Public Opinion Quarterly 51: 201-209.

Lang, Annie and Marian Friestad. 1993. "Emotion, Hemispheric Specialization, and Visual and Verbal Memory for Television Images." Communication Research 20: 647-670.

Lang, Peter J. 1988. "What are the Data of Emotion?" In Cognitive Science Perspectives on Emotion and Motivation, ed. Vernon Hamilton, Gordon H. Bower, and Nico H. Frijda. Amsterdam: Martinus Nijhoff, pp. 173-194.

Lang, Peter J., Mark K. Greenwald, Margaret M. Bradley, and Alfons O. Hamm. 1993. "Looking at Pictures: Affective, Facial, Visceral and Behavioral Reactions." Psychophysiology 30: 261-273.

Larsen, Randy J. and Edward Diener. 1992. "Promises and Problems with the Circumplex Model of Emotions." In Emotion, ed. Margaret S. Clark. Newbury Park: Sage.

Lau, Richard R. 1989. "Construct Accessibility and Electoral Choice." Political Behavior 11: 5-32.

Lau, Richard R. and Gerald M. Pomper. 2004. Negative Campaigning: An Analysis of U.S. Senate Elections. Lanham: Rowman and Littlefield.

Lau, Richard R. and Ivy Brown Rovner. 2009. "Negative Campaigning." Annual Review of Political Science 12: 285-306.

Lau, Richard R., Lee Sigelman, and Ivy Brown Rovner. 2007. The Effect of Negative Political Campaigns: A Meta-Analytic Reassessment. Journal of Politics 69: 1176-209.

Lazarsfeld, Paul F., Bernard R. Berelson, and Hazel Gaudet. 1948. The People's Choice: How the Voter Makes up His Mind in a Presidential Campaign. New York: Columbia University Press. 
Lazarus, Richard S. 1982. "Thoughts on the Relation between Emotion and Cognition." American Psychologist 37: 1019-1024.

Lazarus, Richard S. 1984. "On the Primacy of Cognition." American Psychologist 39: 124-129.

Lazarus, Richard S. 1991. Emotion and Adaptation. New York: Oxford University Press.

Lazarus, Richard S. 2001. "Relational Meaning and Discrete Emotions." In Appraisal Processes in Emotion: Theory, Methods, Research, ed. Klaus R. Scherer, Angela Schorr, and Tom Johnstone. Oxford: Oxford University Press, pp. 37-67.

Lazarus, Richard, James Averill, and Edward Opton. 1970. "Toward a Cognitive Theory of Emotion." In Feelings and Emotions, ed. Magda Arnold. New York: Academic Press.

Le Bon, Gustav. 1952. The Crowd. London: Ernest Benn.

LeDoux, Joseph. 1996. The Emotional Brain: The Mysterious Underpinnings of Emotional Life. New York: Simon and Schuster.

Leichtman, Michelle D., Stephen J. Ceci, and Peter A. Ornstein. 1992. "The Influence of Affect on Memory: Mechanism and Development." In The Handbook of Emotion and Memory: Research and Theory, ed. Sven-Ake Christianson. Hillsdale: Lawrence Erlbaum, pp. 181-199.

Levenson, Robert W. 1994. "Human Emotion: A Functional View." In The Nature of Emotion: Fundamental Questions, ed. Paul Ekman and Richard J. Davidson. New York: Oxford University Press, pp. 123-126.

Lewis, Carolyn D. 1984. Reporting for Television. New York: Columbia University Press.

Lodge, Milton, Kathleen M. McGraw, and Patrick Stroh. 1989. "An Impression-Driven Model of Candidate Evaluation." American Political Science Review 83: 399-419.

Lodge, Milton and Charles S. Taber. 2000. "Three Steps Toward a Theory of Motivated Political Reasoning." In Elements of Reason: Cognition, Choice, and the Bounds of Rationality, ed. Arthur Lupia, Michael McCubbins, and Samuel Popkin. Cambridge: Cambridge University Press.

Lodge, Milton and Charles S. Taber. 2005. "The Automaticity of Affect for Political Leaders, Groups, and Issues: An Experimental Test of the Hot Cognition Hypothesis." Political Psychology 26: 455-482. 
Long, J. Scott and Jeremy Freese. 2006. Regression Models for Categorical Dependent Variables, $2^{\text {nd }}$ ed. College Station: Stata Press.

Lupia, Arthur. 1994. "Short Cuts versus Encylopedias: Information and Voting Behavior in California Insurance Reform Elections." American Political Science Review 88:63-76.

Mackie, Diane M., Thierry Devos, and Eliot R. Smith. 2000. "Intergroup Emotions: Explaining Offensive Action Tendencies in an Intergroup Context." Journal of Personality and Social Psychology 79: 602-616.

MacKenzie, Scott B. 1998. "Context is Key: The Effect of Program-Induced Mood on Thoughts about The Ad." Journal of Advertising 27: 17-31.

MacLeod, Colin and Andrew Matthews. 1988. "Anxiety and the Allocation of Attention to Threat." Quarterly Journal of Experimental Psychology 38: 653-670.

Marcus, George E. 2002. The Sentimental Citizen: Emotion in Democratic Politics. University Park: The Pennsylvania State University Press.

Marcus, George E. and Michael MacKuen. 1993. "Anxiety, Enthusiasm, and the Vote: The Emotional Underpinnings of Learning and Involvement During Presidential Campaigns." American Political Science Review 87: 672-685.

Marcus, George E., Michael MacKuen, Jennifer Wolak, and Like Keele. 2006. "The Measure and Mismeasure of Emotion.” In Feeling Politics: Emotion in Political Information Processing, ed. David P. Redlawsk. New York: Palgrave Macmillan.

Marcus, George E., W. Russell Neuman, and Michael B. MacKuen. 2000. Affective Intelligence and Political Judgment. Chicago: University of Chicago Press.

Marcus, George E., W. Russell Neuman, Michael B. MacKuen, and John L. Sullivan. 1996. "Dynamic Models of Emotional Response: The Multiple Role of Affect in Politics." In Research in Micropolitics, ed. Michael Delli Carpini, Leonie Huddy, and Robert Y. Shapiro. Greenwich: JAI, pp. 33-59.

Marmor-Lavie, Gailt and Gabriel Weimann. 2005. "Measuring Emotional Appeals in Israeli Election Campaigns." International Journal of Public Opinion Research 18: 318-339.

McDermott, Rose. 1998. Risk-Taking in International Politics: Prospect Theory in American Foreign Policy. Ann Arbor: University of Michigan Press.

McGaugh, James L. 2003. Memory and Emotion: The Making of Lasting Memories. New York: Columbia University Press. 
McGaugh, James L. and Larry Cahill. 2003. "Emotion and Memory: Central and Peripheral Contributions." In The Handbook of Affective Sciences, ed. Richard J. Davidson, Klaus R. Scherer, and H. Hill Goldsmith. Oxford: Oxford University Press, pp. 93-116.

McGraw, Kathleen M., Milton Lodge, and Patrick Stroh. 1990. "On-Line Processing in Candidate Evaluation: The Effects of Issue Order, Issue Salience, and Sophistication." Political Behavior 12: 41-58.

McQuail, Denis. 1997. Audience Analysis. Thousand Oaks: Sage.

Mesquita, Batja and Phoebe C. Ellsworth. 2001. "The Role of Culture in Appraisal." In Appraisal Processes in Emotion: Theory, Methods, Research, ed. Klaus R. Scherer, Angela Schorr, and Tom Johnstone. Oxford: Oxford University Press, pp. 233-248.

Messaris, Paul 1994. Visual Literacy: Image, Mind, and Reality. Boulder: Westview Press.

Mineka, Susan and Steven K. Sutton. 1992. "Cognitive Biases and Emotional Disorders." Psychological Science 3: 65-69.

Murphy, Sheila T. and Robert B. Zajonc. 1992. "Affect, Cognition, and Awareness: Affective Priming with Suboptimal and Optimal Stimulus." Journal of Personality and Social Psychology 64: 723-739.

Mutz, Diana C. 2002. "Cross-Cutting Social Networks: Testing Democratic Theory in Practice.” American Political Science Review 96: 111-126.

Nabi, Robin L. 1999. "A Cognitive-Functional Model for the Effects of Discrete Negative Emotions on Information Processing, Attitude Chance, and Recall." Communication Theory 9: 292-320.

Nabi, Robin L. 2003. "Exploring the Framing Effects of Emotion: Do Discrete Emotions Differentially Influence Information Accessibility, Information Seeking, and Policy Preference?" Communication Research 30: 224-247.

Nelson, John S. and G. Robert Boynton. 1997. Video Rhetorics: Televised Advertising in American Politics. Urbana: University of Illinois Press.

Nesbit, Dorothy. 1988. Videostyle in Senate Campaigns. Knoxville: University of Tennessee Press.

Neuman, W. Russell. 1986. The Paradox of Mass Politics. Cambridge: Harvard University Press. 
Neuman, W. Russell, George E. Marcus, Ann N. Crigler, and Michael MacKuen. 2007. "Theorizing Affect's Effects." In The Affect Effect: Dynamics of Emotion in Political Thinking and Behavior, ed. W. Russell Neuman, George E. Marcus, Ann N. Crigler, and Michael MacKuen. Chicago: The University of Chicago Press.

Norris, Pippa. 2000. A Virtuous Cycle: Political Communications in Postindustrial Societies. Cambridge: Cambridge University Press.

Nussbaum, Martha C. 2004. Hiding from Humanity: Shame, Disgust, and the Law. Princeton: Princeton University Press.

Ortony, Andrew, Gerald L. Clore, and Allan Collins. 1988. The Cognitive Structure of Emotions. Cambridge: Cambridge University Press.

Ortony, Andrew, Terence J. Turner, and Stephen J. Antos. 1983. "A Puzzle about Affect for Recognition Memory." Journal of Experimental Psychology: Learning, Memory, and Cognition 9: 725-729.

Ottati, Victor C., Marco R. Steenbergen, and Ellen Riggle. 1992. "The Cognitive and Affective Components of Political Attitudes: Measuring the Determinants of Candidate Evaluations." Political Behavior 14: 423-442.

Padilla-Walker, Laura Maria and Debra Ann Poole. 2002. "Memory for Previous Recall: A Comparison of Free and Cued Recall." Applied Cognitive Psychology 16: 515524.

Pagano, Sabrina J. and Yuen J. Huo. 2007. "The Role of Moral Emotions in Predicting Support for Political Actions in Post-War Iraq." Political Psychology 28: 227255.

Paivio, Allen. 1979. Imagery and Verbal Processes. Hillsdale: Erlbaum.

Parkinson, Brian, Peter Totterdell, Rob Brinner, and Shirley Reynolds. 1996. Changing Moods: The Psychology of Mood and Mood Regulation. London: AddisonWesley Longman.

Patterson, Thomas. 1994. Out of Order. New York: Vintage.

Patterson, Thomas E. and Robert D. McClure. 1976. The Unseeing Eye: The Myth of Television Power in National Elections. New York: Putnam.

Perloff, Richard M. and Dennis Kinsey. 1992. "Political Advertising and Seen by Consultants and Journalists." Journal of Advertising Research 32: 53-60.

Plato. 1974. The Republic, $2^{\text {nd }}$ ed. Translation D. Lee. New York: Penguin. 
Plutchik, Robert and Hope R. Conte. 1997. Circumplex Models of Personality and Emotions. Washington, D.C.: American Psychological Association.

Popkin, Samuel L. 1991. The Reasoning Voter: Communication and Persuasion in Presidential Campaigns. Chicago: University of Chicago Press.

Prior, Markus. 2007. Post-Broadcast Democracy: How Media Choice Increases Inequality in Political Involvement and Polarizes Elections. Cambridge: Cambridge University Press.

Pryluck, Calvin. 1976. Sources of Meaning in Motion Pictures and Television. New York: Arno Press.

Rahn, Wendy M. 2000. "Affect as Information: The Role of Public Mood in Political Reasoning." In Elements of Reasoning: Cognition, Choice, and the Bounds of Rationality, ed. Arthur Lupia, Matthew D. McCubbins, and Samuel L. Popkin. Cambridge: Cambridge University Press.

Rahn, Wendy M., John H. Aldrich, and Eugene Borgida. 1994. "Individual and Contextual Variations in Political Candidate Appraisal." American Political Science Review 88: 193-199.

Rahn, Wendy M., John H. Aldrich, Eugene Borgida, and John L. Sullivan. 1990. “A Social-Cognitive Model of Candidate Appraisal." In Information and Democratic Processes, ed. John Ferejohn and James Kuklinski. Urbana-Champaign: University of Illinois Press.

Redlawsk, David P. 2002. "Hot Cognition or Cool Consideration> Testing the Effects of Motivated Reasoning on Political Decision Making." The Journal of Politics 64: 1021-1044.

Redlawsk, David P. 2006. "Feeling Politics: New Research into Emotion and Politics." In Feeling Politics: Emotion in Political Information Processing, ed. David P. Redlawsk. New York: Palgrave Macmillan.

Redlawsk, David P., Andrew J.W. Civenttini, and Richard Lau. 2007. "Affective Intelligence and Voting: Information Processing and Learning in a Campaign." In The Affect Effect: Dynamics of Emotion in Political Thinking and Behavior, ed. W. Russell Neuman, George E. Marcus, Ann N. Crigler, and Michael MacKuen. Chicago: The University of Chicago Press.

Redlawsk, David P. and Richard R. Lau. 2003. "Do Voters Want Candidates They Like or Candidates They Agree With? Affect versus Cognition in Voter Decision Making." Paper presented at the Shambaugh Conference on Affect and Cognition in Political Action, March 6-9, University of Iowa, Iowa City, IA. 
Remington, Nancy A., Leandre R. Fabrigar, and Penny S. Visser. 2000. "Reexamining the Circumplex Model of Affect." Journal of Social Psychology 79: 286-300.

Richardson, Glenn W., Jr. 2003. Pulp Politics: How Political Advertising Tells the Stories of American Politics. Lanham: Rowman and Littlefield.

Robinson, Michael D. and Gerald L. Clore. 2002. "Belief and Feeling: Evidence for an Accessibility Model of Emotional Self-Report." Psychological Bulletin 6: 934960.

Roseman, Ira J. 1984. "Cognitive Determinants of Emotions: A Structural Theory." In Review of Personality and Social Psychology, ed. Phillip R. Shaver. Beverly Hills: Sage.

Roseman, Ira J., Ann A. Antoniou, and P. E. Jose. 1996. "Appraisal Determinants of Emotions: Constructing a More Accurate and Comprehensive Theory." Cognition and Emotion 10: 241-277.

Rozin, Paul. 2003. "Introduction: Evolutionary and Cultural Perspectives on Affect." In The Handbook of Affective Sciences, ed. Richard J. Davidson, Klaus R. Scherer, and H. Hill Goldsmith. Oxford: Oxford University Press.

Russell, James A. 1980. "A Circumplex Model of Affect." Journal of Personality and Social Psychology 39: 1161-1178.

Rusting, Cheryl L. and Randy L. Larsen. 1995. "Moods as Sources of Stimulation: Relationships between Personality and Desired Mood States." Personality and Individual Differences 18: 321-329.

Schacter, Stanley and Jerome Singer. 1962. "Cognitive, Social, and Physiological Determinants of Emotional State." Psychological Review 69: 379-399.

Scherer, Klaus R. 1979. "Non-linguistic Indicators of Emotion and Psychopathology." In Emotions in Personality and Psychopathology, ed. Carroll E. Izard. New York: Plenum Press, pp. 495-529.

Scherer, Klaus R. 1994. "Emotion Serves to Decouple Stimulus and Response." In The Nature of Emotion, ed. Paul Ekman and Richard J. Davidson. New York: Oxford University Press, pp. 127-130.

Scherer, Klaus R. 2003. "Introduction: Cognitive Components of Emotion." In The Handbook of Affective Sciences, ed. Richard J. Davidson, Klaus R. Scherer, and H. Hill Goldsmith. Oxford: Oxford University Press, pp. 563-571. 
Schneirla, Theodore C. 1959. "An Evolutionary and Developmental Theory of Biphasic Processes Underlying Approach and Withdrawal." In Nebraska Symposium on Motivation. Lincoln: University of Nebraska Press.

Schwarz, Norbert and Gerald L. Clore. 1983. "Mood, Misattribution, and Judgments of Well-Being: Informative and Directive Functions of Affective States." Journal of Personality and Social Psychology 45: 513-523.

Sears, David O. and Jack Citrin. 1982. Tax Revolt: Something for Nothing in California. Cambridge: Harvard University Press.

Shaw, Daron R. 2006. The Race to 270: The Electoral College and the Campaign Strategies of 2000 and 2004. Chicago: University of Chicago Press.

Simon, Adam. F. 2002. The Winning Message: Candidate Behavior, Campaign Discourse, and Democracy. New York: Cambridge University Press.

Sniderman, Paul, Richard A. Brody, and Philip E. Tetlock. 1991. Reasoning and Choice: Explorations in Political Psychology. New York: Cambridge University Press.

Spezio, Michael L. and Ralph Adolphs. 2007. "Emotional Processing and Political Judgment: Toward Integrating Political Psychology and Decision Neuroscience." In The Affect Effect: Dynamics of Emotion in Political Thinking and Behavior, ed. W. Russell Neuman, George E. Marcus, Ann N. Crigler, and Michael MacKuen. Chicago: The University of Chicago Press.

Steenbergen, Marco R. and Milton Lodge. 2003. "Process Matters: Cognitive Models of Candidate Evaluation." In Electoral Democracy, ed. Michael B. MacKuen and George Rabinowitz. Ann Arbor: University of Michigan Press, pp. 125-171

Stevens, Daniel. 2009. "Elements of Negativity: Volume and Proportion in Exposure to Negative Advertising." Political Behavior 31: 429-454.

Stimson, James A. 1999. Public Opinion in America: Moods, Cycles, and Swings. Boulder: Westview Press.

Teasdale, John D. and Sarah J. Fogarty. 1979. "Differential Effects of Induced Mood on Retrieval of Pleasant and Unpleasant Events from Episodic Memory." Journal of Abnormal Psychology 88: 248-257.

Valentino, Nicholas A., Vincent L. Hutchings, Antoine J. Banks, and Anne K. Davis. 2008. "Is a Worried Citizen a Good Citizen? Emotions, Political Information Seeking, and Learning via the Internet." Political Psychology 29: 247-273. 
Van Der Molen, Walma and Tom H. Van Der Voort. 2000. "The Impact of Television, Print, and Audio on Children's Recall of the News." Human Communication Research 26: 3-26.

Watson, David. 2000. Mood and Temperament. New York: Guilford Press.

Watson, David and Lee A. Clark. 1994. "The Vicissitudes of Mood: A Schematic Model." In The Nature of Emotion, ed. Paul Ekman and Richard J. Davidson. New York: Oxford University Press.

Watson, David, David Weise, Jatin Vaidya, and Auke Tellegen. 1999. "The Two General Activation Systems of Affect: Structural Findings, Evolutionary Considerations, and Psychobiological Evidence." Journal of Personality and Social Psychology 76: $820-838$.

Weiner, Bernard. 1974. Achievement Motivation and Attribution Theory. Morristown: General Learning Press.

West, Darrell M. 2001. Air Wars: Television Advertising in Election Campaigns, 19522000. Washington, D.C.: CQ Press.

Woodall, W. Gil. 1986. "Information Processing Theory and Television News." In The Main Source, ed. John P. Robinson and Mark R. Levy. Beverly Hills: Sage.

Wright, Gerald C., Jr. 1977. "Contextual Models of Electoral Behavior: The Southern Wallace Vote.” American Political Science Review 71: 497-508.

Yan, Ting and Roger Tourangeau. 2005. "Fast Times and Easy Questions: The Effects of Age, Experience, and Question Complexity on Web Survey Response Times." Applied Cognitive Psychology 22: 51-68.

Zajonc, Robert B. 1980. "Feeling and Thinking: Preferences Need No Inferences." American Psychologist 35: 151-175.

Zajonc, Robert B. 1984. "On the Primacy of Affect." American Psychologist 39: 117123.

Zajonc, Robert B. 1994. "Evidence for Nonconscious Emotions." In The Nature of Emotion: Fundamental Questions, ed. Paul Ekman and Richard J. Davidson. New York: Oxford University Press, pp. 293-297.

Zajonc, Robert B. 2001. "Mere Exposure: A Gateway to the Subliminal." Current Directions in Psychological Science 10: 224-228.

Zaller, John R. 1992. The Nature and Origins of Mass Opinion. Cambridge: Cambridge University Press. 
Zhao, Xinshu and Steven H. Chaffee. 1995. "Campaign Advertisements Versus Television News as Sources of Political Issue Information." Public Opinion Quarterly 59: 41-65.

Zucker, Gail S. and Bernard Weiner. 1993. "Conservatism and Perceptions of Poverty: An Attributional Analysis." Journal of Applied Social Psychology 23: 925-943. 